Final Report

FHWA/IN/JTRP-2006/13

\title{
INVESTIGATION OF THE PERFORMANCE OF NEAT AND MODIFIED ASPHALT BINDERS
}

\author{
by \\ Yalan Tang \\ Graduate Research Assistant \\ and \\ John E. Haddock \\ Professor \\ School of Civil Engineering \\ Purdue University \\ Joint Transportation Research Program \\ Project Number C-36-56L \\ File Number 2-13-12 \\ SPR-2472 \\ Conducted in Cooperation with the \\ Indiana Department of Transportation \\ and the \\ U.S. Department of Transportation \\ Federal Highway Administration
}

The content of this report reflects the views of the authors who are responsible for the facts and accuracy of the data presented herein. The contents do not necessarily reflect the official views or policies of the Indiana Department of Transportation or the Federal Highway Administration at the time of publication. This report does not constitute a standard, specification, or regulation.

\footnotetext{
Purdue University

West Lafayette, IN 47907

October 2006
} 


\section{TECHNICAL Summary}

INDOT Research

Technology Transfer and Project Implementation Information

\section{Investigation of the Performance of Neat and Modified Asphalt Binders}

\section{Introduction}

The Superpave mixture design method uses performance-based criteria for binder specification and hot-mix asphalt (HMA) mixture design. In pavement construction, modified binders are often used for high stress, high traffic volume, or extreme climate conditions. While the use of Superpave specifications offer many advantages, no standard test protocols currently exist to quantify the performance characteristics of modified binders. Unlike neat (unmodified) binders, which are Newtonian fluids, modified binders typically exhibit a phenomenon known as pseudo-plasticity. Therefore, the Superpave binder test methods may not provide suitable guidance for modified binders.

One example is the determination of mixing and compaction temperatures. It is understood that the appropriate mixing and compaction temperatures should result in complete aggregate coating and adequate field density of HMA mixtures. Both are critical to HMA performance. However, if the determination of mixing and compaction temperatures is based on the Superpave binder test protocols, the results for modified binders can be excessively high. There are several potential dangers associated with elevated mixture temperatures, such as worker safety, thermal separation of the modifier and binder, and excessive oxidation of the binder. These effects may cancel the benefits of using modified binders. For this reason, in practice, mixing and compaction temperatures for modified binders are often empirically recommended. A standard method for determining HMA mixing and compacting temperatures for mixtures containing modified binders needs to be developed. Additionally, questions have arisen about the Superpave binder specification. Namely, it is not known if neat and modified binders of the same Superpave performance grade have the same performance behavior.

The major objectives of this project are to: 1) Develop a rational method of specifying field mixing and compaction temperatures for HMA mixtures that is particularly applicable to modified binders; and 2) determine if neat and modified binders of the same PG grade provide comparable performance.

The first phase of the research focuses on determining mixing and compaction temperatures for HMA mixtures containing modified binders. Various binders were collected from field projects and their mixing and compaction temperatures were determined using Zero Shear Viscosity (ZSV) theory. These temperatures were then compared to the empirically recommended temperatures used for the design and production of the HMA mixtures as well as the temperatures determined using the standard test method. HMA samples were also mixed and compacted in the Superpave Gyratory Compactor (SGC) at the ZSV determined temperatures and the resulting binder contents compared to those measured during completion of the original mixture designs.

The second phase of the study compares the laboratory performance of neat and modified binders of the same Superpave performance grade. HMA mixture specimens were produced in the laboratory using both neat and modified binders. Laboratory performance tests were used to test HMA mixture performance at high, intermediate, and low temperatures. At high temperatures rutting is the predominant HMA mixture distress while fatigue and low temperature cracking occur at intermediate and low temperatures, respectively. The work reported herein used the PURWheel laboratory wheel tracking test to study the rutting performance of HMA mixtures. 
Flexural beam fatigue testing was used to investigate fatigue cracking at intermediate temperatures and the Indirect Tensile Test (IDT) was used to evaluate the thermal cracking (low temperature) behavior of the mixtures. The testing was performed on various HMA mixtures containing one of four neat or modified binders (two neat, two modified) all of which were of the same PG grading.

\section{Findings}

No extreme mixing and compaction temperatures were used for the design and production of the mixtures investigated in the study. Using the binder viscosities at 3.0 and $6.0 \mathrm{~Pa} \cdot \mathrm{s}$ as determined in the $\mathrm{ZSV}$ test for determining mixing and compaction temperatures, respectively, does work for HMA mixtures containing modified binders. However, additional work is required to make the ZSV method compatible with all binder types. Currently, for neat binders, the standard test protocol provides a better estimation of mixing and compaction temperatures.

When the laboratory performance of neat and modified binders of the same performance grade was assessed it was determined that, overall, modified binders appear to improve the performance of HMA mixtures. The mixtures containing modified binder had less rutting than did mixtures containing neat binders, although none of the mixtures had excessive rutting. HMA mixtures made with modified binders have longer fatigue lives than mixtures containing neat binders; and binder modification appears to increase HMA mixture tensile strengths at low temperatures. Additionally, it appears that PG 7022 and PG 75-22 binders produce HMA mixtures that have statistically significant differences in rutting susceptibility regardless of modification.

\section{Implementation}

During the performance of this research two significant changes have occurred. First, the INDOT began using standard mixing and compaction temperatures for HMA laboratory mixture designs. Secondly, additional work has been done with the Superpave binder specification that makes it blinder to binder modification. Given these two developments, the following are suggested as implementation items: 1) The INDOT should review HMA mixture design data to determine if the new mixing and compaction temperature guidelines are effective, particularly for mixtures containing modified binders; and 2) the INDOT should implement the new binder specification when it becomes available.

\section{Contacts}

For more information:

Prof. John E. Haddock

Principal Investigator

School of Civil Engineering

Purdue University

West Lafayette IN 47907

Phone: (765) 496-3996

Fax: (765) 496-1364

E-mail: jhaddock@ecn.purdue.edu

\author{
Indiana Department of Transportation \\ Division of Research \\ 1205 Montgomery Street \\ P.O. Box 2279 \\ West Lafayette, IN 47906 \\ Phone: (765) 463-1521 \\ Fax: (765) 497-1665 \\ Purdue University \\ Joint Transportation Research Program \\ School of Civil Engineering \\ West Lafayette, IN 47907-1284 \\ Phone: (765) 494-9310 \\ Fax: (765) 496-7996 \\ E-mail: jtrp@ecn.purdue.edu \\ http://www.purdue.edu/jtrp
}




\begin{tabular}{|c|c|c|}
\hline $\begin{array}{l}\text { 1. Report No. } \\
\text { FHWA/IN/JTRP-2006/13 }\end{array}$ & 2. Government Accession No. & 3. Recipient's Catalog No. \\
\hline \multirow{2}{*}{\multicolumn{2}{|c|}{$\begin{array}{l}\text { 4. Title and Subtitle } \\
\text { Investigation of the Performance of Neat and Modified Asphalt Binders }\end{array}$}} & $\begin{array}{l}\text { 5. } \quad \text { Report Date } \\
\text { October } 2006\end{array}$ \\
\hline & & 6. Performing Organization Code \\
\hline \multicolumn{2}{|l|}{$\begin{array}{l}\text { 7. Author(s) } \\
\text { Yalan Tang and John E. Haddock }\end{array}$} & $\begin{array}{l}\text { 8. Performing Organization Report No. } \\
\text { FHWA/IN/JTRP-2006/13 }\end{array}$ \\
\hline \multirow{2}{*}{\multicolumn{2}{|c|}{$\begin{array}{l}\text { 9. Performing Organization Name and Address } \\
\text { Joint Transportation Research Program } \\
1284 \text { Civil Engineering Building } \\
\text { Purdue University } \\
\text { West Lafayette, IN 47907-1284 }\end{array}$}} & 10. Work Unit No. \\
\hline & & $\begin{array}{l}\text { 11. Contract or Grant No. } \\
\text { SPR-2472 }\end{array}$ \\
\hline \multirow{2}{*}{\multicolumn{2}{|c|}{$\begin{array}{l}\text { 12. Sponsoring Agency Name and Address } \\
\text { Indiana Department of Transportation } \\
\text { State Office Building } \\
100 \text { North Senate Avenue } \\
\text { Indianapolis, IN } 46204\end{array}$}} & $\begin{array}{c}\text { 13. Type of Report and Period Covered } \\
\text { Final Report }\end{array}$ \\
\hline & & 14. Sponsoring Agency Code \\
\hline
\end{tabular}

15. Supplementary Notes

Prepared in cooperation with the Indiana Department of Transportation and Federal Highway Administration.

16. Abstract

The Superpave binder specifications are performance-based criteria for binder selection for use in hot-mix asphalt mixtures. However, these specifications may not be applicable to modified binders. This research investigates the a new method for determining hot-mix asphalt mixing and compaction temperatures as well as the performance of neat (unmodified) and modified binders of the same performance grade.

The first phase of the research focuses on determining mixing and compaction temperatures for hot-mix asphalt mixtures. Modified binders are shear rate and temperature dependent and the conventional methods of determining mixing and compaction temperatures can yield extreme results. The Zero Shear Viscosity theory is used as an alternative method to determine hot-mix asphalt mixing and compaction temperatures. The results reveal that the method is applicable to determining mixing and compaction temperatures for hot-mix asphalt mixtures containing modified binders, but additional work is needed in order to make the method applicable to neat binders.

The second phase of the study investigates the performance of hot-mix asphalt mixtures containing neat and modified binders. Laboratory tests were performed on similar mixtures that contained neat and modified binders. Simple performance tests, such as accelerated rutting, flexural beam fatigue, and indirect tensile indicate that modified binders may contribute to improved hot-mix asphalt resistance to various distresses. Overall, performance-graded binders of the same grade appear to offer similar performance regardless of the high temperature at which the binder meets the high temperature specification.

Neat binder, modified binder, mixing temperature, compaction temperature

No restrictions. This document is available to the public through the National Technical Information Service, Springfield, VA 22161

\begin{tabular}{|c|c|c|c|}
\hline $\begin{array}{c}\text { 19. Security Classif. (of this report) } \\
\text { Unclassified }\end{array}$ & $\begin{array}{c}\text { 20. Security Classif. (of this page) } \\
\text { Unclassified }\end{array}$ & 21. No. of Pages & 115 \\
\hline
\end{tabular}


TABLE OF CONTENTS

Page

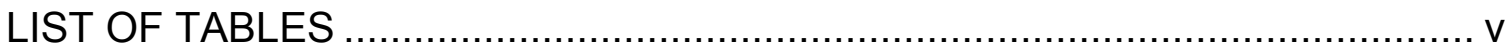

LIST OF APPENDIX TABLES ..........................................................................

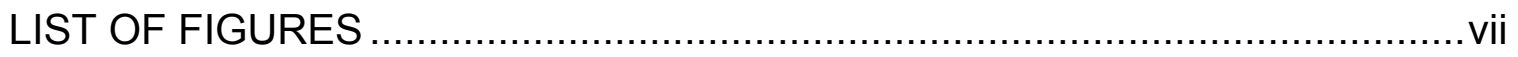

LIST OF APPENDIX FIGURES ...................................................................... vii

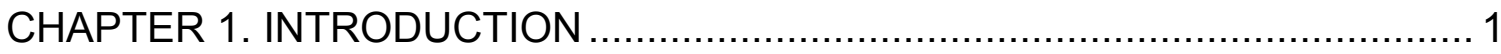

1.1. Background and Problem Statement ................................................... 1

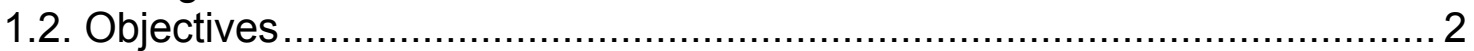

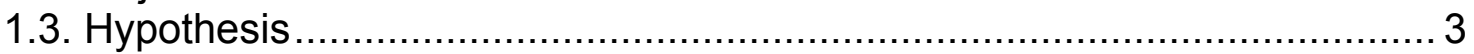

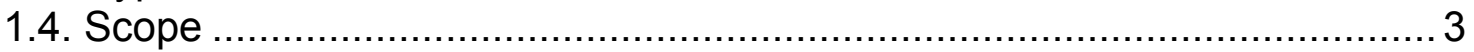

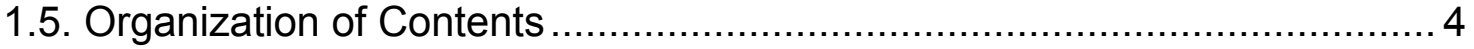

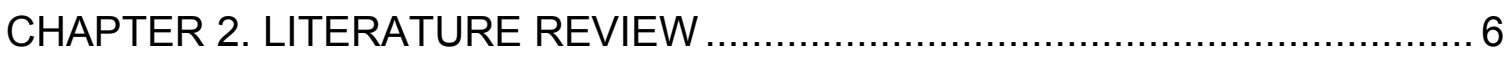

2.1. Superpave Performance Graded System ............................................ 6

2.2. Rheological Properties of Neat and Modified Binder ................................ 8

2.3. Mixing and Compaction Temperature Determination .............................. 9

2.4. Zero Shear Viscosity ........................................................................ 13

2.5. Mechanisms of Pavement Failure Modes............................................. 15

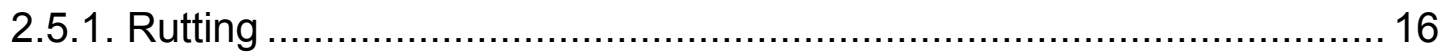

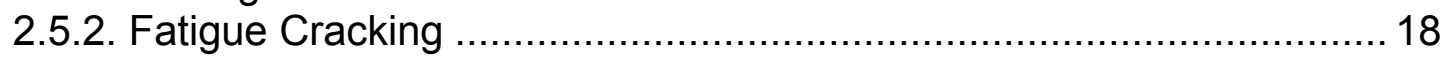

2.5.3. Thermal Cracking ................................................................. 19

2.6. Influence of HMA Components on Pavement Properties .......................20

2.6.1. Influence of Modified Binder on Pavement Properties ....................... 20

2.6.2. Aggregate Size, Type, and Gradation ............................................. 22

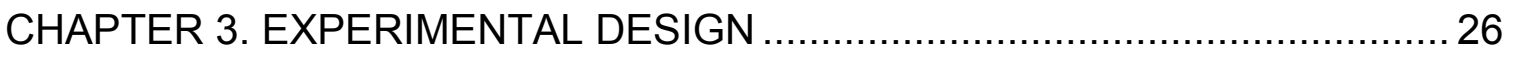

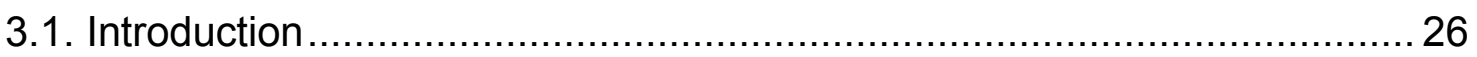

3.2. Mixing and Compaction Temperatures .............................................. 26

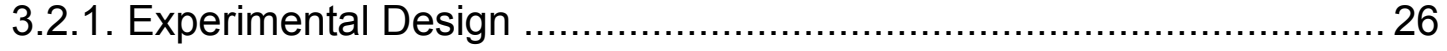

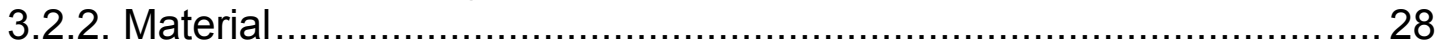




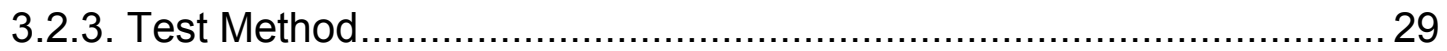

3.3. Neat and Modified Binders ................................................................... 29

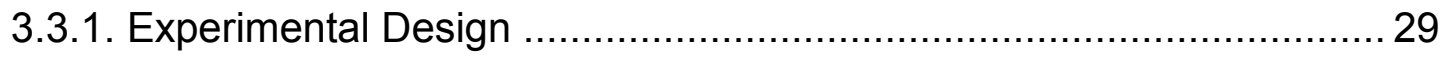

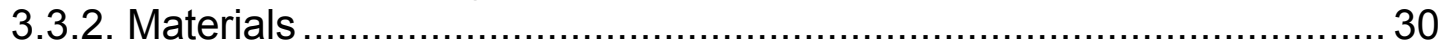

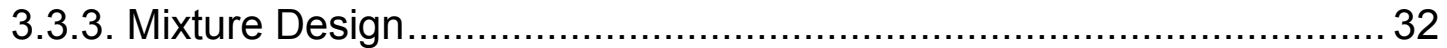

3.3.4. Test Specimen Preparation Procedures ........................................ 33

3.3.5. Statistical Data Analysis Procedure ............................................... 35

CHAPTER 4. DETERMINATION OF MIXING AND COMPACTION

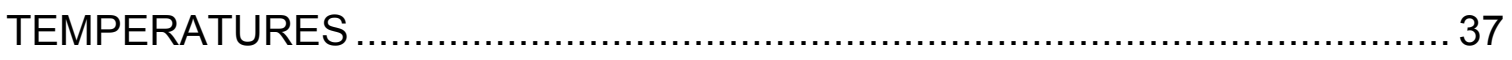

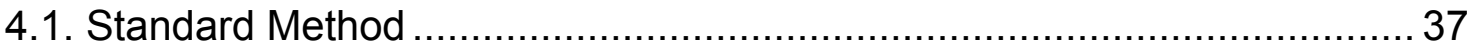

4.2. Zero Shear Viscosity Test Procedure ................................................ 39

4.2. Mixing and Compaction Temperature Test Results .............................. 42

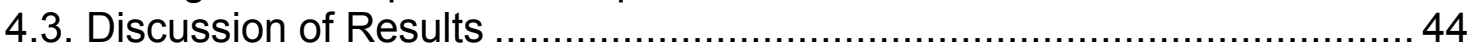

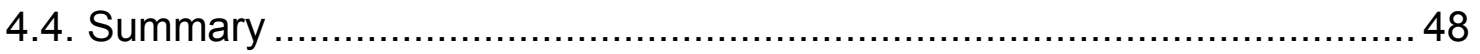

CHAPTER 5. PERMANENT DEFORMATION............................................. 50

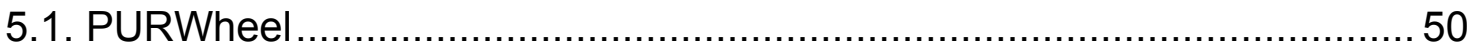

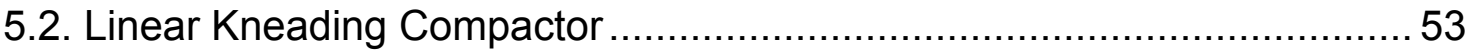

5.3. PURWheel Specimen Preparation and Test Procedure ......................... 54

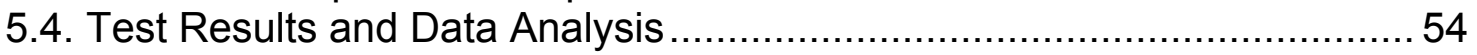

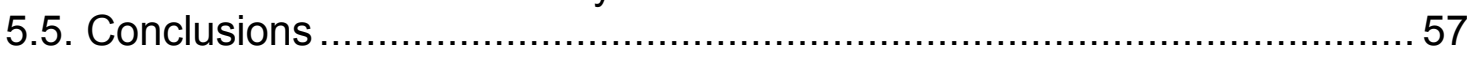

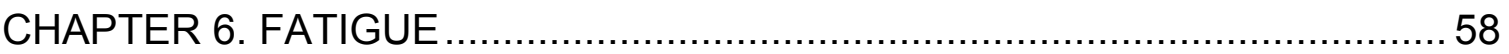

6.1. Flexural Beam Fatigue Specimen Preparation ..................................... 59

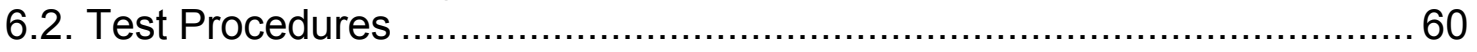

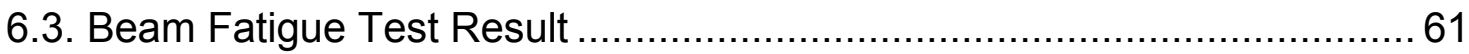

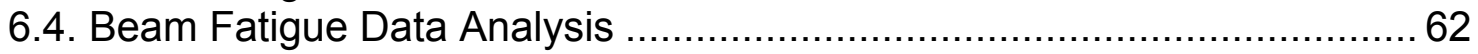

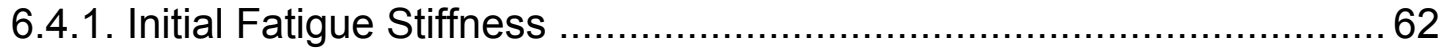

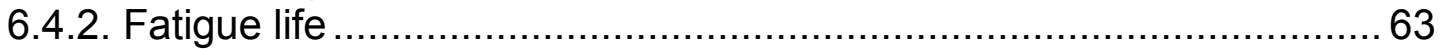

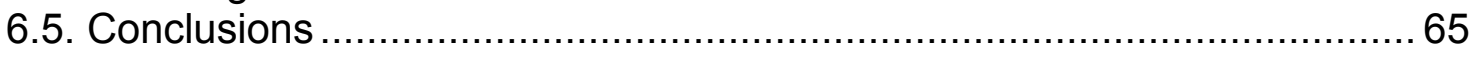

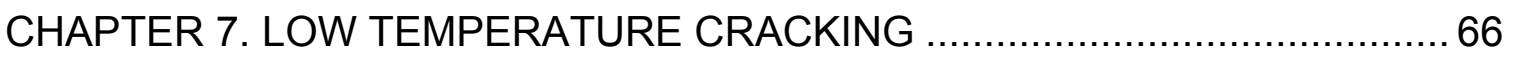

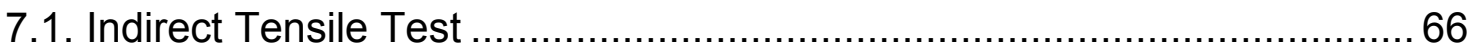

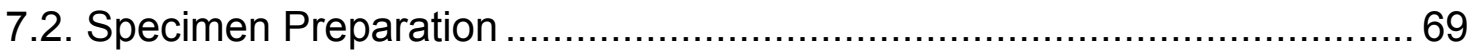

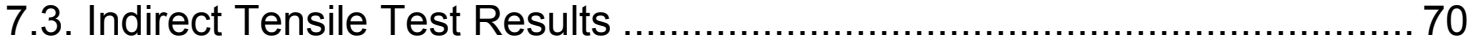

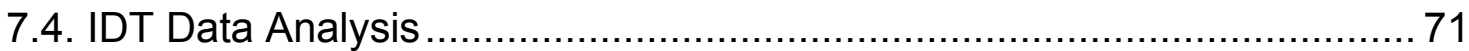

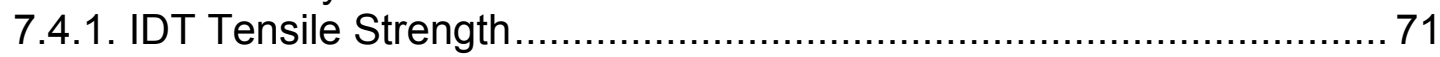

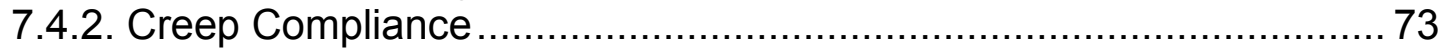

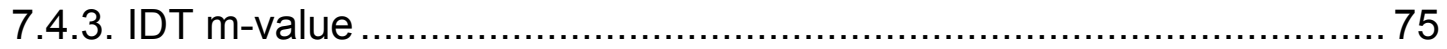


CHAPTER 8. CONCLUSIONS AND RECOMMENDATIONS...........................77

8.1. Mixing and Compaction Temperatures ............................................... 77

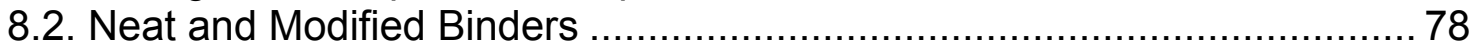

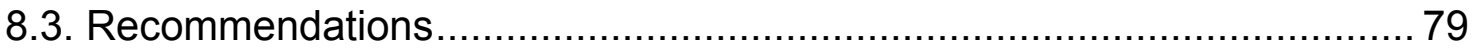

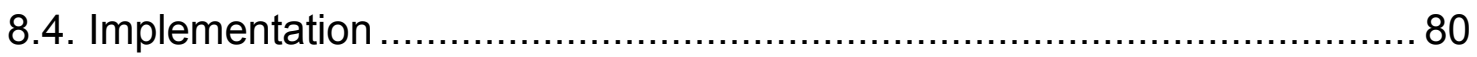

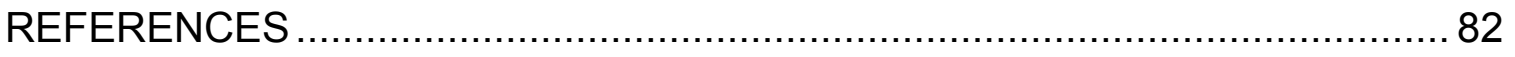

\section{APPENDICES}

Appendix A. Determining Mixing and Compaction Temperatures .................. 92

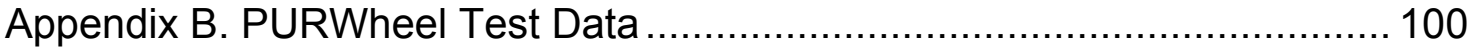

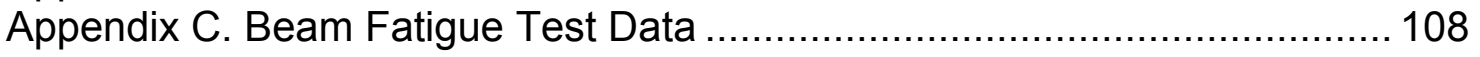

Appendix D. Indirect Tensile Test Data ................................................... 115 


\section{LIST OF TABLES}

Table

Page

Table 3.1 Mixing and Compaction Temperature Experimental Matrix ............... 27

Table 3.2 Selected Projects.................................................................. 28

Table 3.3 Neat vs. Modified Binder Experimental Matrix .................................. 30

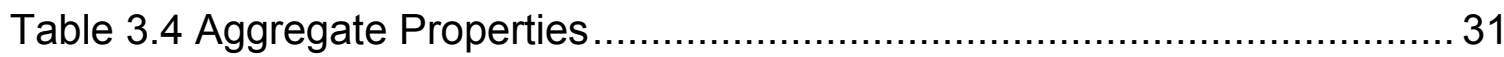

Table 3.5 Mixture Design Summary .......................................................... 33

Table 4.1 Example of Viscosity Test Data ..................................................... 40

Table 4.2 Mixing and Compaction Temperatures .......................................... 43

Table 4.3 Comparison of Optimum Binder Contents ..................................... 48

Table 5.1 ANOVA Summary of Factor Effects on Rut Depth.............................55

Table 5.2 t-test Result of Main Factor Effect on Rutting ….................................56

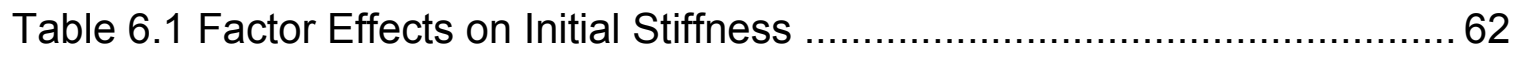

Table 6.2 t-test Result of Main Factor Effect on Fatigue Stiffness ...................... 63

Table 6.3 Summary of Factor Effects on Fatigue life ........................................ 64

Table 6.4 t-test Result of Main Factor Effect on Fatigue life ............................. 64

Table 7.1 IDT Test Result Data Summary ................................................... 71

Table 7.2 Full Model Statistical Analysis of Tensile Strength ........................... 72

Table $7.3 \mathrm{t}$-test Comparison of Main Factors.................................................. 73

Table 7.4 Statistical Analysis on Creep Compliance ...................................... 73

Table $7.5 \mathrm{t}$-test Comparison of Main Factors .............................................. 74

Table 7.6 Statistical Analysis of m-value at 60 Seconds ............................... 755 


\section{LIST OF APPENDIX TABLES}

Table B1 PURWheel Test Data ........................................................ 100

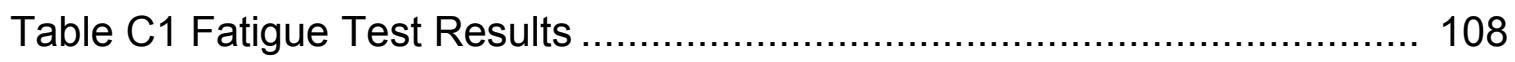

Table D1 Indirect Tensile Test Results ............................................. 115 


\section{LIST OF FIGURES}

Figure

Figure 2.1 Relationship of Rheological Parameters (after Barnes et al. 1989) ..... 9

Figure 2.2 Viscosity-Temperature Chart (ASTM D2493) ............................... 11

Figure 2.3 Binder Shear Rate Dependency .................................................. 14

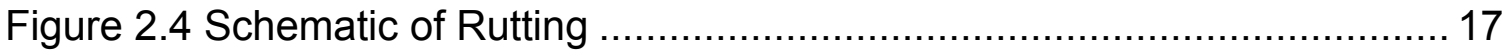

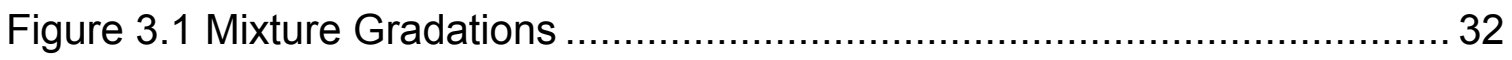

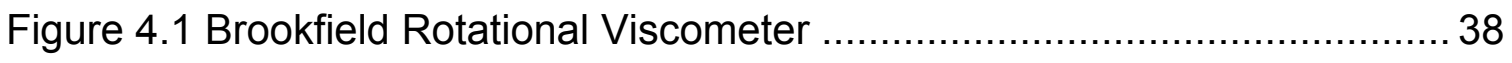

Figure 4.2 Example of a Graphed Data Points and Fitted Curve...................... 41

Figure 4.3 Interpolation Example from ZSV-Temperature Profile ..................... 41

Figure 4.4 Mixing Temperature Comparison ............................................ 44

Figure 4.5 Compaction Temperature Comparison........................................... 44

Figure 4.6 Mixing Temperature Relationship .............................................. 45

Figure 4.7 Compaction Temperature Relationship ....................................... 45

Figure 4.8 ZSV and RV temperature relationship ..................................... 46

Figure 4.9 ZSV and RV temperature relationship (without outliers) .................. 47

Figure 5.1 Purdue University Laboratory Wheel Tracking Device ..................... 51

Figure 5.2 Slab in the Sample Tray (a) Before and (b) After testing .................. 53

Figure 5.3 Linear Kneading Compactor........................................................ 54

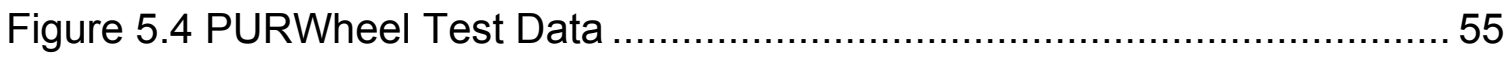

Figure 6.1 Beam Fatigue Test Apparatus ................................................. 59

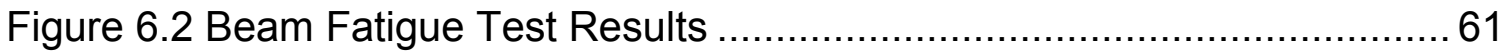

Figure 7.1 Indirect Tensile Tester: (a) Test Equipment, and (b) Test Specimen. 67

Figure 7.2 Example of IDT Creep Compliance Results .................................... 70

Figure 7.3 Plot of Critical Pavement Temperature ........................................ 700 


\section{LIST OF APPENDIX FIGURES}

Figure

Page

Figure A1 R-23396 ZSV Temperature Calculation ....................................... 92

Figure A2 R-23924 ZSV Temperature Calculation ........................................ 93

Figure A3 R-24326 ZSV Temperature Calculation ......................................... 94

Figure A4 R-24564 ZSV Temperature Calculation ........................................ 95

Figure A5 R-25053 ZSV Temperature Calculation .......................................... 96

Figure A6 R-25056 ZSV Temperature Calculation ........................................ 97

Figure A7 R-25113 ZSV Temperature Calculation ....................................... 98

Figure A8 R-25723 ZSV Temperature Calculation ...................................... 989

Figure B1 Coarse-Graded, 9.5-mm Mixture with Neat PG 70-22 ................... 101

Figure B2 Coarse-Graded, 9.5-mm Mixture with Neat PG 75-22 …............... 102

Figure B3 Coarse-Graded, 9.5-mm Mixture with Modified PG 71-22 .............. 102

Figure B4 Coarse-Graded, 9.5-mm Mixture with Modified PG 75-22 .............. 103

Figure B5 Coarse-Graded, 12.5-mm Mixture with Neat PG 70-22 …............. 103

Figure B6 Coarse-Graded, 12.5-mm Mixture with Neat PG 75-22 …............. 104

Figure B7 Coarse-Graded, 12.5-mm Mixture with Modified PG 71-22 ............ 104

Figure B8 Coarse-Graded, 12.5-mm Mixture with Modified PG 75-22 ............ 105

Figure B9 Fine-Graded, 9.5-mm Mixture with Neat PG 70-22 ..................... 105

Figure B10 Fine-Graded, 9.5-mm Mixture with Modified PG 71-22 ................ 106

Figure B11 Fine-Graded, 12.5-mm Mixture with Neat PG 70-22 ................... 106

Figure B12 Fine-Graded, 12.5-mm Mixture with Modified PG 71-22 .............. 107

Figure C1 Coarse-Graded, 9.5-mm Mixture with Neat PG 70-22 …............... 109

Figure C2 Coarse-Graded, 9.5-mm Mixture with Neat PG 75-22 …............... 109

Figure C3 Coarse-Graded, 9.5-mm Mixture with Modified PG 71-22 .............. 110 
Figure

Figure C4 Coarse-Graded, 9.5-mm Mixture with Modified PG 75-22 ............. 110

Figure C5 Coarse-Graded, 12.5-mm Mixture with Neat PG 70-22 ................ 111

Figure C6 Coarse-Graded, 12.5-mm Mixture with Neat PG 75-22 ................ 111

Figure C7 Coarse-Graded, 12.5-mm Mixture with Modified PG 71-22 ............ 112

Figure C8 Coarse-Graded, 12.5-mm Mixture with Modified PG 75-22 ............ 112

Figure C9 Fine-Graded, 9.5-mm Mixture with Neat PG 70-22 ...................... 113

Figure C10 Fine-Graded, 9.5-mm Mixture with Modified PG 71-22 ................ 113

Figure C11 Fine-Graded, 12.5-mm Mixture with Neat PG 70-22 .................. 114

Figure C12 Fine-Graded, 12.5-mm Mixture with Modified PG 71-22 ............... 114 


\section{CHAPTER 1. INTRODUCTION}

\subsection{Background and Problem Statement}

Hot-Mix Asphalt (HMA) has been widely used as a cost-effective pavement material for many years. In 1987, the Strategic Highway Research Program (SHRP) began working on a new system for specifying and designing HMA. The

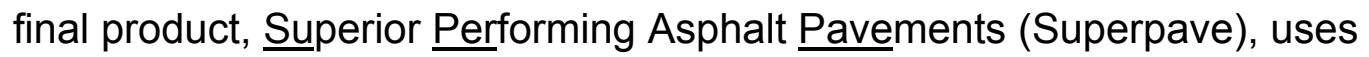
performance-based criteria for binder specification and HMA mixture design (Asphalt Institute Superpave Series SP-2, 1995).

Today, modified binders are frequently used to improve HMA mixture performance. For example, modified binders are often used for high stress, high traffic volume, and/or extreme climate conditions. While the use of Superpave specifications offers many advantages, no standard test protocols currently exist to quantify the performance characteristics of modified binders. Unlike unmodified (neat) binders, which are Newtonian fluids, modified binders typically exhibit a phenomenon known as pseudo-plasticity (i.e., the viscosity values depend on the shear rate). Therefore, the Superpave binder test methods may not provide suitable guidance for the use of modified binders.

As an example, it is understood that the use of appropriate mixing and compaction temperatures results in complete aggregate coating and adequate 
field density of HMA mixtures. Both are critical to HMA performance. However, if the determination of mixing and compaction temperatures is based on the Superpave binder test protocols, the results for modified binders can often be excessively high. There are several potential dangers associated with elevated HMA mixture temperatures; worker safety, thermal separation of modifier and binder, and excessive oxidation of the binder. These effects may negate the benefits of using modified binders. For this reason, in practice, mixing and compaction temperatures for modified binders are often recommended based on the binder suppliers' experience. A standard method for determining HMA mixing and compacting temperatures for mixtures containing modified binders needs to be developed.

In addition, questions have arisen about the Superpave binder specification itself. Namely, it is not known if neat and modified binders of the same Superpave performance grade exhibit similar performance behavior. If HMA mixtures were produced so that the only difference is that one contains a neat PG 70-22 and the other a modified PG 70-22, it is not known if the two mixtures would have similar performance. The performance of similar HMA mixtures, one containing neat and the other a modified binder, both of the same Superpave binder grade, needs to be compared (Haddock, 2001).

\subsection{Objectives}

The major objectives of this project are: 
1. Develop a rational method of specifying field mixing and compaction temperatures for HMA mixtures. This method should be particularly applicable to modified PG-graded binders; and

2. Determine if similar HMA mixtures containing either a neat or a modified binder of the same PG grade provide comparable performance.

\subsection{Hypothesis}

There are two hypotheses to be tested by the research project. The first depends on the fact that, at high temperatures, modified binders exhibit different rheological properties than do neat binders. The hypothesis is that a potential window exists where the mixing and compaction temperatures for the HMA mixtures containing modified binders can be decreased while still achieving the necessary aggregate coating and HMA density, but without increasing the compaction effort and/or binder content.

The second hypothesis is that similar HMA mixtures containing a neat and a modified binder of the same PG grade have comparable performance behavior with regards to rutting, fatigue, and thermal cracking.

\subsection{Scope}

The first phase of the research focuses on a new method for determining mixing and compaction temperatures for HMA mixtures. The shear rate dependent properties of modified binders provide a basis for decreasing the mixing and compaction temperatures of HMA mixtures containing them. Various binders 
were collected from field projects and their mixing and compaction temperatures were determined using Zero Shear Viscosity (ZSV) theory. These temperatures were then compared to the empirically recommended temperatures used for the design and production of the HMA mixtures. HMA samples were also mixed and compacted in the Superpave Gyratory Compactor (SGC) at the ZSV determined temperatures and the resulting optimum binder contents compared to those measured during completion of the original mixture designs.

The second phase of the study compares the laboratory performance of neat and modified binders of the same Superpave performance grade. HMA mixture specimens were produced in the laboratory using either a neat or modified binder, both of the same PG grade. Simple performance tests, including laboratory wheel tracking, flexural beam fatigue, and indirect tensile were performed. The effect of binder type and grade, gradation, and nominal maximum aggregate size (NMAS) were assessed.

\subsection{Organization of Contents}

In Chapter 1, the background of the project is briefly introduced, followed by a description of study objectives, hypotheses to be investigated, and scope of the project.

Chapter 2 provides a literature review of topics including the Superpave performance graded binder system, comparison of rheological properties of neat and modified binders, approaches for determining mixing and compaction temperatures, the ZSV theory and model, and mechanisms of several pavement 
failure modes. Findings from previous studies on the effects of modified binders are also described.

Chapter 3 presents the experimental design used in the research, the performance test methods used, and the data analysis methodology applied.

In Chapter 4, the mixing and compaction temperatures derived from both the standard and ZSV tests are compared and discussed. The results are further correlated to the Rotational Viscometer (RV) temperatures.

Chapter 5 analyzes the permanent deformation (rutting) test results from the PURWheel; Chapter 6 presents and discusses the fatigue test method and data analysis. Chapter 7 contains a description of the low temperature cracking test approach along with the data and analysis. Finally, Chapter 8 summarizes the project results and recommends future research. 
CHAPTER 2. LITERATURE REVIEW

\subsection{Superpave Performance Graded System}

Asphalt binders, or binders, have for decades been selected using semiempirical procedures. Frequently, this method lead to HMA laboratory mixture designs unable to satisfy field performance requirements. To address this issue, the Superpave Performance-Graded (PG) binder system was developed as a part of the SHRP research. Compared to the traditional specification methods of penetration and viscosity, the PG system more accurately characterizes binder properties and relates them to the field performance of HMA mixtures.

PG grades are selected based on expected in-service temperature. A PG 7022 binder will meet the high temperature physical property requirements up to $70 \mathrm{C}(158 \mathrm{~F})$ and low temperature physical property requirements down to a temperature of $-22 \mathrm{C}(-4 \mathrm{~F})$. For binder specification purposes, both the high and low temperatures change in $6 \mathrm{C}(11 \mathrm{~F})$ increments. Thus standard high temperature grades are denoted as $46,52,58,64,70,76$, and 82 ; the low temperature grades are $-10,-16,-22,-28,-34$, and -40 . A project might therefore specify that a PG 64-22 binder be used.

The Association of American State Highway and Transportation Officials (AASHTO) MP1a, "Standard Specification for Performance-Graded Asphalt 
Binders," denotes the test methods for binder grade classification. PG binders are tested at three critical stages of life under conditions similar to the expected in-service environmental and traffic conditions. Binders are first tested in their original, un-aged state in the Rotational Viscometer (RV). This test is thought to be indicative of the ability to transport, store, handle, and pump a binder. For the second series of tests, binders are first aged in the Rolling Thin Film Oven (RTFO). This is thought to simulate short-term aging that can occur during HMA production and placement procedures. Prior to completing a third series of tests, RTFO aged binder samples are further aged by the Pressure Aging Vessel (PAV), a process thought to simulate long-term aging that binders experience from many years of in-service conditions.

In addition to the $\mathrm{RV}$, three tests are used to measure the physical properties of binders under Superpave PG binder protocol. The Dynamic Shear Rheometer (DSR) measures binder stiffness $\left(G^{*}\right)$ and phase angle $(\delta)$ at intermediate and high temperatures. For high temperatures, DSR tests are completed on original (unaged) and RTFO aged binder. The results indicate binder resistance to permanent deformation (rutting). At intermediate temperatures, PAV aged binder samples are tested in the DSR to determine resistance to fatigue cracking. The Bending Beam Rheometer (BBR) measures the creep stiffness and the rate of stiffness change (m-value) for PAV aged binder samples. Additionally, the Direct Tension Test (DTT) can be used to determine ductility at low temperatures for PAV aged binder samples. The BBR and DTT values are used to predict the low temperature performance of binders (Roberts, 1996). 
In general, the Superpave specification considers that stiff, elastic binders are beneficial for rutting resistance, while soft, elastic binders benefit the fatigue cracking characteristics. Soft binders with a high rate of stiffness change (fast stress relaxation) are desirable for resistance to low temperature cracking (Asphalt Institute Superpave Series SP-2, 1995).

\subsection{Rheological Properties of Neat and Modified Binder}

As noted previously, binder stiffness is an effective index for differentiating binder types and frequently stiffness can be associated with binder performance. Measuring binder stiffness is therefore of great importance. Binder stiffness is typically quantified using rheological parameters. Rheology refers to a fluid's resistance to flow. Figure 2.1 is a schematic interpretation of the relationship between rheological parameters such as shear stress and shear rate. Fluids such as water, air, and alcohol are Newtonian materials. This means a plot of shear stress versus shear rate at a given temperature is a straight line with a constant slope. The slope is the viscosity of the fluid (Branes et al.1989). It is well known that most neat binders are Newtonian materials.

Modified binders are often used to improve HMA mixture performance when neat binders cannot meet specific requirements under severe in-service conditions. Binders can be modified with additives such as polymers, crumb rubber, and hydrocarbons. Experiments conducted by Zaman et al. (1995) showed that the viscosity of modified binders can be highly shear rate dependent. Modified binders were shear thinning liquids at low shear rates and 
shear thickening at high shear rates. That is, the slope of shear stress versus shear rate curve was not a constant. Shear thinning indicates that the viscosity decreases as the shear rate increases; conversely, shear thickening indicates that the viscosity increases with increasing shear rate. Since shear stress and shear rate are not linearly related, modified binders are classified as nonNewtonian.

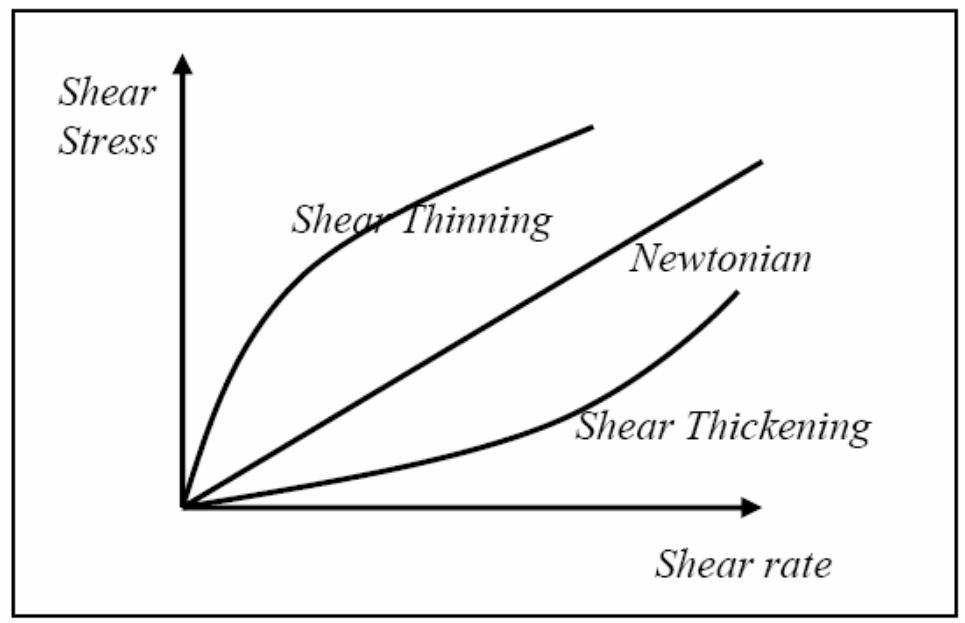

Figure 2.1 Relationship of Rheological Parameters (after Barnes et al. 1989)

Using normal Superpave viscosity test methods, modified binders typically show higher viscosities than the neat binders from which they were produced. In a study conducted by Lu and Isacsson, (1997), it was found that the higher the binder modification, the greater the deviation from Newtonian behavior.

\subsection{Mixing and Compaction Temperature Determination}

Appropriate mixing and compaction temperatures are important in achieving complete aggregate coating and adequate field density during HMA mixture 
production and placement. Ideally, the HMA mixing temperature is the minimum temperature at which the binder viscosity allows for quick and complete coating of the aggregate; the compaction temperature is an important factor influencing HMA mixture workability and initial in-place density. Excessive temperatures should be avoided during mixing and compaction. Compaction temperatures that are too low can result in poor workability and inadequate density. A compaction temperature that is too high can damage the binder causing the mixture to move under compaction resulting in poor density. To allow for the selection of optimum mixing and compaction temperatures, the temperature-viscosity relationship of the binder must be established (Yildrim et al. 2000).

Historically, the American Society for Testing and Materials (ASTM) D2493, "Standard Viscosity-Temperature Chart for Asphalts," has been used to establish HMA mixing and compaction temperatures. This approach is simple and provides reasonable temperatures for neat binders. However, experience has shown that the mixing and compaction temperatures of HMA mixtures containing modified binders can be different from nearly identical mixtures containing neat binders.

The concept that HMA mixing and compaction temperature ranges can be based on binder viscosity was first introduced as early as 1962 by the Asphalt Institute. This method required that HMA mixtures be mixed and compacted at binder temperatures corresponding to $170 \pm 20$ and $280 \pm 30$ centistokes, respectively. The Superpave mixture design method adopted these same requirements, but with different units. In the Superpave mixture design, HMA specimens are mixed and compacted at equiviscous binder temperatures 
corresponding to viscosities of $0.17 \pm 0.02$ and $0.28 \pm 0.03$ Pascal-seconds (Pa.s), respectively (Asphalt Institute Superpave Series SP-2, 1995).

To meet the requirements of AASHTO MP1a, the rotational viscosity is determined at 135 and $165 \mathrm{C}$ (275 and 330F) using the RV (AASHTO T316).

These measurements establish two points on the log-log plot as shown in Figure 2.2. The viscosity-temperature relationship is assumed to be linear and a line is drawn as shown. The mixing and compaction temperatures are then established by the ranges previously noted and as shown in the figure.

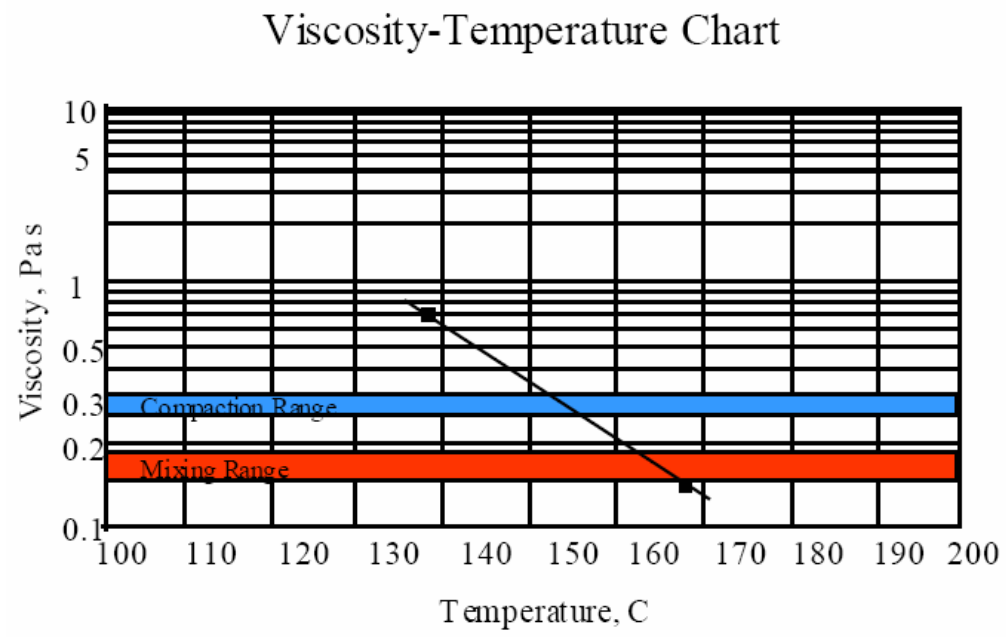

Figure 2.2 Viscosity-Temperature Chart (ASTM D2493)

When using this method to establish mixing and compaction temperatures, if the mixing temperature is higher than $175 \mathrm{C}(350 \mathrm{~F})$, it may indicate that the binder is modified. Binders should not be heated beyond 175C (350F) since damage to the binder can occur at such elevated temperatures. Additionally, other problems can occur. Many binders may begin to smoke when heated to temperatures of 163 to $165 \mathrm{C}$ (325 to 330F) (Hensley, 1998 and Zubeck, 1999). 
While it is obvious that adjustments of the mixing and compaction temperatures need to be made for HMA mixtures containing modified binders, lowering the mixing temperature significantly may cause problems in the paving operations. By lowering the mixing temperature, the compaction temperature is also lowered and the amount of compaction time may be shortened. Moisture problems can also occur (McLeod, 1967). Kennedy et al. (1984) conducted a study on various compaction temperatures during construction operations and found that a majority of the pavement distresses occurred when the compaction temperatures had been lower than approximately 92C (198F).

In an effort to establish realistic mixing and compaction temperatures for modified binders, several studies have been conducted. De Sombre, et al. (1998) tried to determine the laboratory compaction temperature ranges of HMA by using the SGC and the shear rate during compaction. The approach is based on the equation:

$$
\tau=\mu \dot{\gamma}
$$

where,

$$
\begin{aligned}
& \mathrm{T}=\text { shear stress; } \\
& \mu=\text { viscosity; and } \\
& \dot{\gamma}=\text { shear rate. }
\end{aligned}
$$

De Sombre et al. postulated that by knowing the relationship between the shear stresses in the SGC during compaction and the corresponding temperatures, it is possible to determine the desirable range of compaction 
temperatures for a given mixture. However, this theory tends to produce overly high mixing and compaction temperatures for modified binders. Yildrim et al (2000) suggested that the reason for this is the low shear rate at which binders are tested in the RV as opposed to the high shear rates found in the SGC during mixture compaction. They proposed a procedure to account for the binder shear rate dependency during determination of the mixing and compaction temperatures.

Khatri et al. (2001) also conducted research on the mixing and compaction temperatures for HMA mixtures containing modified binders using the SGC. Their results showed that compaction in the SGC and mixing using conventional laboratory mixers can be accomplished at much higher viscosity values (lower binder temperatures) without affecting mixture volumetric or binder content.

According to Shenoy (2001), several critical factors must be accounted for when determining HMA mixing and compaction temperatures. First, the mixing temperature should be high enough to ensure that the binder viscosity is shear rate independent; second, the mixing temperature should be low enough to ensure that modified binder does not degrade and binder hardening accelerated.

\subsection{Zero Shear Viscosity}

Most modified binders and many stiffer neat binders are known to have nonNewtonian behavior. The viscosities of non-Newtonian materials are dependent upon the rate at which they are sheared. However, at very low or very high shear rates, the viscosity reaches a constant value as shown in Figure 2.3. These 
regions are known as the first and second Newtonian regions, respectively. The high constant viscosity value in the very low shear rate region is commonly referred to as zero shear viscosity. It has been noted that during the mixing and compaction process, the ZSV is the most important factor controlling the densification (Sybilski 1996 and Bahia et al.2001).

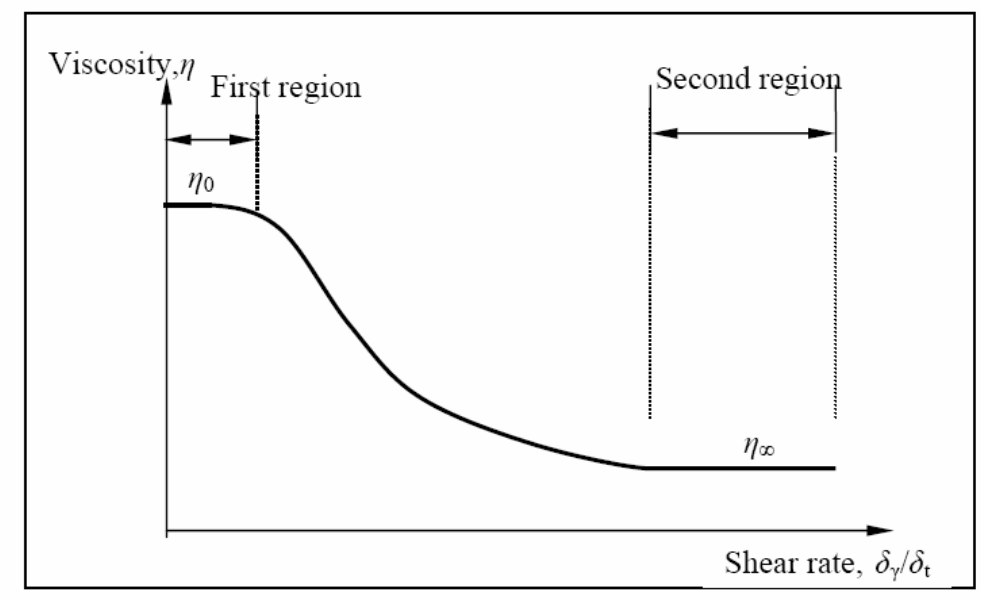

Figure 2.3 Binder Shear Rate Dependency

ZSV can be determined directly from long-term creep tests, but such tests are time consuming and often difficult to perform. Several alternative methods for determining the ZSV exist including the extrapolation of the dynamic viscosity to zero frequency, the application of the Cross-Williamson model to dynamic data, and the use of the superposition of multiple short-term, non-steady state creep test results (Anderson et al., 2001).

Researchers at the University of Wisconsin-Madison in cooperation with the National Cooperative Highway Research Program (NCHRP) developed a 
recommended protocol for measuring ZSV as a function of shear rate and temperature. The relationship was used to determine the required mixing and compaction temperatures for neat and modified binders (Khatri et al., 2001). Along with the test, the Cross-Williamson model was adopted to calculate the mixing and compaction temperatures. The model describes the flow curves of pseudo-plastic fluids in the form of a four-parameter model:

$$
\eta=\eta_{\infty}+\frac{\left(\eta_{0}-\eta_{\infty}\right)}{1+\left(\kappa \delta_{\gamma} / \delta_{t}\right)^{n}}
$$

where,

$$
\begin{aligned}
& \eta=\text { complex viscosity }(\mathrm{Pa} \cdot \mathrm{s}) ; \\
& \eta_{0}=\text { Zero Shear Viscosity }(\mathrm{Pa} \cdot \mathrm{s}) ; \\
& \eta_{\infty}=\text { limiting viscosity in the second Newtonian region }(\mathrm{Pa} \cdot \mathrm{s}) ; \\
& \delta_{\mathrm{V}} / \delta_{\mathrm{t}}=\text { angular frequency }(\mathrm{rad} / \mathrm{s}) ; \text { and } \\
& \mathrm{K} \text { and } \mathrm{n}=\text { constants. }
\end{aligned}
$$

As part of the research, a spreadsheet was developed to analyze the data and simplify the calculations. The general guidelines for using this program and interpreting the data are described in Chapter 4.

\subsection{Mechanisms of Pavement Failure Modes}

Since HMA mixtures are viscoelastic, HMA pavements present different failure modes when exposed to various temperature profiles and loading histories. Rutting, fatigue cracking, and thermal cracking are the three most frequently 
observed distresses in HMA pavements. These can result in poor service conditions and reduce HMA pavement service life.

To perform satisfactorily over the pavement design life, HMA must meet structural and functional requirements. Numerous factors affect the performance of HMA in the specific service environment under traffic loadings. Mixture design, construction practices, properties of the different component materials (aggregates and binder), and the use of additives all play important roles.

\subsubsection{Rutting}

Rutting is one form of permanent deformation in HMA pavements and is characterized by depressions (ruts) in the wheel paths. HMA rutting results in decreased pavement service life and is a hydroplaning hazard when water stands in the ruts.

Rutting can occur in one or more layers as shown in Figure 2.4. Surface rutting can occur when one or more of the HMA layers fails and is usually accompanied by depressions in the surface. Plastic rutting is similar, but also has uplift of the mixture on both sides of the rut. Subgrade rutting occurs when the subgrade is unable to support the loads to which it is exposed. In this case, the pavement settles into the subgrade causing surface depressions in the wheel path. 


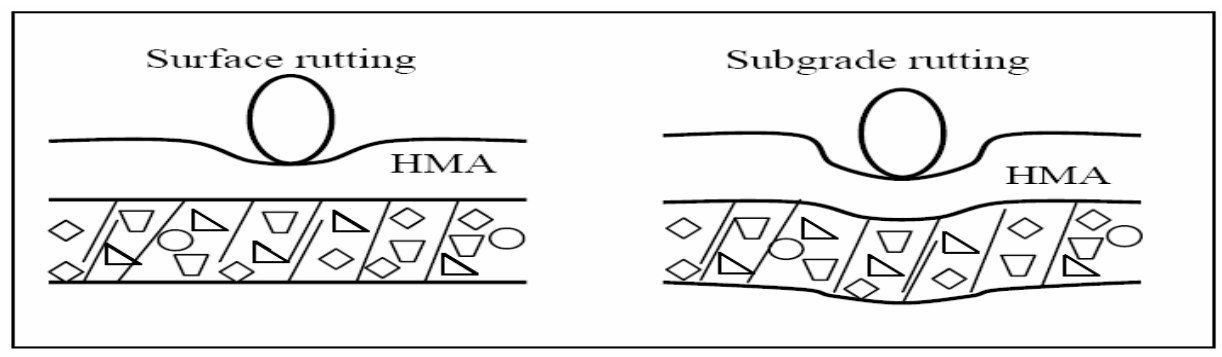

Figure 2.4 Schematic of Rutting

Rutting from plastic deformation typically occurs early in a pavement's life. The increase in plastic deformation gradually slows down as the HMA mixture strain hardens (White et al., 2002). In the process of plastic deformation, aggregate particles move slightly relative to one another, accompanied by the viscous flow in the binder (Christensen and Bonaquist, 2002).

Considerable research has been conducted to quantify binder and aggregate influence on rutting potential. The viscosity of the binder plays an important role in rut resistance; it must be sufficiently strong to resist excessive shear loads generated between the aggregate particles. It has been shown that a higher viscosity (stiffer) binder, especially at higher temperatures, results in HMA mixtures better able to resist rutting. Researchers believe that the stiffer binder increases HMA mixture shear strength from increased cohesion or viscosity (Christensen and Bonaquist, 2002).

Binder content, dust to binder ratio, percent of mineral filler, and film thickness are also HMA mixture properties found to affect mixture rutting potential and performance (McGennis et al. 1994). 


\subsubsection{Fatigue Cracking}

Fatigue cracking occurs when HMA pavements are subjected to repeat bending due to traffic loading over time. As the internal damage accumulates, there is a reduction in HMA pavement stiffness and degradation of the load carrying capacity and ability to resist additional damage. The resulting cracks gradually grow until they reach a size at which fracture occurs under regular service stresses (Monismith, 1995). Such cracking can be recognized by its pattern of interconnected cracks in the pavement surface. Fatigue cracking normally occurs at low to moderate temperatures and can be accelerated by pavement aging (Galal and White, 2001). Possible causes of fatigue cracking can be inadequate structural support for the given loading, increased loading, inadequate structural design, mixture composition, and poor construction techniques.

The stiffness of HMA mixtures containing neat binders and their cycles to failure in the flexural beam tests has been shown to correlate well with the fatigue life of in-service mixtures (Monismith, 1995). Harvey et al. (1995) concluded that within practical ranges, increased binder content and decreased air voids content may result in the increased fatigue life of HMA mixtures. It is postulated that increased binder content increases binder film thickness between aggregate particles resulting in smaller strains and less stress in the binder. As the air voids content decreases, both the stiffness and the ultimate strength of HMA increase; the stress level in both the aggregate and binder will decrease. Lower air voids contents also make a more homogenous binder-aggregate structure resulting in less stress concentration at critical solid-air interfaces. In mixtures with the 
combination of high binder content and low air-void content, the damage that begins to develop under repetitive loading may grow more slowly and take longer to interconnect thus providing longer fatigue life.

\subsubsection{Thermal Cracking}

Thermal cracking occurs in HMA pavements when the temperature drops and the pavement begins to contract. When this happens, tensile stresses occur in the pavement due to the restraint forces from the underlying layer. Once these tensile stresses become greater than the tensile strength of the HMA pavement, a crack occurs. The cracking first develops at the edge and surface of the pavement where the stresses are highest and then propagates inward and

downward. Thermal cracks are evenly spaced and perpendicular to the roadway centerline. Control of thermal cracking becomes a matter of selecting suitable stiffness parameters and setting a limiting value to prevent excessive binder stiffening at the low temperatures expected for a specific geographic area (Shahin and McCullough, 1972).

Thermal cracking can be classified into two types. The first is caused by a single temperature drop that occurs during a relatively short amount of time. This quick change in temperature occurs so rapidly that the stress developed in the pavement cannot relax quickly enough and thus pavement cracks. The second type of thermal cracking is caused by repeated temperature cycling with thermal stresses less than the tensile strength of the HMA mixture. Under extremely cold 
temperatures or repeated temperature cycles, the crack penetrates through the full depth and width of the HMA layer (Epps, 1999).

Binder stiffness at low temperatures and the temperature susceptibility of a binder are the most important factors affecting the degree of low-temperature cracking in an HMA mixture. A less stiff binder will produce a lower rate of increase in stiffness at decreasing temperatures and thus can reduce the potential for low-temperature cracking. When the binder is cooled beyond its brittle point and it loses its ability to flow within the mixture matrix, it cannot shrink and instead cracks (Young, 1998).

Change in HMA binder content within a reasonable range does not have a significant influence on a mixture's low-temperature cracking performance. Increasing the binder content increases the coefficient of thermal contraction but lowers the stiffness (Kanerva et al, 1994).

\subsection{Influence of HMA Components on Pavement Properties}

The appropriate composition of an HMA mixture appears to be one of the most important factors affecting HMA pavement performance. It is critical to understand how the two major components, the binder and the aggregate, affect the ability of HMA mixtures to resist distresses.

\subsubsection{Influence of Modified Binder on Pavement Properties}

In the past two decades modified binders have been used to improve the HMA pavement performance and the role of modified binders on HMA performance 
has been studied extensively. It is understood that soft (less stiff) binders inherently provide improved flexibility and reduce cracking at lower temperatures. However, such binders do not usually perform well at higher temperatures.

Several studies have shown HMA mixtures containing polymer modified binders are more rut resistant than mixtures with neat binders. Modified binders can be designed to satisfy pavement service conditions at both high and low temperature extremes. Button et al. (1987) found that a softer than usual binder can be used along with an additive capable of reducing the temperature susceptibility of the binder in the high temperature range. At higher temperatures and/or lower loading rates, the additives will increase the viscosity (stiffness) and provide equal or better performance than the base neat binder. At the lower temperatures and/or higher loading rates, the additives increase binder tensile strength. Consequently the additives can increase the strain or deformation at failure.

Carpenter and Vandam (1987) illustrated that a proper polymer modification can produce a binder with high stiffness at elevated temperatures, and low stiffness at low temperature. In comparison to mixtures containing neat binders, there are significant improvements in the rutting resistance. Also, the increased strain at low temperature allows for better thermal cracking resistance as well.

Goodrich (1988) found that at low temperatures, the viscous flow capacity (creep) of the binder primarily relies on the viscosity of the base binder. As the temperature increases, the viscosity of the base binder decreases, allowing its elastic nature to become a functional property of the binder. Under controlled 
strain testing, Leahy et al. (1994) found that both base binder type and modifier type substantially affect stiffness, fatigue, and cumulative energy dissipation of the HMA. While the proper balance of the viscous and elastic properties can exist naturally in some binders due to an effective elastic network created by molecular associations, an effective elastic network can also be formed by creating molecular entanglement in binders through the use of high molecular weight polymeric additives.

The research findings regarding the fatigue properties of HMA pavements containing modified binders are varied. Modified binder mixtures can either degrade or enhance HMA mixture fatigue life as measured by flexural beam fatigue tests. Studies by Harvey et al., (1997) and Bahia et al., (2001) have shown that addition of a modifier to certain binders may reduce the number of strain cycles to failure, while the same modifier mixed with a different binder may result in increased fatigue life.

\subsubsection{Aggregate Size, Type, and Gradation}

Aggregate properties also have a significant effect on the performance of HMA mixtures. The resistance of an HMA pavement to different failure mechanisms can depend on aggregate size, type, and gradation. Tests indicate that HMA mixtures with larger Nominal Maximum Aggregate Size (NMAS) generally have better resistance to rutting than do mixtures containing smaller aggregates. Mixtures with larger aggregate sizes also require less binder. Increasing the NMAS in an HMA mixture gradation can also improve the mixture quality in terms 
of creep performance, resilient modulus, and tensile strength (Brown and Basset, 1990). However, Stiady (2000) reported that mixtures with an NMAS of 9.5- and 19.0-mm (0.375- and 0.75-inches) perform similarly in terms of resistance to rutting when tested with the PURWheel.

Much research has been conducted to better understand the relationship between aggregate gradation and HMA mixture performance (Ahlrich, 1996). A study by Hand et al. (2001) showed that gradation along with the Superpave defined restricted zone cannot ensure acceptable rutting performance under accelerated pavement testing. Similar results have been found in other studies (Kandhal and Cooley 2001; Chowdhury et al. 2001).

Based on results of the resilient modulus, tensile strength, retained strength ratios, and permanent deformation testing, Sebaaly et al (1997) concluded that mixtures having gradations passing through the restricted zone were the most favorable. Gradations passing above the restricted zone were concluded to be the least favorable. The HMA mixtures with gradations plotting above or through the restricted zone were reported to have better fatigue performance than gradations passing below the restricted zone (Sousa et al., 1998).

Haddock et al. (1999) concluded that both 9.5- and 19.5-mm (0.375- and 0.75-inch) NMAS mixtures with gradations passing above the restricted zone have higher strengths than those with gradations passing below the restricted zone. Kim et al. (1992) reported that coarse gradations that had a larger proportion of coarse aggregates with the same NMAS did not show significant effects on permanent deformation. Matthews and Monismith (1992) found that 
intermediate-graded mixtures showed better performance in resisting rutting than coarse-graded mixtures.

Kim et al. (1992) reported that aggregate type has a significant effect on the fatigue resistance and permanent deformation of HMA mixtures. Better performance likely comes from mixtures having aggregates with rough surface textures and angular shapes. Such aggregates better resist low temperature cracking and lead to fracture at higher stress levels and lower temperatures (Kanerva et al., 1994).

Maximum resistance to transverse cracking is associated with aggregates that have high abrasion resistance, low freeze-thaw loss, and low absorption. Aggregates that possess these characteristics show little variation in the lowtemperature strengths. Absorptive aggregates reduce the low-temperature strength since the binder that remains in the mixture and is available for bonding is reduced compared to a mixture with a less absorptive aggregate. Mallick et al., (1995) found that the type of crushed aggregate and the percent of crushed particles can also affect the permanent strain values. The strain values increased with an increase in natural sand content. The mixture with more angular aggregates performed better.

Aggregate shape characteristics have also been shown to influence HMA mixture performance by directly controlling the internal friction in the HMA mixtures. Mixtures containing crushed aggregates generally have higher internal friction angles than do mixtures containing rounded aggregates. By evaluating the field and laboratory performance of various HMA mixtures, Brown and Cross 
(1991) concluded that coarse aggregate angularity (CAA) and the uncompacted voids content significantly affected the HMA mixture rutting performance. The results indicated that HMA mixtures containing higher amounts of angular aggregates were the most resistant to rutting. 


\section{CHAPTER 3. EXPERIMENTAL DESIGN}

\subsection{Introduction}

The experiment was completed in two phases and thus the experimental design consists of two parts. The first part of the experimental plan was designed to investigate methods for determining the mixing and compaction temperatures of modified binders. The second phase was designed to investigate the performance of HMA mixtures containing neat and modified binders to see if mixtures containing binders of the same grade would perform similarly regardless of whether the binders were neat or modified.

\subsection{Mixing and Compaction Temperatures}

\subsubsection{Experimental Design}

Density is one of the most important factors in the construction of the HMA pavements and it can affect performance throughout the service life of the pavement. Furthermore, the binder grade, anticipated traffic level and aggregate size and gradation are all important factors affecting the pavement density. The experiment was therefore designed using various levels of these factors. Compaction effort was used as a surrogate for anticipated traffic level; pavements with higher anticipated traffic are typically constructed with higher 
compaction efforts. The experiment used three factor levels for binder grade (PG 64-22, PG 70-22, PG 76-22), aggregate gradation (coarse, fine, Stone Matrix Asphalt (SMA)), and nominal maximum aggregate size (9.5-, 12.5-, and 19.0$\mathrm{mm}$ ), and two factor levels for compaction effort (high, low). The experimental matrix is shown in Table 3.1.

Table 3.1 Mixing and Compaction Temperature Experimental Matrix

\begin{tabular}{|c|c|c|c|c|c|c|c|}
\hline \multicolumn{2}{|c|}{ Compaction Effort } & \multicolumn{2}{|c|}{ High } & \multicolumn{3}{c|}{ Low } \\
\hline \multirow{3}{*}{ Gradation } & NMAS & \multicolumn{2}{|c|}{ PG Binder Grade } & \multicolumn{2}{|c|}{ PG Binder Grade } \\
\hline & $(\mathrm{mm})$ & $64-22$ & $70-22$ & $76-22$ & $64-22$ & $70-22$ & $76-22$ \\
\hline \multirow{4}{*}{ Coarse } & 9.5 & & $\mathrm{X}$ & $\mathrm{X}$ & & & \\
\cline { 2 - 8 } & 12.5 & & $\mathrm{X}$ & & $\mathrm{X}$ & & \\
\hline & 19.0 & & & $\mathrm{X}$ & $\mathrm{X}$ & & \\
\hline \multirow{4}{*}{ Fine } & 9.5 & & & & & & \\
\cline { 2 - 8 } & 12.5 & & & & & & \\
\hline & 19.0 & & & & & & \\
\hline \multirow{3}{*}{ SMA } & 9.5 & & & & & & \\
\cline { 2 - 7 } & 12.5 & & & $\mathrm{X}$ & & & \\
\cline { 2 - 7 } & 19.0 & & & & & & \\
\hline
\end{tabular}

Not all of the factor level combinations in Table 3.1 are used in Indiana and fine-graded mixtures can thus be eliminated. Additionally, the SMA mixtures are normally 12.5-mm NMAS, contain only PG 76-22, and are used only in high traffic applications; low volume roads usually contain PG 64-22 binders. When all of the unlikely combinations are eliminated, 12 coarse-graded cells and one SMA cell remain as indicated by the lack of shading in Table 3.1. The Indiana Department of Transportation (INDOT) was contacted for assistance in locating possible projects. 


\subsubsection{Material}

A total of eight projects were identified by INDOT that met the experimental design criteria shown in Table 3.1. A listing of these mixtures is in Table 3.2. No high compactive effort, coarse-graded HMA mixtures with PG 64-22 were found. A 12.5-mm, coarse-graded mixture with PG 76-22 was also not available.

Finally, no 19.0-mm, coarse-graded mixture with PG70-22 or a low compactive effort, 9.5-mm, coarse-graded mixture with PG 64-22 were found. A second 12.5-mm mixture with PG 64-22 was substituted for this latter mixture. Materials from each of the eight field construction projects were collected along with construction information. Collected materials included HMA mixture samples, aggregates, and binders. Construction information included optimum binder content, mixture gradation, laboratory mixing and compaction temperatures, and field mixing and compaction temperatures.

Table 3.2 Selected Projects

\begin{tabular}{|c|c|c|c|c|c|}
\hline $\begin{array}{c}\text { Project } \\
\text { Designation }\end{array}$ & Road & $\begin{array}{c}\text { Aggregate } \\
\text { Gradation }\end{array}$ & $\begin{array}{c}\text { NMAS } \\
(\mathrm{mm})\end{array}$ & $\begin{array}{c}\text { PG Binder } \\
\text { Grade }\end{array}$ & $\begin{array}{c}\text { Compaction } \\
\text { Effort }\end{array}$ \\
\hline R-23396 & US 40 & Coarse & 9.5 & $76-22$ & High \\
\hline R-23924 & SR 46 & Coarse & 19.0 & $76-22$ & High \\
\hline R-24326 & $\begin{array}{c}\text { Greensboro } \\
\text { Pike }\end{array}$ & Coarse & 19.0 & $64-22$ & Low \\
\hline R-24564 & SR 9 & Coarse & 12.5 & $70-22$ & High \\
\hline R-25053 & US 231 & Coarse & 9.5 & $70-22$ & High \\
\hline R-25056 & SR 75 & Coarse & 12.5 & $64-22$ & Low \\
\hline R-25113 & SR 37 & Coarse & 12.5 & $64-22$ & Low \\
\hline R-25723 & $86^{\text {th }}$ Street & SMA & 12.5 & $76-22$ & High \\
\hline
\end{tabular}




\subsubsection{Test Method}

To determine the mixing and compaction temperatures for the field collected binders, the Brookfield Viscometer was used to make viscosity measurements at various shear rates in accordance with the ZSV test protocol. Additional details are provided in Chapter 4 . Once the ZSV mixing and compaction temperatures were established, Superpave Gyratory Compactor (SGC) compacted specimens were prepared and the optimum binder contents determined. These were compared to the optimum binder contents obtained in the original mixture designs using the empirically specified mixing and compaction temperatures.

\subsection{Neat and Modified Binders}

\subsubsection{Experimental Design}

Table 3.3 shows the experimental design matrix for phase two of the study. As can be seen, the factors of NMAS and mixture gradation each have two factor levels. Additionally, the experimental factor of binder type includes two modified and two neat binders. Once the appropriate materials were identified and acquired, the binders and aggregates were tested in order to characterize the materials. Mixture designs were then completed, test specimens fabricated, and physical testing completed. The PURWheel, beam fatigue, and indirect tension tests were used to characterize each of the HMA mixtures. 
Table 3.3 Neat vs. Modified Binder Experimental Matrix

\begin{tabular}{|c|c|c|c|}
\hline \multirow{2}{*}{$\begin{array}{c}\text { NMAS } \\
(\mathrm{mm})\end{array}$} & & \multicolumn{2}{|c|}{ HMA Mixture Gradation } \\
\hline \multirow{4}{*}{9.5} & Peat 70-22 & & Fine \\
\cline { 2 - 4 } & Neat 75-22 & & $-^{\mathrm{a}}$ \\
\cline { 2 - 4 } & Modified 70-22 & & \\
\cline { 2 - 4 } & Modified 75-22 & & $-^{\mathrm{a}}$ \\
\hline \multirow{4}{*}{12.5} & Neat 70-22 & & \\
\cline { 2 - 4 } & Neat 75-22 & & $-^{\mathrm{a}}$ \\
\cline { 2 - 4 } & Modified 70-22 & & \\
\cline { 2 - 4 } & Modified 75-22 & & $-^{\mathrm{a}}$ \\
\hline
\end{tabular}

${ }^{\mathrm{a}}$ These combinations were not tested by design.

\subsubsection{Materials}

\subsubsection{Binders}

Binders meeting the current INDOT specifications for PG70-22 were selected for use in the project. The main reasons for selecting this grade are that it can be produced in both neat and modified versions and it is a common binder type used in Indiana. As shown in Table 3.3, two neat and two modified binders all meeting the requirements of a PG 70-22 were selected for use. One pair of modified and neat binders meets the high temperature stiffness specification at approximately $70 \mathrm{C}(158 \mathrm{~F})$. The remaining pair of modified and neat binders meets the high temperature stiffness specification at approximately $75 \mathrm{C}(167 \mathrm{~F})$. According to the Superpave binder grading protocols, all four binders have a high temperature stiffness grade of PG 70. The low temperature grade of each of the binders is a -22. This was necessary due to binder manufacturing limitations. 


\subsubsection{Aggregate Properties}

The properties of the aggregates used in the study are shown in Table 3.4. Uncrushed gravel and natural sand were selected as aggregates in order to lessen the influence of the aggregate structure in the HMA mixtures. The aggregates were blended to achieve the mixture gradations plotted in Figure 3.1. All mixtures meet the applicable INDOT gradation specifications. The 9.5-mm mixtures were made by scalping the oversized material from the uncrushed gravel $\mathrm{A}$.

Table 3.4 Aggregate Properties

\begin{tabular}{|c|c|c|c|c|}
\hline Aggregate Type & $\begin{array}{c}\text { Uncrushed } \\
\text { Gravel A }\end{array}$ & $\begin{array}{c}\text { Uncrushed } \\
\text { Gravel B }\end{array}$ & $\begin{array}{c}\text { Natural } \\
\text { Sand }\end{array}$ & $\begin{array}{c}\text { Limestone } \\
\text { Filler }\end{array}$ \\
\hline Sieve Size (mm) & \multicolumn{5}{|c|}{ Percent Passing } \\
\hline 19.0 & 100.0 & & & \\
\hline 12.5 & 87.2 & 100.0 & & \\
\hline 9.5 & 30.5 & 98.2 & 100.0 & \\
\hline 4.75 & 0.5 & 1.9 & 99.7 & \\
\hline 2.36 & 0.4 & 0.6 & 93.7 & \\
\hline 1.18 & 0.4 & 0.5 & 66.2 & \\
\hline 0.600 & 0.4 & 0.4 & 39.3 & \\
\hline 0.300 & 0.4 & 0.4 & 15.2 & 100.0 \\
\hline 0.150 & 0.4 & 0.4 & 3.9 & 85.0 \\
\hline 0.075 & 0.3 & 0.4 & 2.3 & 57.0 \\
\hline $\mathrm{G}_{\mathrm{sb}}$ & 2.617 & 2.572 & 2.595 & 2.708 \\
\hline
\end{tabular}




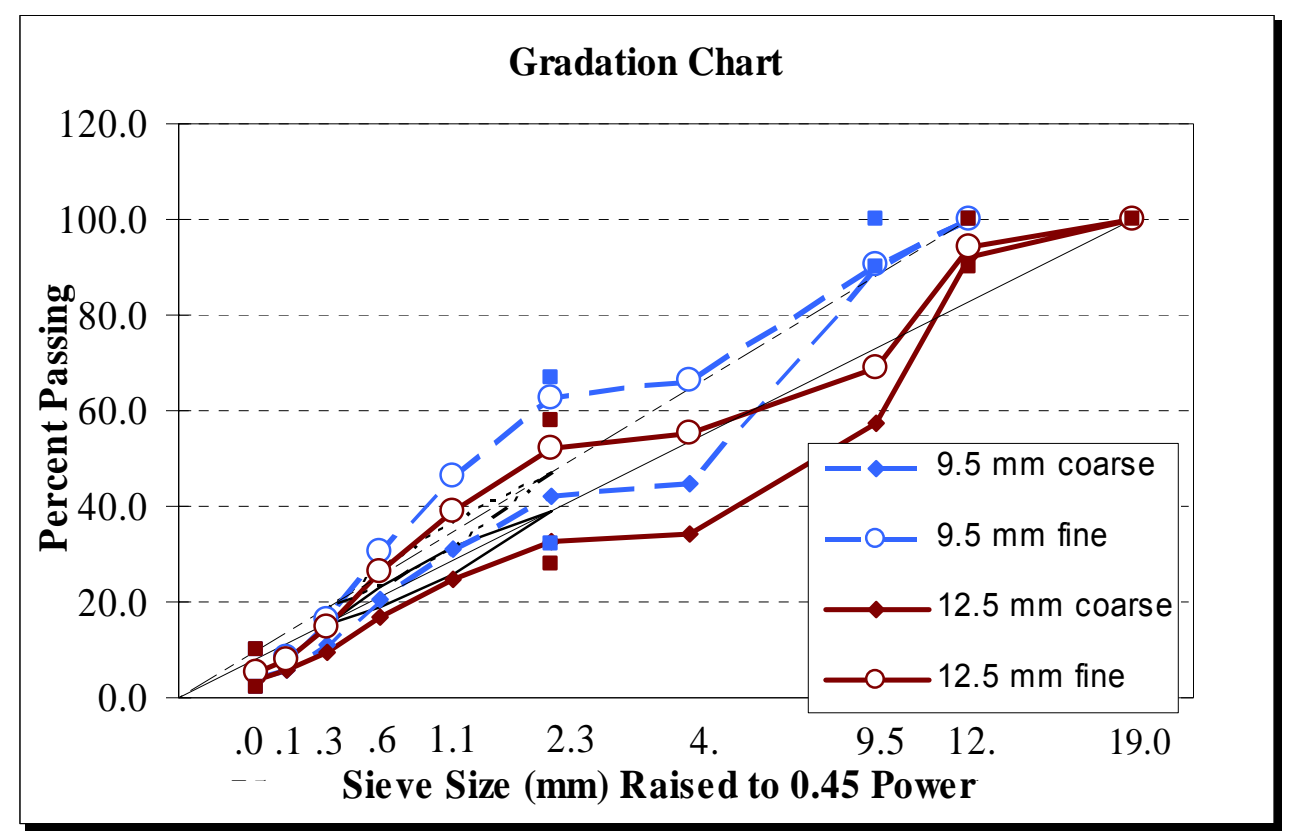

Figure 3.1 Mixture Gradations

\subsubsection{Mixture Design}

When completing the mixture designs, all specimens were prepared following the Superpave mixture design procedures prescribed in AASHTO PP28. The selected traffic level was 3 to 30 million Equivalent Single Axle Loads (ESAL) and the number of gyrations for initial $\left(\mathrm{N}_{\text {ini }}\right)$, design $\left(\mathrm{N}_{\text {des }}\right)$, and maximum $\left(\mathrm{N}_{\max }\right)$ were chosen to be 8,100 , and 160 , respectively. The mixing and compaction temperatures were 168 and $157 \mathrm{C}$ (334 and $315 \mathrm{~F}$ ) respectively. Table 3.5 shows a summary of the designs at an air voids content of 4 percent. It was not possible to meet the VMA requirements with the coarse-graded mixtures due to the rounded aggregates used. 
Table 3.5 Mixture Design Summary

\begin{tabular}{|c|c|c|c|c|}
\hline Sieve Size $(\mathrm{mm})$ & \multicolumn{2}{|c|}{$9.5-\mathrm{mm}$ NMAS } & \multicolumn{2}{c|}{ 12.5-mm NMAS } \\
\cline { 2 - 5 } & Coarse & Fine & Coarse & Fine \\
\hline 19.0 & & & 100 & 100 \\
\hline 12.5 & 100 & 100 & 92 & 96 \\
\hline 9.5 & 90 & 98 & 57 & 80 \\
\hline 4.75 & 47 & 78 & 33 & 69 \\
\hline 2.36 & 42 & 65 & 30 & 57 \\
\hline 1.18 & 30 & 47 & 22 & 41 \\
\hline 0.600 & 19 & 30 & 14 & 26 \\
\hline 0.300 & 9 & 15 & 8 & 12 \\
\hline 0.150 & 4 & 7 & 4 & 5 \\
\hline 0.075 & 3 & 4 & 3 & 3 \\
\hline Binder Content, \% & 4.8 & 6.0 & 4.3 & 6.4 \\
\hline VMA, \% & $14.3^{\mathrm{a}}$ & 15.7 & $11.3^{\mathrm{a}}$ & 15.8 \\
\hline VFA, \% & 71.0 & 71.0 & 68.0 & 71.0 \\
\hline Dust Proportion, \% & 0.7 & 0.7 & 0.8 & 0.9 \\
\hline
\end{tabular}

${ }^{\mathrm{a}}$ Does not meet specification

\subsubsection{Test Specimen Preparation Procedures}

Three laboratory performance tests, PURWheel, beam fatigue, and indirect tensile test, were used in the experiment. These tests were designed to evaluate the rutting, fatigue cracking, and thermal cracking distress modes, respectively. Sample preparation for the three performance tests involved several procedures as described below.

\subsubsection{Aging}

The different performance tests required variable aging conditions. The Superpave volumetric mixture design method requires that HMA mixtures be aged for 2 hours \pm 5 minutes in a forced-draft oven at the compaction temperature prior to compaction. To prepare specimens for mechanical property 
testing, short term conditioning of the mixtures is required. This involves aging the mixture 4 hours \pm 5 minutes at $135 \pm 3 \mathrm{C}(275 \pm 10 \mathrm{~F})$ before compaction of test specimens. This is thought to simulate the aging that occurs during plant mixing and construction. For the indirect tensile test, after the specimens were compacted and saw-cut, they received additional long-term aging of 5 days at $85 \pm 3 C(185 \pm 10 F)$.

\subsubsection{Compaction and Specimen Sawing}

When preparing the specimens for PURWheel and beam fatigue tests the linear kneading compactor was used. The SGC was employed to compact the samples for the indirect tensile test. Chapter 5 provides detailed information about the linear kneading compactor. Once the compacted samples had cooled to room temperature, a wet saw was used to cut them to the correct dimensions for the specific test. The specimens were then allowed to air dry before volumetric measurements were made.

\subsubsection{Air Voids Measurement}

The target air voids content for all of the test specimens was $7 \pm 1$ percent. This range is thought to simulate the initial in-situ density. For PURWheel specimens, the bulk specific gravity is determined by dividing the mass by bulk volume. The bulk volume is calculated by multiplying the length, width, and thickness of the compacted slab. The bulk specific gravity of beam fatigue and IDT specimens were determined according to AASHTO T166. 


\subsubsection{Statistical Data Analysis Procedure}

Statistical analysis was used to evaluate the study results. The three main factors along with the interactions between them were considered. The simplified model used to evaluate the effects is:

$$
\mu_{i j}=\mu+\alpha_{i}+\beta_{j}+\gamma_{k}+(\alpha \beta)_{i j}+(\alpha \gamma)_{i k}+(\beta \gamma)_{j k}+(\alpha \beta \gamma)_{i j k}+\varepsilon
$$

where,

$$
\begin{aligned}
& \mu_{\mathrm{ij}}=\text { response variable; } \\
& \alpha_{\mathrm{i},}, \beta_{\mathrm{j},}, \gamma_{\mathrm{k}}=\text { main effect of factors; } \\
& (\alpha \beta)_{\mathrm{ij}},(\alpha \gamma)_{\mathrm{ik}},(\beta \gamma)_{\mathrm{jk}},(\alpha \beta \gamma)_{\mathrm{ijk}}=\text { interaction effects between main factors; } \\
& \quad \text { and } \\
& \varepsilon=\text { error term. }
\end{aligned}
$$

The analysis of variance (ANOVA) procedure was used when more than one independent variable was evaluated; the multi-factorial (two-way) ANOVA accounts for possible interaction between the main factors. As shown in Equation 3-1, the results of a multi-factorial ANOVA are divided into main effects, which reflect the variability due to each independent variable, and interactive effects, that reflect the effects of one variable across different levels of other independent variables. The model is considered to be statistically significant if the outcome ( $p$ value) is less than that at the standard significance level (5 percent in this study). The ANOVA only indicates whether or not a difference exists among all group means; therefore, to determine between which groups differences do occur, additional statistical tests must be used. 
The t-test was used to compare the means of two sample groups. This test involves calculating a critical difference between pairs of group means that must be exceeded in order for the group means to be considered significantly different. For example, to test for the difference among binder effects, only the binder grade is accounted for regardless of the NMAS or gradation values. If the difference of the data means between two binder types exceeds the critical difference determined by the statistical procedure, the effects of the two binders upon the measured outcome is considered significantly different. Additional details on statistical data analysis and interpretation can be found in texts by Neter et al. (1996), Bickel and Doksum (2001), and Montgomery (2000). 


\section{CHAPTER 4. DETERMINATION OF MIXING AND COMPACTION TEMPERATURES}

\subsection{Standard Method}

The objective for this portion of the research was to develop a rational method of specifying field mixing and compaction temperatures for HMA mixtures that is particularly applicable to modified PG-graded binders. The concept of establishing HMA mixing and compaction temperature ranges based on binder viscosity has a historical context and was adopted as part of the Superpave mixture design method. In the Superpave method, HMA specimens are mixed and compacted at equiviscous binder temperatures corresponding to binder viscosities of $0.17 \pm 0.02$ and $0.28 \pm 0.03 \mathrm{~Pa} \cdot \mathrm{s}(170 \pm 20$ and $280 \pm 30$ centistokes), respectively. To determine the appropriate mixing and compaction temperatures, a Rotational Viscometer (RV) is used according to AASHTO T316, "Standard Test Method for Viscosity Determination of Asphalt Binder using Rotational Viscometer." The test is used to measure the viscosities of a binder at 135 and 165C (275 and 330F). These measurements establish two points on the log-log plot as was shown earlier in Figure 2.2. The mixing and compaction temperatures are then established by the ranges noted and as shown in the figure. Figure 2.2 is repeated here for clarity. 
Viscosity-Temperature Chart

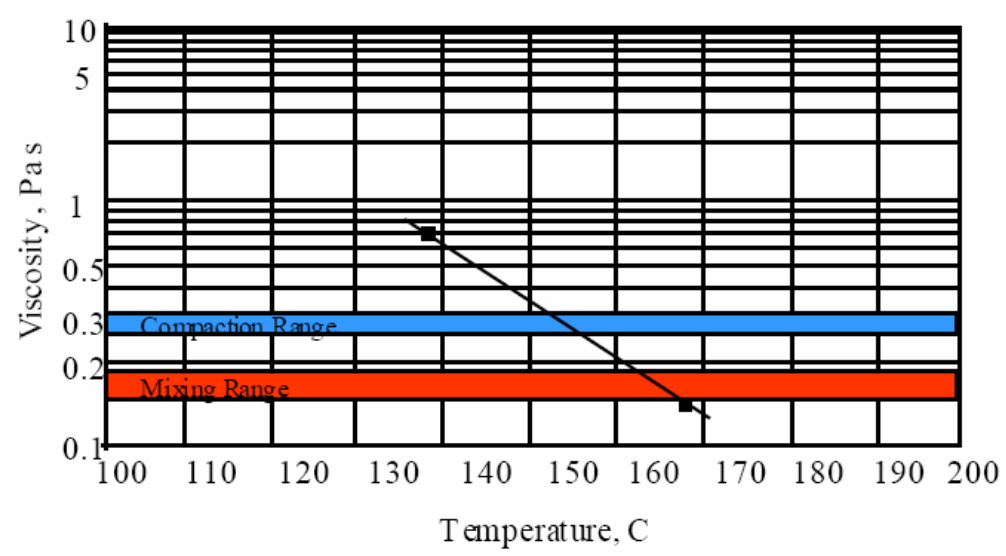

Figure 2.2 Viscosity - Temperature chart (ASTM D2493)

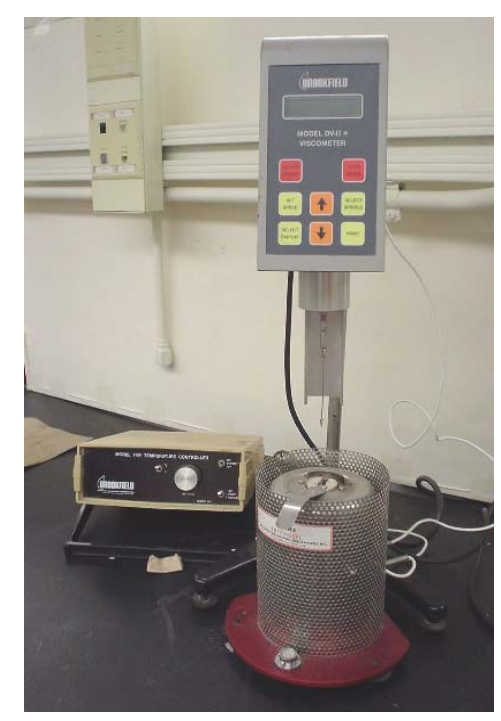

Figure 4.1 Brookfield Rotational Viscometer

In this study, a Brookfield model DV-II+ rotational viscometer (Figure 4.1

Figure 4.1) was used for all rotational viscosity testing. The conventional Superpave mixing and compaction temperatures were determined for each of the 
binders obtained from the eight field projects (see Table 3.2). This data is included with in Table 4.2 where it has been denoted as Standard RV.

\subsection{Zero Shear Viscosity Test Procedure}

The ZSV method of determining HMA mixing and compaction temperatures used in this research was developed as part of the NCHRP 9-10 study (Khatri et al., 2001) and is based upon the use of the RV to determine the zero shear viscosity of a binder as discussed in Chapter 2.

According to the NCHRP 9-10 protocol, the ZSV test is performed on original binder to measure viscosities at varying shear rates. In order to get the widest possible range of data the test is performed at temperatures of 105,135 , and 165C $(221,275$, and 329F) using the No. 21 spindle. As soon as the test temperature has stabilized the test begins with the lowest shear rate. Example data is shown in Table 4.1. At each shear rate the reading is taken after it has stabilized for 5-10 minutes. The test is conducted at increasing shear rates, with a rest period of 1 minute between each shear rate. Similar to the RV method, four measurements are reported for each binder sample. This procedure is continued until the percent torque falls outside the range of 2 and 98 percent. 
Table 4.1 Example of Viscosity Test Data

\begin{tabular}{|c|c|c|c|c|c|}
\hline $\begin{array}{c}\text { Temperature } \\
\text { C }\end{array}$ & $\begin{array}{c}\text { Shear Rate, } \\
\mathrm{s}^{-1}\end{array}$ & $\begin{array}{l}\text { Shear Stress } \\
\text { dynes } / \mathrm{cm}^{2}\end{array}$ & $\begin{array}{c}\text { Viscosity, } \\
\text { cP }\end{array}$ & Fit $(C W)^{a}$ & $(d \eta)^{2}$ \\
\hline \multirow{9}{*}{165} & 2.3 & 11.1 & 482.61 & 483.81 & 1.45 \\
\hline & 2.8 & 13.3 & 475.00 & 470.93 & 16.60 \\
\hline & 3.7 & 17.0 & 459.46 & 463.26 & 14.47 \\
\hline & 4.7 & 21.6 & 459.57 & 460.83 & 1.58 \\
\hline & 5.6 & 25.7 & 458.93 & 460.03 & 1.22 \\
\hline & 9.3 & 42.8 & 460.22 & 459.32 & 0.80 \\
\hline & 11.2 & 51.5 & 459.82 & 459.26 & 0.32 \\
\hline & 18.6 & 85.7 & 460.75 & 459.21 & 2.38 \\
\hline & 27.9 & 128.2 & 459.50 & 459.20 & 0.09 \\
\hline \multirow{10}{*}{135} & 0.9 & 16.7 & 1855.56 & 1855.57 & 0.00 \\
\hline & 1.4 & 24.6 & 1757.14 & 1756.25 & 0.80 \\
\hline & 1.9 & 33.0 & 1736.84 & 1743.48 & 44.09 \\
\hline & 2.3 & 40.2 & 1747.83 & 1740.88 & 48.28 \\
\hline & 2.8 & 48.8 & 1742.86 & 1739.72 & 9.83 \\
\hline & 3.7 & 64.6 & 1745.95 & 1739.12 & 46.59 \\
\hline & 4.7 & 80.9 & 1721.28 & 1738.96 & 312.55 \\
\hline & 5.6 & 97.4 & 1739.29 & 1738.91 & 0.14 \\
\hline & 9.3 & 162.0 & 1741.94 & 1738.87 & 9.39 \\
\hline & 11.2 & 195.1 & 1741.96 & 1738.87 & 9.59 \\
\hline
\end{tabular}

${ }^{a}$-Indicates the fit of the Cross-Williamson model

The procedure for calculating the ZSV mixing and compaction temperatures for each binder based on the Cross-Williamsons model has been simplified by using a spreadsheet developed by the NCHRP 9-10 research team. Initial values of the four parameters $\left(\eta_{0}, \eta_{\infty}, K\right.$ and $\left.n\right)$ in the model, as shown in Equation 2-2, are input according to values recommended by the spreadsheet developers. The embedded solver then solves for each parameters in the Cross-Williamsons model at each test temperature. A typical set of data points and curve fitting based on the Cross-Williamson model is presented in Figure 4.2

Figure 4.. 


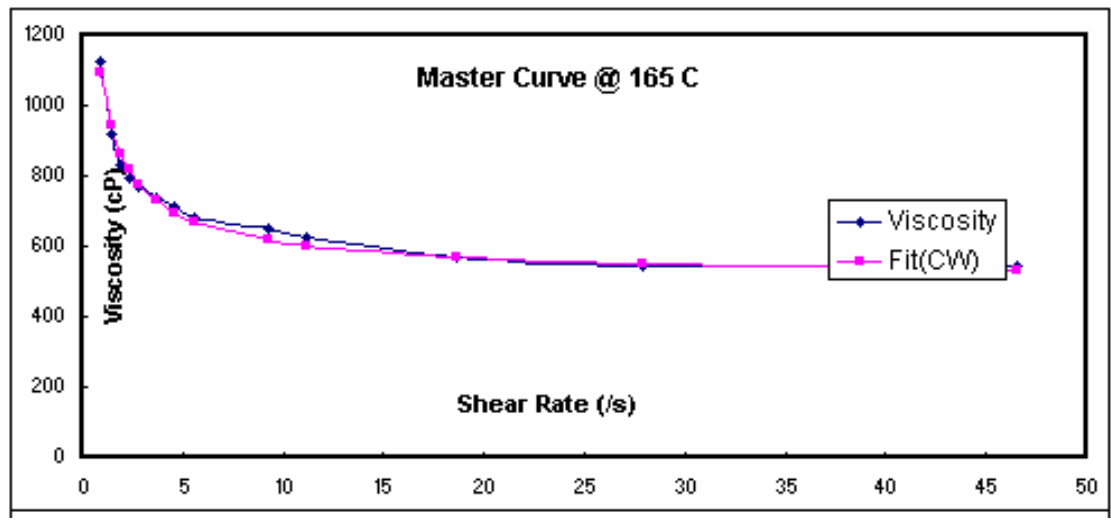

Figure 4.2 Example of a Graphed Data Points and Fitted Curve

Using the solved ZSV $\left(\eta_{0}\right)$ values at three different test temperatures, the viscosity-temperature profile is obtained by plotting the ZSV as a function of temperature as shown in Figure 4.3. The corresponding mixing and compaction temperatures at 3.0 and $6.0 \mathrm{~Pa} \cdot \mathrm{s}$ are determined using this profile.

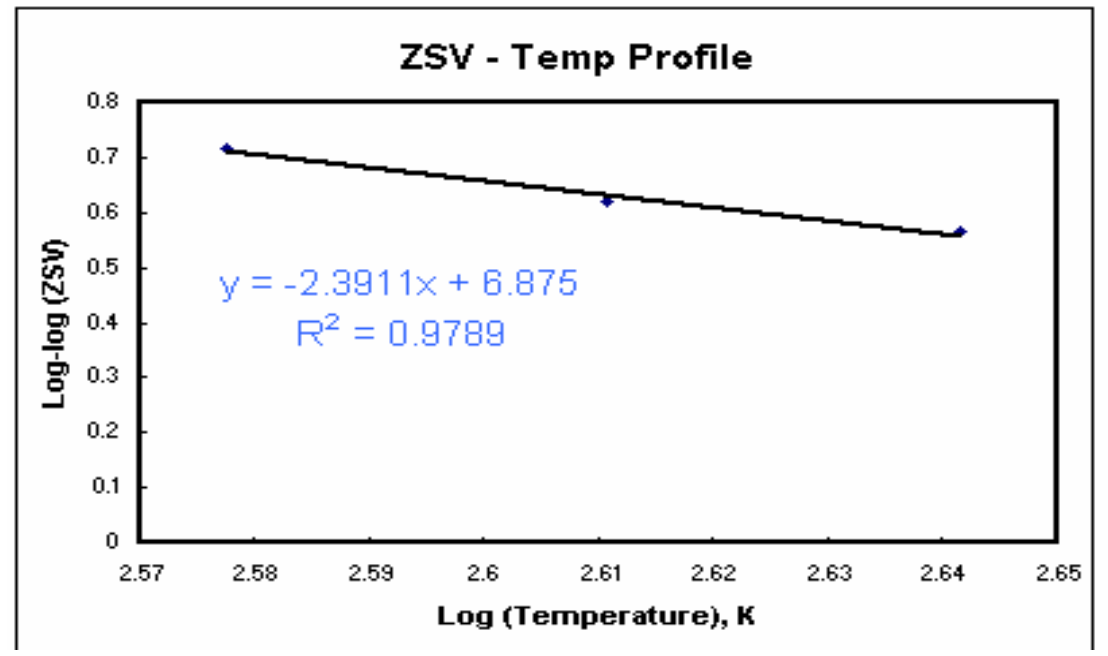

Figure 4.3 Interpolation Example from ZSV-Temperature Profile 


\subsection{Mixing and Compaction Temperature Test Results}

The mixing and compaction temperatures data is shown in Table 4.2. Field temperatures for some projects were not available. The neat binders did not have ZSV temperatures and thus no optimum binder contents based on ZSV. The data is plotted in Figures 4.4 and 4.5.

For projects involving PG 64-22 binders the ZSV mixing and compaction temperatures appear unreasonably low. Also, these mixtures show little difference between the standard $\mathrm{RV}$ determined temperatures and the original laboratory mixture design temperatures. The PG 64-22 mixture that has field data shows that the field mixing temperature was also approximately the same as these. No alternative mixing and compacting temperatures are therefore necessary.

The PG 70-22 binder used in Project R-24564 may be a modified binder, but both the standard RV and ZSV tests show that the binder exhibits Newtonian behavior. The resulting ZSV temperatures for this project were therefore lower than the mixing and compaction temperatures used in the project just like the three neat binders.

Four projects (R-23396, R-23924, R-25053, R-25723) used modified binders and have ZSV mixing and compaction temperatures lower than determined by the standard RV method, but comparable to the design and production temperatures actually used. This is because for modified binders, INDOT currently uses laboratory design and construction temperatures as recommended by binder suppliers rather than the standard RV determined temperatures. 
Table 4.2 Mixing and Compaction Temperatures

\begin{tabular}{|c|c|c|c|c|c|c|c|c|c|}
\hline \multicolumn{2}{|c|}{ Project Designation } & R-23396 & R-23924 & R-24326 & R-24564 & R-25053 & R-25056 & R-25113 & R-25723 \\
\hline \multicolumn{2}{|c|}{ PG Binder Grade } & $76-22$ & $76-22$ & $64-22$ & $70-22$ & $70-22$ & $64-22$ & $64-22$ & $76-22$ \\
\hline \multirow{4}{*}{$\begin{array}{c}\text { Mixing } \\
\text { Temperature, C }\end{array}$} & Standard RV & 198 & 196 & 159 & 165 & 172 & 158 & 157 & 233 \\
\hline & Design & 163 & 156 & 160 & 149 & 160 & 152 & 154 & 168 \\
\hline & Field & 164 & 155 & -1 & 177 & 152 & 149 & -1 & 176 \\
\hline & ZSV & 157 & 153 & 116 & 120 & 154 & 115 & 118 & 173 \\
\hline \multirow{4}{*}{$\begin{array}{l}\text { Compaction } \\
\text { Temperature, C }\end{array}$} & Standard RV & 181 & 181 & 147 & 153 & 160 & 144 & 146 & 210 \\
\hline & Design & 152 & 150 & 143 & 138 & 149 & 141 & 143 & 160 \\
\hline & Field & 143 & -1 & -1 & 138 & 146 & -1 & -1 & 158 \\
\hline & ZSV & 144 & 141 & 104 & 112 & 145 & 103 & 106 & 157 \\
\hline \multicolumn{2}{|c|}{$\begin{array}{c}\text { Design Optimum } \\
\text { Binder Content, \% }\end{array}$} & 6.1 & 4.1 & 4.5 & 5.3 & 5.9 & 5.8 & 6.2 & 5.6 \\
\hline \multicolumn{2}{|c|}{$\begin{array}{c}\text { ZSV Optimum } \\
\text { Binder Content, \% }\end{array}$} & 6.1 & 4.1 & $-{ }^{2}$ & $-{ }^{2}$ & 4.7 & $-{ }^{2}$ & $-{ }^{2}$ & 5.6 \\
\hline
\end{tabular}

1 - Data not available,

${ }^{2}$ - Neat binders, no ZSV temperatures 


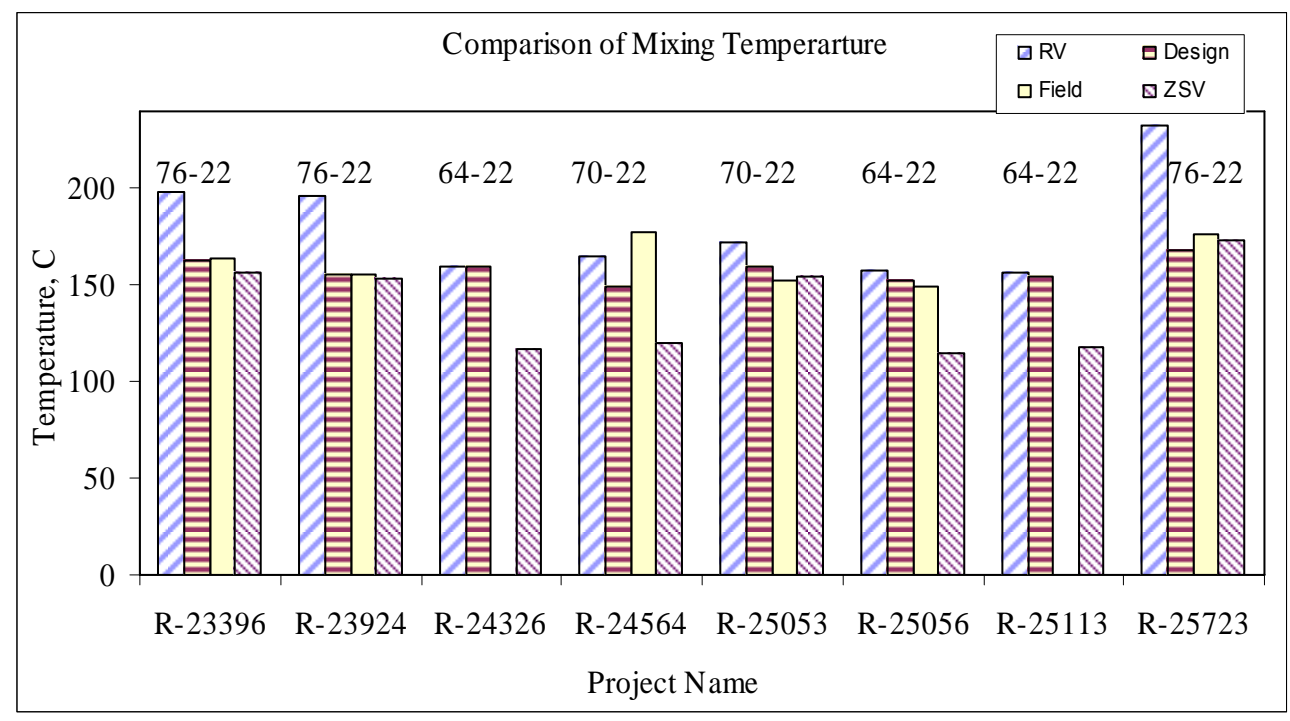

Figure 4.4 Mixing Temperature Comparison

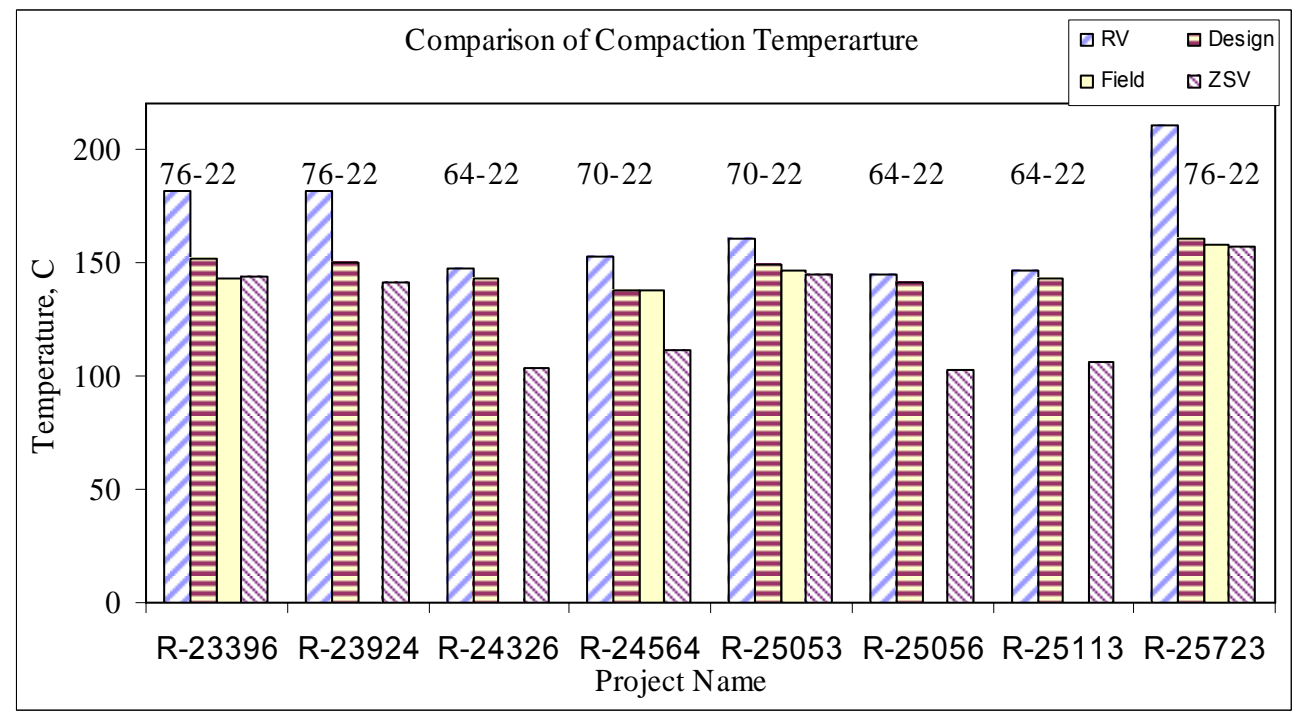

Figure 4.5 Compaction Temperature Comparison

\subsection{Discussion of Results}

Figures 4.6 and 4.7 are plots showing the relationships between the standard RV and the ZSV mixing and compaction temperatures, respectively. Both plots indicate that the relationship between the standard RV and ZSV methods are 
linear. For each binder in the experiment, the ZSV temperatures are lower than the standard RV temperatures.

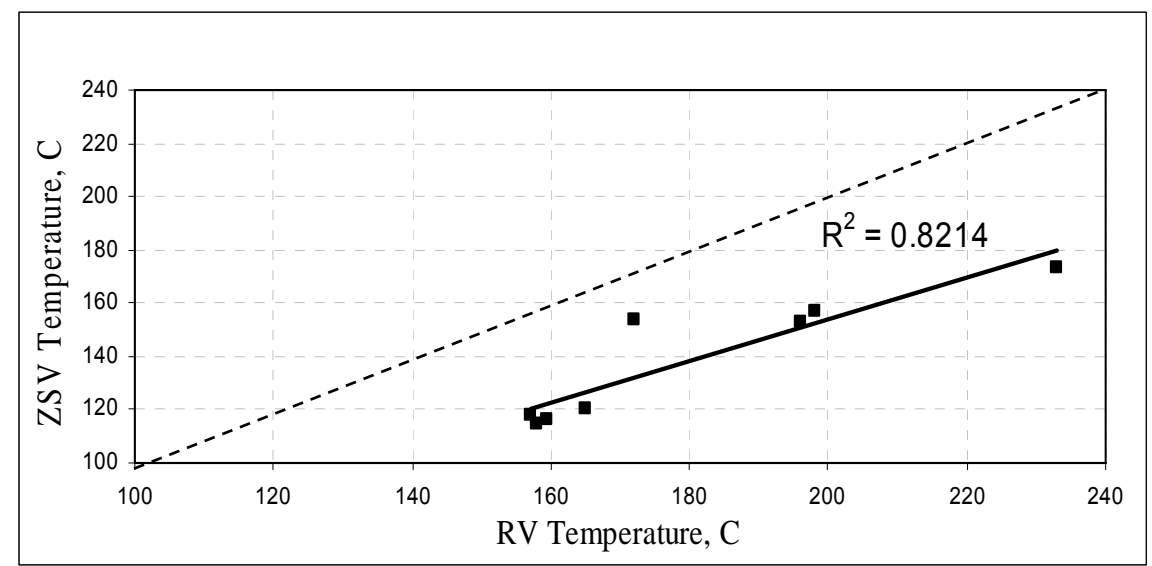

Figure 4.6 Mixing Temperature Relationship

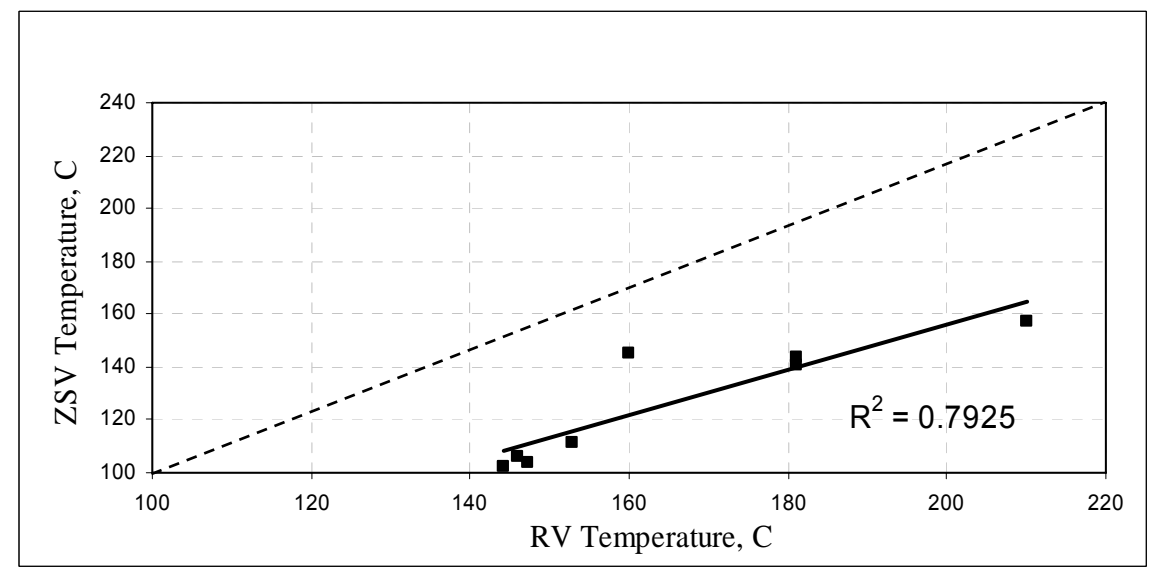

Figure 4.7 Compaction Temperature Relationship

The relationship between RV and ZSV mixing and compaction temperatures was statistically examined and the results are shown in Figure 4.8. The upper and lower confidence interval (95\% confidence level) bounds are also shown on the graph. A confidence interval gives an estimated range of values which is 
likely to include an unknown population parameter. Most data are located within the 95 percent confidence interval. This means that if additional samples are selected from the population, 95 percent of these intervals will contain the population mean. However, the mixing and compaction temperature data from project R-25053 appear to be outliers. Statistical testing confirmed that these two data points are indeed outliers. If they are excluded, the plot shown in Figure 4.9 is linear $(Z S V=-16.645+0.845 R V)$ with an $R^{2}$ value of 0.97 indicating that the linear regression fit explains 97 percent of the total variation in the data about the mean.

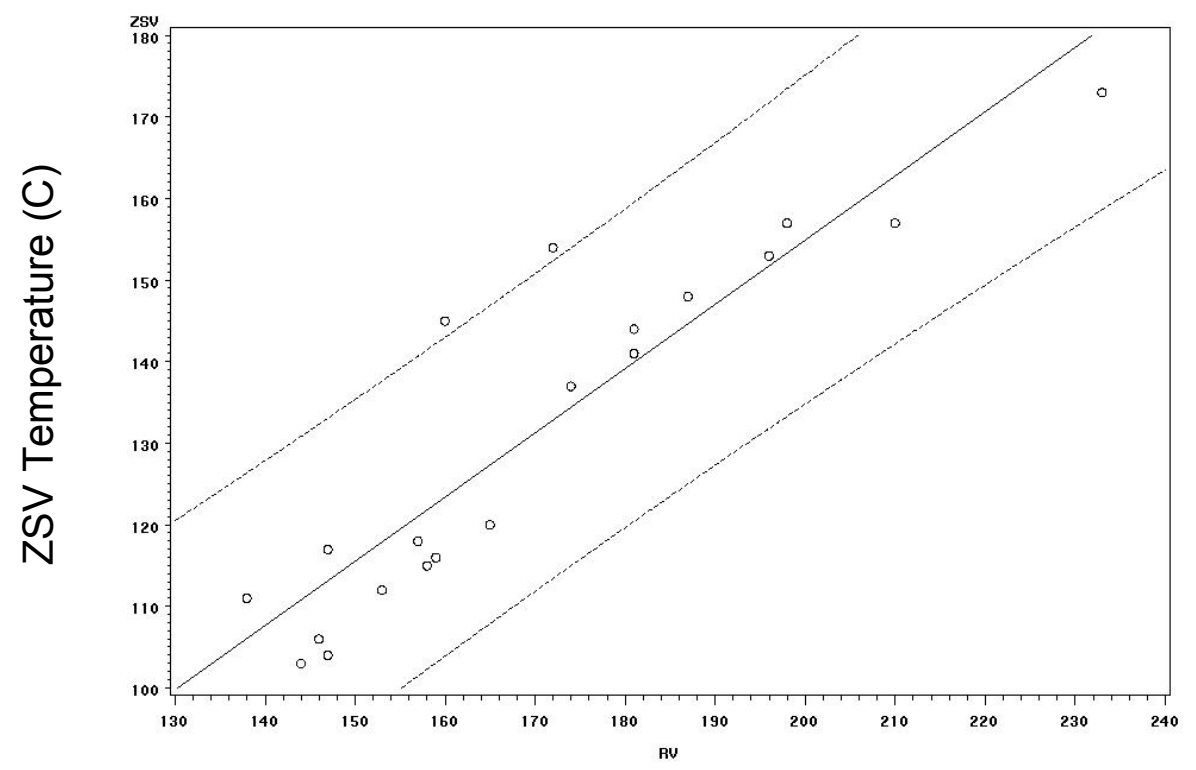

RV Temperature (C)

Figure 4.8 ZSV and RV Temperature Relationship 


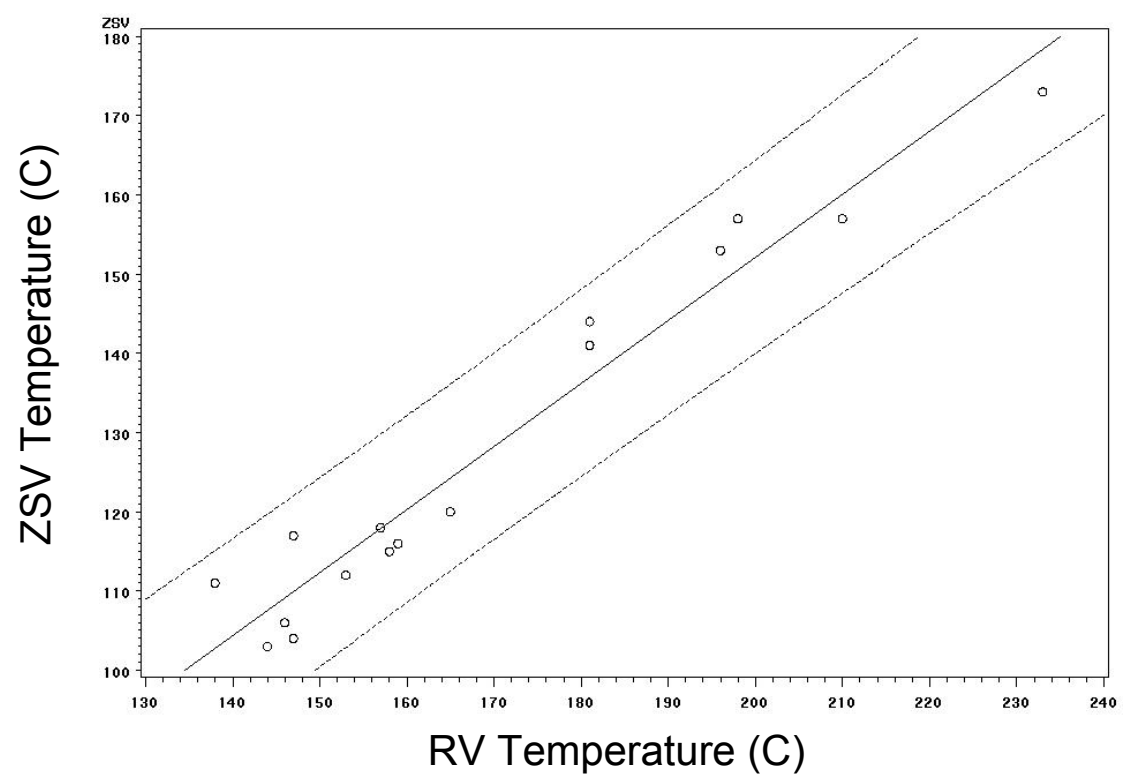

Figure 4.9 ZSV and RV Temperature Relationship (without outliers)

One hypothesis of the research was that by using the ZSV method the mixing and compaction temperatures could be decreased while maintaining density and aggregate coating, and without increasing compaction effort and/or binder content. In order to test this hypothesis, laboratory specimens were mixed and compacted using the ZSV recommended temperatures for the mixtures containing non-Newtonian binders (R-23396, R-23924, R-25053 and R-25723).

For each project, the aggregates that had been sampled from the plant during construction were separated into individual size fractions and the appropriate amount of each size batched to duplicate the mixture design aggregate gradation. The batched aggregate samples were then heated at the appropriate ZSV mixing temperature and combined and mixed with the appropriate binder for the project. After oven-aging for two-hours at the ZSV compaction temperatures, each sample was compacted in the SGC using the project specific required 
number of gyrations. The bulk specific gravity of each compacted specimen and the theoretical maximum specific gravity of comparable loose mixtures were measured and the air voids and optimum binder contents calculated to determine if the optimum binder content using ZSV temperatures varied from those used during the original mixture design process. The results are shown in Table 4.3.

Table 4.3 Comparison of Optimum Binder Contents

\begin{tabular}{|c|c|c|c|c|c|c|c|c|}
\hline Project Designation & R-23396 & R-23924 & R-24326 & R-24564 & R-25053 & R-25056 & R-25113 & R-25273 \\
\hline PG Binder Grade & $76-22$ & $76-22$ & $64-22$ & $70-22$ & $70-22$ & $64-22$ & $64-22$ & $76-22$ \\
\hline $\begin{array}{c}\text { Mixture Design } \\
\text { Optimum Binder } \\
\text { Content, \% }\end{array}$ & 6.1 & 4.1 & 4.5 & 5.3 & 5.9 & 5.8 & 6.2 & 5.6 \\
\hline $\begin{array}{c}\text { ZSV Determined } \\
\text { Optimum Binder } \\
\text { Content, \% }\end{array}$ & 6.1 & 4.1 & -1 & -1 & 4.7 & -1 & -1 & 5.6 \\
\hline
\end{tabular}

${ }^{1}$ No ZSV temperatures for these binders

From Table 4.3 it can be seen that the optimum binder contents for the mixtures containing modified binders did not change significantly. The optimum binder content of the R-25053 mixture is much lower than the original mixture design, but this is believed to be due to an error in the laboratory during the mixing and compaction of the mixture specimens. Unfortunately, there were insufficient materials to repeat the procedure.

\subsection{Summary}

The mixing and compaction temperature data for this study show that for the eight projects investigated, no extreme temperatures (>175C (>350F)) were used in the field or laboratory. This indicates that pavement engineers have 
recognized the undesirable effects of extremely high temperatures in the HMA construction; empirically specified field mixing and compaction temperatures are intentionally lower.

Although reasonable mixing and compaction temperatures are used for both the design and construction, they lack a sound theoretical background. Using the binder viscosities at 3.0 and 6.0 Pa.s as determined in the ZSV method as criteria to determine the mixing and compaction temperatures, respectively, can provide a theoretical foundation for HMA paving operations using modified binders. 


\section{CHAPTER 5. PURMANENT DEFORMATION}

The Purdue University wheel tracking device (PURWheel) was developed by Habermann (1994). In this study the PURWheel device was used as an effective tool to study the rutting performance of HMA mixtures containing modified binders.

\subsection{PURWheel}

The PURWheel as shown in Figure 5.1 includes six sub-systems: water level control, water and air temperature control, wander control, air cylinder control, rut depth tracking, and data acquisition. Tests can be conducted either in dry or wet conditions over a range of temperatures. The dry heating system uses electric resistance heating elements to heat the air in the sample chamber with the temperature control system ensuring that the heating system provides a uniform temperature environment. The steel sample tray also heats the test slabs from the bottom to minimize temperature difference between the top and bottom of the slab. To ensure a stable testing environment during testing for this project, all test slabs were temperature conditioned in the PURWheel chamber for 2 hours prior to test initiation. 


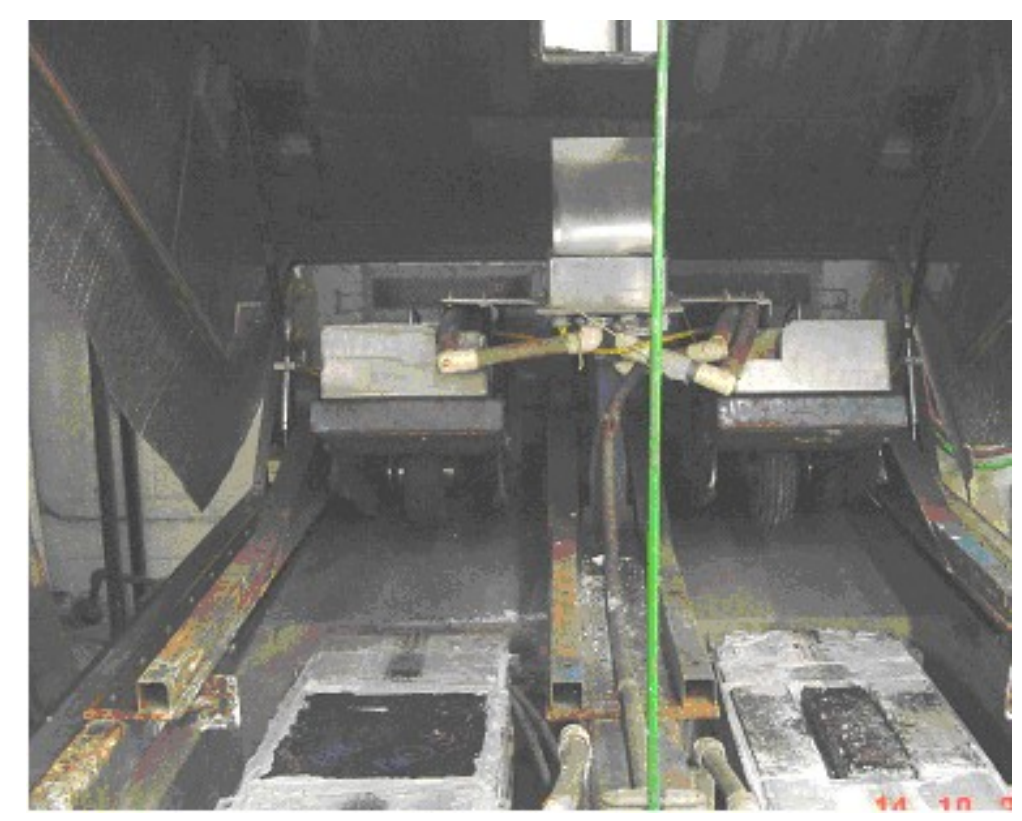

Figure 5.1 Purdue University Laboratory Wheel Tracking Device

The air cylinder system drives the wheels back and forth over the test slab at a constant speed that can be varied from 0.20 to $0.40 \mathrm{~m} / \mathrm{s}(0.66$ to $1.3 \mathrm{ft} / \mathrm{s})$. A pneumatic rubber tire with an inflation pressure of up to $860 \mathrm{kPa}(125 \mathrm{psi})$ is used. For this study slabs were tested in a dry state at a temperature of $50 \pm$ $0.2 \mathrm{C}(122 \pm 7 \mathrm{~F})$. Wheel speed was $0.33 \pm 0.02 \mathrm{~m} / \mathrm{s}(1.1 \pm 0.13 \mathrm{ft} / \mathrm{s})$ with a tire inflation pressure of $689 \mathrm{kPa}$ (100 psi). Each tire was loaded with $697 \mathrm{~N}$ (157 Ibs). The wheel wander feature was not utilized in the study.

The PURWheel measurement system consists of one plunger type Linear Variable Differential Transducer (LVDT) and one cable type LVDT. The cable type LVDT locates the horizontal positions while the plunger type LVDT takes the measurement in the vertical direction. Using this LVDT combination allows the rut depth to be measured at any point along the wheel path at any interval as desired by the user. The rut depth is measured on the surface of slabs; rut depth 
measurements are calculated and recorded at the desired number of wheel pass intervals. Rut depths were recorded every 200 wheel passes during testing for this project. A PURWheel test is usually considered to be complete when 20,000 wheel passes have been applied or until $20 \mathrm{~mm}$ (0.08 in.) of rutting has developed, whichever comes first. At the $0.33 \mathrm{~m} / \mathrm{s}(1.1 \mathrm{ft} / \mathrm{s})$ test speed, it takes approximately 8.5 hours to complete 20,000 wheel passes.

The test specimen is fixed in the center of the sample tray and a series of concrete blocks with the same height as the test slab are placed at both ends of the slab to prevent it from sliding during testing. High strength Plaster-of-Paris fills any gaps around the periphery of the test slab and concrete blocks. Figure $5.2(a)$ and (b) show a slab mounted in the sample tray before and after testing, respectively. The rut depth is recorded and calculated by the computer system and is defined as the height from the original surface before testing to the curved, indented surface after testing. The height difference between the uplift beside the wheel path and the downward measurement from the original surface is defined as total rut depth. The total rut depth is manually measured using the perpendicular tool and a caliper, as shown in Figure 5.2. 


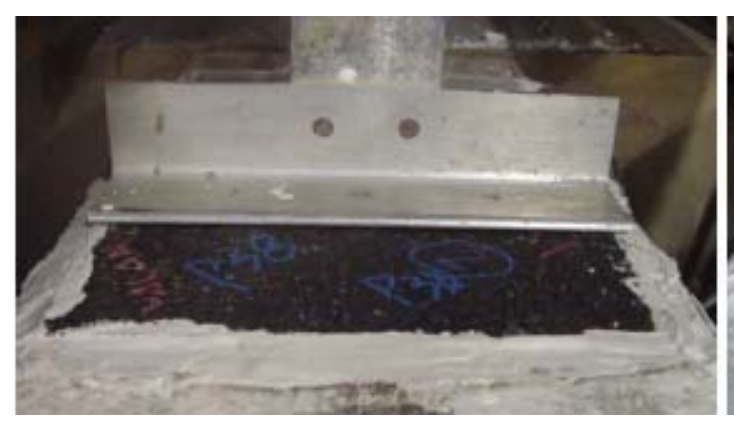

(a)

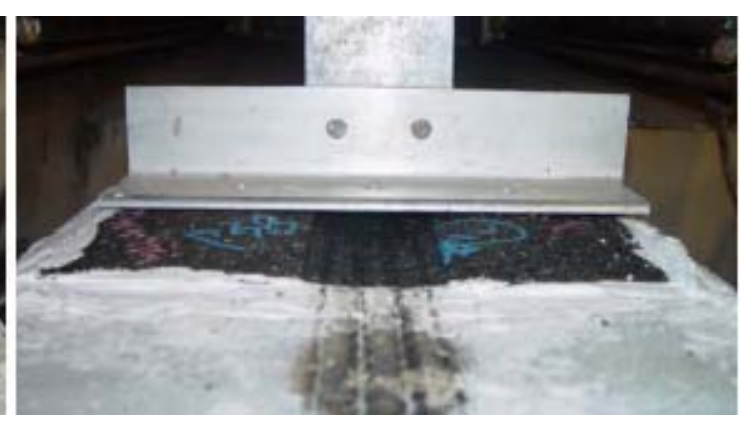

(b)

Figure 5.2 Slab in the Sample Tray (a) Before and (b) After Testing

\subsection{Linear Kneading Compactor}

Laboratory samples for the PURWheel are compacted using a linear kneading compactor as shown in Figure 5.3. The compactor has the capability to compact slabs as large as $625 \mathrm{~mm}$ (25 in.) long, $300 \mathrm{~mm}$ (12 in.) wide, and $100 \mathrm{~mm}$ (4 in.) thick. Steel plates of varying heights can be placed on the bottom of the compactor to control sample thickness. The mixture to be compacted is then placed in the compactor and a thin sheet of tin was placed on top. Above this, a series of steel plates are vertically inserted. A hydraulic ram applies a downward force through a steel roller that is driven back and forth over the steel plates by an air cylinder, thus compacting the mixture below. The applied pressure is kept approximately constant at $1380 \mathrm{kPa}(200 \mathrm{psi})$ throughout the process. When the steel plates are level with the upper edge of the mold, the compaction process is finished. 


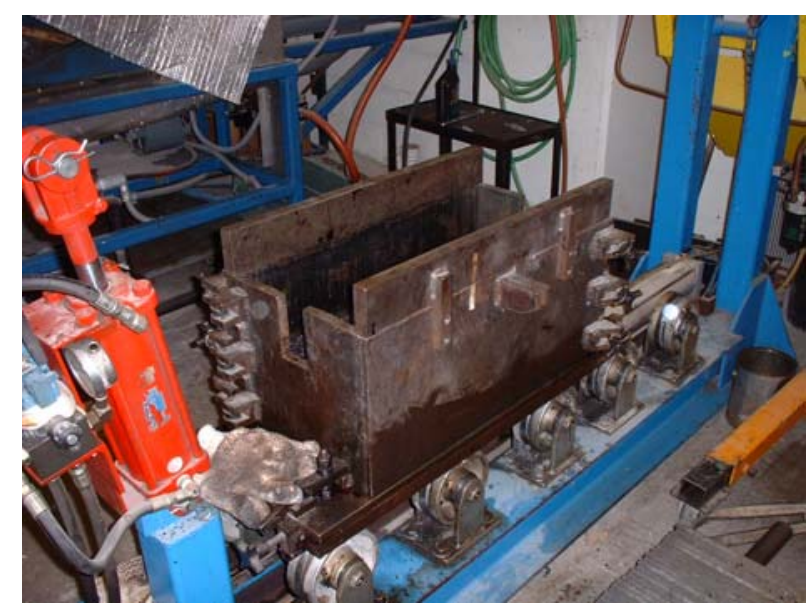

Figure 5.3 Linear Kneading Compactor

\subsection{PURWheel Specimen Preparation and Test Procedure}

To prepare the specimens used in this test, the amount of the mixture needed to make a test slab of the correct thickness and air void content was estimated using volumetric calculations. Test slab thickness depends on the NMAS. As is normal, a thickness of 38 and $50 \mathrm{~mm}$ (1.5 and $2.0 \mathrm{in}$.) were used for mixtures with a NMAS of $9.5-$ and $12.5-\mathrm{mm}$, respectively. Once compaction is completed, two replicates are obtained by wet saw cutting. The dimensions and mass of each specimen are measured in order to calculate the specimen air voids content (density).

\subsection{Test Results and Data Analysis}

The relationship between the rut depth and the number of wheel pass repetitions is illustrated in Figure 5.4. The results of all four replicates for one mixture are usually plotted in one chart to make sure that similar rut depths were obtained for each replicate. Plots for the remaining mixtures are shown in Appendix B. 


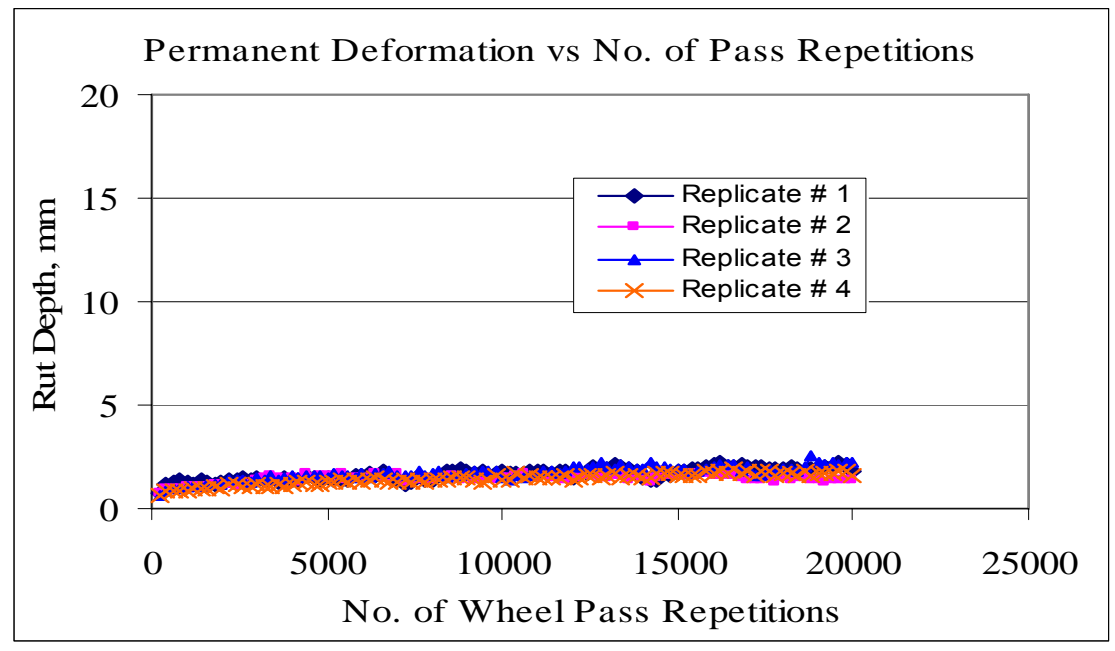

Figure 5.4 PURWheel Test Data

Using the statistical model presented in Chapter 3 with total rut depth as the dependent variable, it can be seen from the Table 5.1 that the model is indeed significant and thus significant differences exist among the factor effects. Having established the model significance, a t-test was used to further investigate the factor effects. The results are summarized in Table 5.1 where it can be seen that except for interaction between aggregate gradation and NMAS, the main factors and all other interaction effects do significantly affect the rut depth.

Table 5.1 ANOVA Summary of Factor Effects on Rut Depth

\begin{tabular}{|c|c|c|c|c|c|c|}
\hline \multicolumn{2}{|c|}{ Model p-value } & $<0.0001$ & \multicolumn{2}{c|}{ Significant } & \multicolumn{2}{c|}{ Yes } \\
\hline Source & DF & Type III SS & Mean Square & F Value & Pr $>$ F & Significant \\
\hline Binder Type & 3 & 6.47 & 2.16 & 4.56 & 0.0083 & Yes \\
\hline Aggregate Gradation & 1 & 17.02 & 17.02 & 35.92 & $<0.0001$ & Yes \\
\hline $\begin{array}{c}\text { Binder Type } \times \text { Aggregate } \\
\text { Gradation }\end{array}$ & 1 & 6.34 & 6.34 & 13.38 & 0.0008 & Yes \\
\hline NMAS & 1 & 2.07 & 2.07 & 4.38 & 0.0435 & Yes \\
\hline Binder Type $\times$ NMAS & 3 & 4.67 & 1.60 & 3.29 & 0.0326 & Yes \\
\hline Aggregate Gradation $\times$ NMAS & 1 & 0.001 & 0.001 & 0 & 0.9601 & No \\
\hline $\begin{array}{c}\text { Binder Type } \times \text { Aggregate } \\
\text { Gradation } \times \text { NMAS }\end{array}$ & 1 & 11.36 & 11.36 & 23.97 & $<0.0001$ & Yes \\
\hline
\end{tabular}


Table 5.2 presents the results of t-test comparison of binder types. The grouping in the same letter means that the difference is not significant. The $\mathrm{N}$ and $\mathrm{M}$ binder type prefixes indicate the binder was either neat (unmodified) or modified. The analysis shows that binder type effect is significant. Mixtures with neat PG 75-22 and PG 70-22 binders show no significant difference in rutting performance; nor do the mixtures with neat PG 70-22 and modified PG 71-22 binders. The modified PG 75-22 appears to have better HMA rutting performance than the other three binders. Overall, the results appear to indicate that the binders of the same PG grade do not necessarily deliver equivalent rutting performance when incorporated into the similar HMA mixtures.

Table 5.2 t-test Result of Main Factor Effect on Rutting

\begin{tabular}{|c|c|c|c|c|}
\hline \multicolumn{2}{|c|}{ Grouping } & Mean Rut Depth (mm) & No. of Observations & Binder Type $^{\mathrm{a}}$ \\
\hline & A & 3.0 & 16 & M 71-22 \\
\hline$B$ & A & 2.6 & 16 & N 70-22 \\
\hline B & & 2.1 & 8 & N 75-22 \\
\hline & C & 1.2 & 8 & M 75-22 \\
\hline Grc & ping & Mean Rut Depth (mm) & No. of Observations & Gradation \\
\hline & 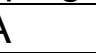 & 3.5 & 16 & Fine \\
\hline & 3 & 1.9 & 32 & Coarse \\
\hline Grc & ping & Mean Rut Depth (mm) & No. of Observations & NMAS (mm) \\
\hline & 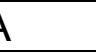 & 2.6 & 24 & 9.5 \\
\hline & 3 & 2.2 & 24 & 12.5 \\
\hline
\end{tabular}

Finally, Table 5.2 also indicates that fine-graded HMA mixtures incorporating smaller NMAS aggregates tend to have higher rut susceptibility than more coarsely-graded, larger NMAS aggregate mixtures. 


\subsection{Conclusions}

From the above data analysis it appears that HMA mixtures produced with PG 70-22 binders meeting the binder high performance temperature grade at varying temperatures and being either neat or modified, may have significant rutting performance differences. Overall, in the t-test comparison, as measured by the PURWheel, the mixtures containing modified PG75-22 binder had one-half to one-third less rutting as did the mixtures containing the other three binders. Additionally, the larger maximum aggregate size appears to improve the rutting resistance of the HMA mixtures. 


\section{CHAPTER 6. FATIGUE}

Fatigue failure is caused by repeated traffic loading at intermediate temperatures. It begins with small cracks in the longitudinal direction along the wheel paths, then propagates to form more sever forms of crack patterns.

Beam fatigue testing was developed to determine the laboratory fatigue characteristics of the HMA and it can provide an estimate of the number of wheel load applications a pavement can carry before fatigue failure. The beam fatigue testing procedure used in this research is AASHTO TP8 and is an accelerated laboratory test method which simulates the in-service fatigue failure mode under either controlled strain or controlled stress conditions. The test system consists of a beam cradle with specimen clamping system, the control and data acquisition system and a temperature control cabinet into which the beam fatigue apparatus will fit. The test apparatus is shown in Figure 6.1. 


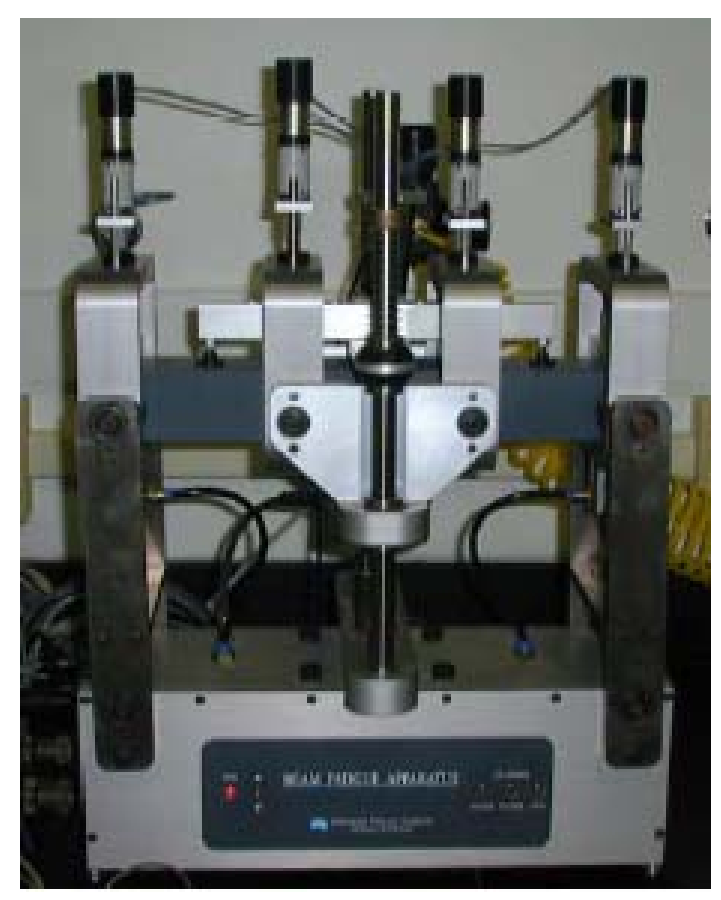

Figure 6.1 Beam Fatigue Test Apparatus

\subsection{Flexural Beam Fatigue Specimen Preparation}

For the beam fatigue testing, two replicate specimens for each mixture were fabricated and tested. The beam specimens were prepared by first compacting a slab of a given mixture in the linear kneading compactor as previously described. The test beams were then sawn from the compacted slabs. Four fatigue beams can be prepared from each compacted slab. The beams thus produced are $380 \pm$ $6 \mathrm{~mm}(15 \pm 0.5 \mathrm{in}$.$) long, 50 \pm 6 \mathrm{~mm}(2 \pm 0.5 \mathrm{in}$.) tall, and $63 \pm 6 \mathrm{~mm}(2.5 \pm 0.5$ in.) wide. After being sawn, the air void content of the individual beams was calculated using the bulk specific gravity of the beam as determined by AASHTO T166 and the maximum theoretical specific gravity of the mixture as determined by AASHTO T209. 


\subsection{Test Procedures}

The test apparatus was placed in a controlled-temperature chamber during testing and all the tests were performed at a temperature of $20 \pm 1 \mathrm{C}(68 \pm 2 \mathrm{~F})$.

The beam specimens were subjected to repeated third-point, controlled-strain, flexural loading in order to determine their stiffness and fatigue resistance properties. A sinusoidal wave form was used at a frequency of $10 \mathrm{~Hz}$ and a peak to peak deformation of 500 micro-strains. The control and data acquisition system recorded load and deformation data at predefined cycles and the initial stiffness was determined at 50 repetitions. Failure was defined as the number of load cycles where the beam stiffness reached half of its initial value. A minimum of 10,000 cycles needed to be applied before significant stiffness reduction occurs.

The flexible stress, strain, and stiffness were determined using the equations:

$$
\begin{gathered}
S=\frac{\sigma_{\mathrm{t}}}{\varepsilon_{\mathrm{t}}} \\
\sigma_{\mathrm{t}}=\frac{3 \mathrm{aP}}{\mathrm{bh}^{2}} \\
\varepsilon_{\mathrm{t}}=\frac{12 \delta \mathrm{h}}{3 \mathrm{~L}^{2}-4 \mathrm{a}^{2}}
\end{gathered}
$$

where,

$$
\begin{aligned}
& \sigma_{\mathrm{t}}=\text { peak-to-peak stress }(\mathrm{Pa}) ; \\
& \varepsilon_{\mathrm{t}}=\text { peak-to-peak strain }(\mathrm{m} / \mathrm{m}) ; \\
& S=\text { flexible stiffness }(\mathrm{Pa}) ; \\
& P=\text { applied peak-to-peak load }(\mathrm{N}) ;
\end{aligned}
$$


$L=$ the length of outer clamps $(m)$;

$a=1 / 3$ of the length of outer clamps $(m)$;

$b=$ beam width $(m)$;

$\mathrm{h}=$ beam height $(\mathrm{m}) ;$ and

$\delta=$ beam deflection at center of beam $(m)$.

\subsection{Beam Fatigue Test Result}

Figure 6.2 shows a plot of the typical relationship between beam stiffness and number of loading cycles applied. As the numbers of repetitions accumulate the beam stiffness gradually decreases. A similar plot was made for each of the beam specimens as shown in Appendix C. The effects of aggregate gradation, binder type, and their interactions were investigated using ANOVA techniques.

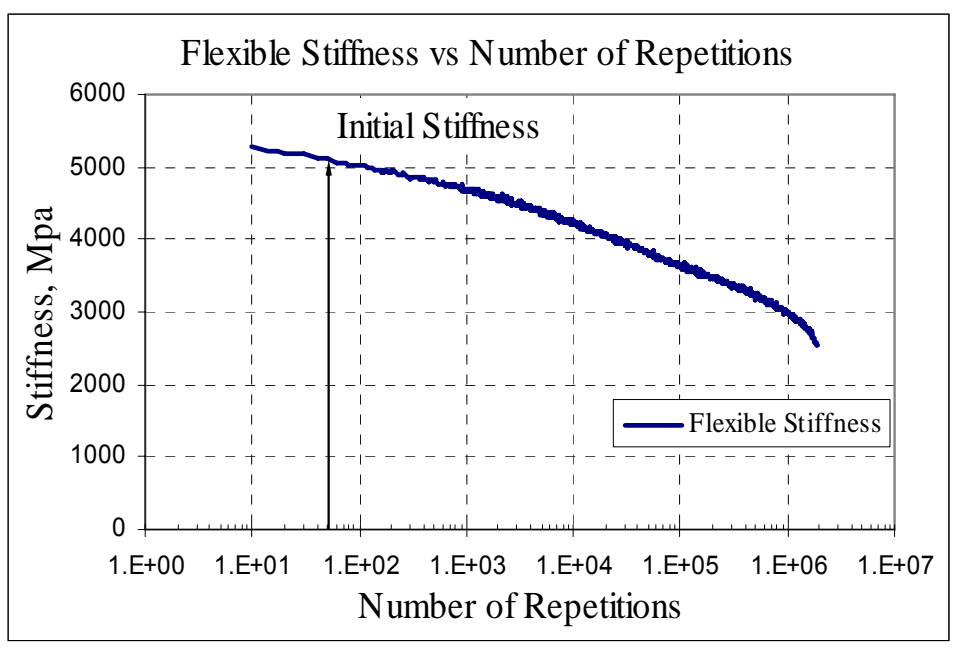

Figure 6.2 Beam Fatigue Test Results 


\subsection{Beam Fatigue Data Analysis}

\subsubsection{Initial Fatigue Stiffness}

Using the model described in Chapter 3, a full-model ANOVA was completed using initial flexural stiffness as the dependent variable. The results shown in Table 6.1 indicate that the model is valid. The main factors do affect the model outcome. Since the model appears valid, additional tests were completed to further investigate the effects of the main factors and their interactions on the model. The results show that the binder type and NMAS significantly affect the initial beam stiffness. Aggregate gradation and main factor interactions do not appear to be significant.

Table 6.1 Factor Effects on Initial Stiffness

\begin{tabular}{|c|c|c|c|c|c|c|}
\hline \multicolumn{2}{|c|}{ Model p-value } & 0.0093 & \multicolumn{2}{c|}{ Significant } & \multicolumn{2}{c|}{ Yes } \\
\hline Source & DF & Type III SS & Mean Square & F Value & Pr>F & Significant \\
\hline Binder Type & 3 & 5827907 & 1942636 & 8.40 & 0.0028 & Yes \\
\hline Aggregate Gradation & 1 & 376996 & 376996 & 1.63 & 0.2258 & No \\
\hline $\begin{array}{c}\text { Binder Type } \times \text { Aggregate } \\
\text { Gradation }\end{array}$ & 1 & 582169 & 582169 & 2.52 & 0.1385 & No \\
\hline NMAS & 1 & 1543815 & 1543815 & 6.68 & 0.0239 & Yes \\
\hline Binder Type $\times$ NMAS & 3 & 1494890 & 498297 & 2.16 & 0.1464 & No \\
\hline Aggregate Gradation $\times$ NMAS & 1 & 509082 & 509082 & 2.20 & 0.1636 & No \\
\hline $\begin{array}{c}\text { Binder Type } \times \text { Aggregate } \\
\text { Gradation } \times \text { NMAS }\end{array}$ & 1 & 584460 & 584460 & 2.53 & 0.1378 & No \\
\hline
\end{tabular}

Table 6.2 presents the t-test results for multiple comparisons of main factors. The data in the tables show that the mixtures with neat PG 70-22 have the highest initial stiffness values. The remaining differences are not as pronounced. Mixtures with neat PG 75-22 and PG 70-22 show a significant difference in fatigue stiffness as do the mixtures with neat PG 70-22 and modified PG 71-22 
binders. The fine-graded mixtures have slightly higher initial stiffness than the coarse-graded, but there appears to be no statistically significant difference. It also statistically appears that mixtures with the smaller, 9.5-mm NMAS are initially stiffer than the 12.5-mm NMAS mixtures.

Table 6.2 t-test Result of Main Factor Effect on Fatigue Stiffness

\begin{tabular}{|c|c|c|c|}
\hline Grouping & Mean Stiffness (MPa) & No. of Observations & Binder Type $^{\text {a }}$ \\
\hline A & 5499 & 8 & N 70-22 \\
\hline B & 4594 & 8 & M 71-22 \\
\hline B & 4404 & 4 & M 75-22 \\
\hline B & 4311 & 4 & N 75-22 \\
\hline Grouping & Mean Stiffness (MPa) & No. of Observations & Aggregate Gradation \\
\hline A & 4893 & 8 & Fine \\
\hline A & 4779 & 16 & Coarse \\
\hline Grouping & Mean Stiffness (MPa) & No. of Observations & NMAS (mm) \\
\hline A & 5071 & 12 & 9.5 \\
\hline B & 4563 & 12 & 12.5 \\
\hline
\end{tabular}

a Proceeding letters for the PG grades indicate neat $(\mathrm{N})$ or modified $(\mathrm{M})$ binders

\subsubsection{Fatigue life}

The full-model ANOVA result using the number of cycles to failure as the dependent variable is shown in Table 6.3. Again the results show the model to be valid. The effects of each of the main factors and their interactions were therefore investigated. Significance is indicated for the main factors of binder type and aggregate gradation, and for the interactions between binder type and aggregate gradation, and binder type and NMAS. 
Table 6.3 Summary of Factor Effects on Fatigue life

\begin{tabular}{|c|c|c|c|c|c|c|}
\hline \multicolumn{2}{|c|}{ Model p-value } & $<0.0001$ & \multicolumn{2}{c|}{ Significant } & \multicolumn{2}{c|}{ Yes } \\
\hline Source & DF & Type III SS & Mean Square & F Value & Pr $>$ F & Significant \\
\hline Binder Type & 3 & $6.39 \times 10^{12}$ & $2.13 \times 10^{12}$ & 64.54 & $<0.0001$ & Yes \\
\hline Aggregate Gradation & 1 & $4.30 \times 10^{12}$ & $4.30 \times 10^{12}$ & 130.24 & $<0.0001$ & Yes \\
\hline $\begin{array}{c}\text { Binder Type } \times \text { Aggregate } \\
\text { Gradation }\end{array}$ & 1 & $2.73 \times 10^{12}$ & $2.73 \times 10^{12}$ & 82.73 & $<0.0001$ & Yes \\
\hline NMAS & 1 & $7.57 \times 10^{9}$ & $7.57 \times 10^{9}$ & 0.23 & 0.6405 & No \\
\hline Binder Type $\times$ NMAS & 3 & $9.11 \times 10^{11}$ & $3.04 \times 10^{11}$ & 9.21 & 0.0019 & Yes \\
\hline Aggregate Gradation $\times$ NMAS & 1 & $1.11 \times 10^{11}$ & $1.11 \times 10^{11}$ & 3.35 & 0.0922 & No \\
\hline $\begin{array}{c}\text { Binder Type } \times \text { Aggregate } \\
\text { Gradation } \times \text { NMAS }\end{array}$ & 1 & $9.61 \times 10^{10}$ & $9.61 \times 10^{10}$ & 2.91 & 0.1137 & No \\
\hline
\end{tabular}

Table 6.4 presents the multiple comparisons of the main factors. The HMA mixtures containing modified binders have higher numbers of cycles to failure than do those mixtures containing neat binders. However, the difference in number of cycles to failure for the two mixtures containing neat binders and for the two mixtures containing modified binders is not significantly different.

Table 6.4 t-test Result of Main Factor Effect on Fatigue Life

\begin{tabular}{|c|c|c|c|}
\hline Grouping & Mean Fatigue Life & No. of Observations & Binder Type $^{\text {a }}$ \\
\hline A & 1229895 & 8 & M 71-22 \\
\hline A & 1150788 & 4 & M 75-22 \\
\hline B & 195285 & 8 & N 70-22 \\
\hline B & 131470 & 4 & N 75-22 \\
\hline Grouping & Mean Fatigue Life & No. of Observations & Aggregate Gradation \\
\hline A & 1230794 & 8 & Fine \\
\hline B & 417758 & 16 & Coarse \\
\hline Grouping & Mean Fatigue Life & No. of Observations & NMAS (mm) \\
\hline A & 706533 & 12 & 9.5 \\
\hline A & 671006 & 12 & 12.5 \\
\hline
\end{tabular}

${ }^{a}$ Proceeding letters for the PG grades indicate neat $(\mathrm{N})$ or modified $(\mathrm{M})$ binders

Table 6.4 shows that the fine-graded HMA mixtures tend to have better resistance to fatigue cracking (more numbers of cycles to failure) than do the 
coarse-graded mixtures. Also, there does not appear to be a significant difference in the fatigue lives of 9.5- and 12.5-mm NMAS HMA mixtures.

\subsection{Conclusions}

Based on statistical multiple comparisons, binder type appears to play a key role in both the initial HMA mixture stiffness and fatigue life. Further, it appears that the NMAS has an important influence on initial HMA mixture stiffness while aggregate gradation has influences on the mixture fatigue life. Thus, the HMA mixtures with the same binder high temperature stiffness and aggregate gradation may not have similar performance. Finally, modified binders appear to have improved HMA mixture fatigue performance over mixtures containing neat binders. 


\section{CHAPTER 7. LOW TEMPERATURE CRACKING}

The properties of viscoelastic materials are temperature and time of loading dependent. When exposed to low temperature climates HMA mixtures become more brittle and when the temperature drops to an extremely low level in a short period of time, excessive tensile stresses can develop in the HMA mixture due to mixture contraction. When these tensile stresses exceed the tensile strength of the HMA mixture, thermal cracking occurs. Since the aggregate cannot contribute to tensile strength, thermal cracking is therefore dependent upon the tensile strength of the binder.

The Indirect Tensile Test (IDT) as developed by Roque and other researchers is a mechanistic-based approach used to evaluate the thermal cracking behavior of HMA mixtures (Roque and Buttlar, 1992; Hiltunen and Roque, 1994; Roque, et al, 1995). The main advantage of the IDT is that during the test, the stress state inside the HMA mixture specimen is similar to the stress state at the bottom of the HMA pavement layer under traffic loading $(\mathrm{NHI}, 2000)$

\subsection{Indirect Tensile Test}

The IDT apparatus is shown in Figure 7.1. It consists of a vertical loading device, specimen deformation measuring devices, an environmental chamber, and a 
data acquisition and control system. The latter system allows the user to easily control the test temperature, apply desired loads to test specimens, acquire data, and perform data analysis and storage.

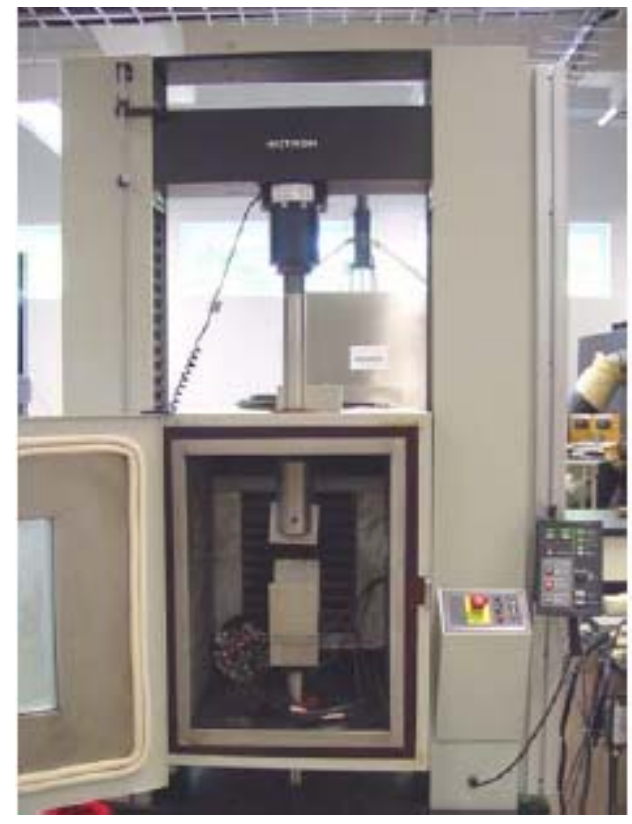

(a)

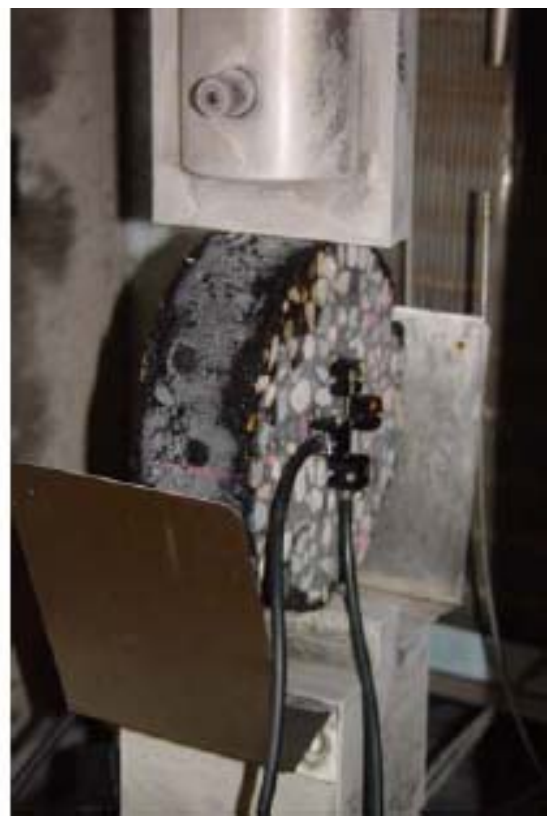

(b)

Figure 7.1 Indirect Tensile Tester: (a) Test Equipment, and (b) Test Specimen

According to AASHTO TP9, "Standard Test Method for Determining the Creep Compliance and Strength of Hot Mix Asphalt (HMA) Using the Indirect Tensile Test Device," specimen deformation is measured by four LVDT's, two on each side of the specimen, glued at right angles in order to measure both horizontal and vertical deformations. The LVDT gauge length is $38 \mathrm{~mm}(1.5 \mathrm{in}$.) and was chosen so as to minimize the effect of large aggregates between the two gauge points and stress concentrations in the area of the loading strips. Test 
specimens are loaded diametrically for a period of 100 seconds and loads are selected so as to keep strains in the linear viscoelastic range.

Creep compliance is the inverse of the mixture stiffness and is calculated using the measured horizontal and vertical displacements in a specimen. For each mixture, three replicates are tested at temperatures of $0,-10$, and $-20 \mathrm{C}(32$, 14, and -4F). Using time-temperature superposition, the master creep compliance curve can then be constructed from the creep compliance curves determined for the different test temperatures (Hiltunen and Roque, 1995). The $\mathrm{m}$-value is defined as the slope of the compliance curve as a function of time and indicates a material's ability to relax and deform under stress rather than crack. The higher the m-value, the more resistant a material is to thermal cracking.

When compliance testing of the specimens is completed, the indirect tensile strength of each replicate is determined at $-10 \mathrm{C}(14 \mathrm{~F})$ by loading the specimen at a constant strain rate until the load begins to decrease due to failure. The loading rate is $12.5 \mathrm{~mm} / \mathrm{min}(0.5 \mathrm{in} . / \mathrm{min})$. Higher tensile strengths are necessary to resist the tensile stresses that develop in the pavement at low temperatures.

The creep compliance or creep stiffness (reciprocal of creep compliance), mvalue, and tensile strength are used as criteria for the evaluation of low temperature binder performance. In 1998, Christensen developed a computer spreadsheet to analyze the test data from the IDT (Christensen, 1998). The power law function used to fit the creep compliance data is:

$$
\mathrm{D}(\mathrm{t})=\mathrm{D}_{0}+\mathrm{D}_{1} \mathrm{~T}^{\mathrm{m}}
$$


where,

$D(t)=$ creep compliance at time $T(1 / p s i) ;$

$\mathrm{D}_{0}, \mathrm{D}_{1}=$ best fit coefficients;

$\mathrm{T}=$ time of loading (s); and

$\mathrm{m}=$ power law exponent as the loading time $\mathrm{T}$ gets closer to infinity.

Here, $m$ is the slope of the linear portion of the creep compliance master curve when plotted on a logarithmic scale. The m-value as a function of loading time $t$, can be found by taking the derivative of equation $7-1$ as shown in equation 7-2.

$$
m(t)=\frac{D_{1} m T^{m}}{D_{0}+D_{1} T^{m}}
$$

\subsection{Specimen Preparation}

IDT specimens were compacted in the laboratory using the SGC after the mixtures were subjected to short-term aging in a forced-draft oven for four hours. Each of the compacted specimens was $150 \mathrm{~mm}$ (6 in.) in diameter and $125 \mathrm{~mm}$ (5 in.) in height. Two test replicates were obtained from each SGC specimen by wet sawing such that the IDT specimens were $150 \mathrm{~mm}(6 \mathrm{in}$.) in diameter and 50 $\mathrm{mm}(2 \mathrm{in}$.) in height. The air voids content of each specimen were determined using the bulk specific and maximum theoretical gravities according to AASHTO T209. Three of the four specimens were chosen for testing and were long-term oven aged for five days at $85 \mathrm{C}(185 \mathrm{~F})$ prior to testing. 


\subsection{Indirect Tensile Test Results}

Figure 7.2 shows a plot of a typical creep compliance master curve and its shift factor at a reference temperature of $-20 \mathrm{C}(-4 \mathrm{~F})$. The estimated pavement critical temperature is the temperature at which estimated thermal stress exceeds HMA mixture tensile strength. It is at this temperature that thermal cracking is expected to occur.
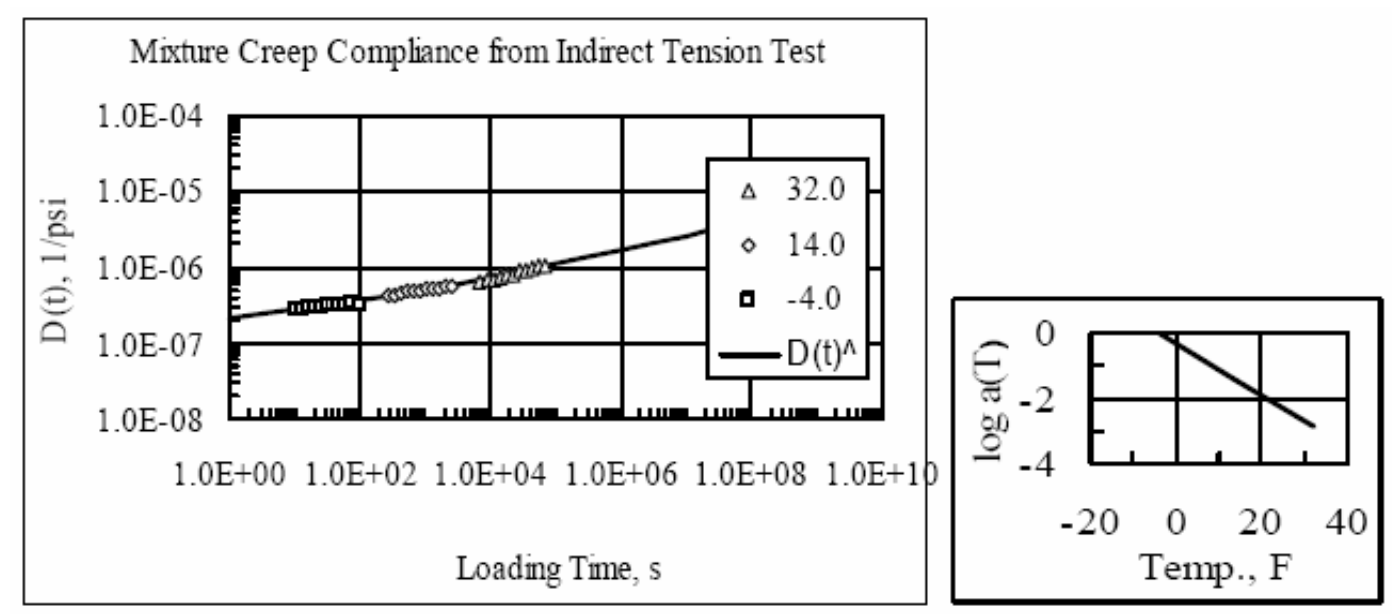

Figure 7.2 Example of IDT Creep Compliance Results

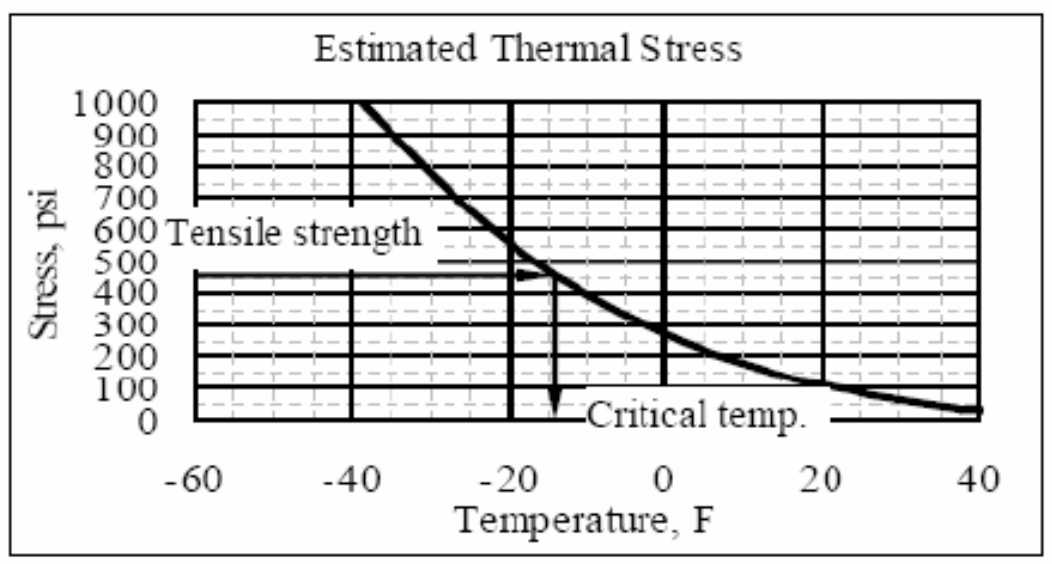

Figure 7.3 Plot of Critical Pavement Temperature 
By using the previously cited spreadsheet, the estimated pavement critical temperature and a plot of the estimated thermal stress as a function of temperature can be obtained as shown in Figure 7.3. Table 7.1 shows the IDT test data including tensile strength, compliance, and m-value at 60 seconds.

Table 7.1 IDT Test Result Data Summary

\begin{tabular}{|c|c|c|c|c|c|}
\hline Binder Type & Gradation & NMAS $(\mathrm{mm})$ & $\begin{array}{c}\text { Tensile } \\
\text { Strength }(\mathrm{kPa})\end{array}$ & $\begin{array}{c}\text { Compliance } \\
60 \mathrm{~s}\left(\mathrm{kPa} \mathrm{C}^{-1}\right)\end{array}$ & $\begin{array}{c}\mathrm{m}-\mathrm{value} \\
\text { ( } 60 \mathrm{~s}\end{array}$ \\
\hline N 70-22 & Coarse & 9.5 & 2724 & $2.63 \times 10^{-6}$ & 0.110 \\
\hline N 75-22 & Coarse & 9.5 & 3061 & $3.30 \times 10^{-6}$ & 0.102 \\
\hline M 71-22 & Coarse & 9.5 & 3656 & $2.37 \times 10^{-6}$ & 0.030 \\
\hline M 75-22 & Coarse & 9.5 & 3402 & $2.47 \times 10^{-6}$ & 0.126 \\
\hline N 70-22 & Coarse & 12.5 & 2150 & $2.24 \times 10^{-6}$ & 0.088 \\
\hline N 75-22 & Coarse & 12.5 & 2033 & $2.32 \times 10^{-6}$ & 0.111 \\
\hline M 71-22 & Coarse & 12.5 & 2724 & $2.39 \times 10^{-6}$ & 0.037 \\
\hline M 75-22 & Coarse & 12.5 & 2642 & $2.30 \times 10^{-6}$ & 0.128 \\
\hline N 70-22 & Fine & 9.5 & 2896 & $3.93 \times 10^{-6}$ & 0.123 \\
\hline M 71-22 & Fine & 9.5 & 3124 & $3.61 \times 10^{-6}$ & 0.156 \\
\hline N 70-22 & Fine & 12.5 & 2849 & $3.50 \times 10^{-6}$ & 0.137 \\
\hline M 71-22 & Fine & 12.5 & 3289 & $3.06 \times 10^{-6}$ & 0.084 \\
\hline
\end{tabular}

${ }^{a}$ Proceeding letters for the $P G$ grades indicate neat $(\mathrm{N})$ or modified $(\mathrm{M})$

\subsection{IDT Data Analysis}

\subsubsection{IDT Tensile Strength}

The statistical model described in Chapter 3 was again used to analyze the IDT data. The model shows that the p-value is smaller than the significance level. The data from the coarse-graded, NMAS 9.5-mm mixture containing modified PG 75-22 appeared to be an outlier and statistical testing was completed to confirm this hypothesis. Since the value was statistically shown to be an outlier it was excluded from the analysis. The resulting analysis shows that the model is 
significant and further analyses were completed to specifically assess the factor effects. Table 7.2 shows that binder type and NMAS and the interaction between gradation and NMAS may significantly affect the low temperature tensile strength of HMA mixtures. Mixtures with the higher tensile strengths are preferred for better resistance to low temperature cracking. Table 7.3 presents the t-test results for comparison of the main factors. The data in the table indicate that HMA mixtures containing modified binders have slightly higher tensile strengths than do the HMA mixtures containing neat binders and the difference does appear to be significant. The data also indicates that HMA mixtures with a 9.5mm NMAS tend to have statistically significant higher tensile strengths than do mixtures with a 12.5-mm NMAS. Although the fine-graded HMA mixtures appear to have a slightly higher initial stiffness than the coarse-graded mixtures, the difference between them is statistically insignificant.

Table 7.2 Full Model Statistical Analysis of Tensile Strength

\begin{tabular}{|c|c|c|c|c|c|c|}
\hline \multicolumn{2}{|c|}{ Model p-value } & 0.0065 & \multicolumn{2}{c|}{ Significant } & \multicolumn{2}{c|}{ Yes } \\
\hline Source & DF & Type III SS & Mean Square & F Value & Pr>F & Significant \\
\hline Binder Type & 3 & 49936 & 16645 & 3.97 & 0.02 & Yes \\
\hline Aggregate Gradation & 1 & 6437 & 6437 & 1.54 & 0.23 & No \\
\hline $\begin{array}{c}\text { Binder Type } \times \text { Aggregate } \\
\text { Gradation }\end{array}$ & 1 & 5537 & 5537 & 1.32 & 0.26 & No \\
\hline NMAS & 1 & 33408 & 33408 & 7.97 & 0.01 & Yes \\
\hline Binder Type $\times$ NMAS & 3 & 1650 & 550 & 0.13 & 0.94 & No \\
\hline Aggregate Gradation $\times$ NMAS & 1 & 20770 & 20770 & 4.96 & 0.04 & Yes \\
\hline $\begin{array}{c}\text { Binder Type } \times \text { Aggregate } \\
\text { Gradation } \times \text { NMAS }\end{array}$ & 1 & 2573 & 2573 & 0.61 & 0.44 & No \\
\hline
\end{tabular}


Table $7.3 \mathrm{t}$-test Comparison of Main Factors

\begin{tabular}{|c|c|c|c|c|}
\hline \multicolumn{2}{|c|}{ Grouping } & Mean Tensile Strength (kPa) & No. of Observations & Binder Type \\
\hline & A & 3200 & 12 & M 71-22 \\
\hline $\mathrm{B}$ & A & 3021 & 6 & M 75-22 \\
\hline B & C & 2655 & 12 & N 70-22 \\
\hline & $\mathrm{C}$ & 2441 & 5 & N 75-22 \\
\hline Grol & ing & Mean Tensile Strength $(\mathrm{kPa})$ & No. of Observations & Gradation \\
\hline & & 3041 & 12 & Fine \\
\hline & & 2786 & 23 & Coarse \\
\hline Grol & oing & Mean Tensile Strength $(\mathrm{kPa})$ & No. of Observations & NMAS $(\mathrm{mm})$ \\
\hline & & 3152 & 17 & 9.5 \\
\hline & & 2614 & 18 & 12.5 \\
\hline
\end{tabular}

${ }^{a}$ Proceeding letters for the PG grades indicate neat (N) or modified (M)

\subsubsection{Creep Compliance}

Creep compliance is a function of time and to analyze the data the compliance at a given time must be used. For this research, the creep compliance at 60 seconds was chosen and determined using equation 7-1. The model herein uses the three main factors as dependant variables and creep compliance as the response variable. Table 7.4 present the statistical results and indicates that the model involving the three main factors of creep compliance is significant. The aggregate gradation and NMAS do appear to influence the creep compliance at 60 seconds. However binder type does not appear to be a significant factor. This is expected since all of the binders were of the same low temperature PG grade, $-22$.

Table 7.4 Statistical Analysis on Creep Compliance

\begin{tabular}{|c|c|c|c|c|c|c|}
\hline \multicolumn{2}{|c|}{ Model p-value } & 0.0037 & \multicolumn{2}{c|}{ Significant } & \multicolumn{2}{c|}{ Yes } \\
\hline Source & DF & Type III SS & Mean Square & F Value & Pr>F & Significant \\
\hline Binder Type & 3 & $7.40 \times 10^{-15}$ & $2.47 \times 10^{-15}$ & 2.06 & 0.2066 & No \\
\hline Aggregate Gradation & 1 & $1.09 \times 10^{-14}$ & $1.09 \times 10^{-14}$ & 9.13 & 0.0233 & Yes \\
\hline NMAS & 1 & $5.25 \times 10^{-14}$ & $5.25 \times 10^{-14}$ & 43.88 & 0.0006 & Yes \\
\hline
\end{tabular}


Table 7.5 shows the t-test results for the main factors. The mixtures containing modified PG 75-22 have the lowest creep compliance while the mixtures with neat PG 70-22 have the highest compliance. While the difference between the mixtures containing these two binders is statistically different, the variations in creep compliance across the four binder types are slight. This is due to the fact that the binders all had the same low temperature PG stiffness. As is expected, the high temperature binder grade appears to have little effect on the low temperature performance of the binder.

Table 7.5 t-test Comparison of Main Factors

\begin{tabular}{|c|c|c|c|c|}
\hline \multicolumn{2}{|c|}{ Grouping } & Mean Compliance $\left(\mathrm{kPa}^{-1}\right)$ & No. of Observations & Binder Type \\
\hline & A & $3.08 \times 10^{-6}$ & 4 & $\mathrm{~N} 70-22$ \\
\hline$B$ & A & $2.85 \times 10^{-6}$ & 4 & M 71-22 \\
\hline$B$ & $A$ & $2.81 \times 10^{-6}$ & 2 & N 75-22 \\
\hline $\mathrm{B}$ & & $2.39 \times 10^{-6}$ & 2 & M 75-22 \\
\hline \multicolumn{2}{|c|}{ Grouping } & Mean Compliance $\left(\mathrm{kPa}^{-1}\right)$ & No. of Observations & Gradation \\
\hline \multicolumn{2}{|c|}{$\mathrm{A}$} & $3.05 \times 10^{-6}$ & 6 & Coarse \\
\hline \multicolumn{2}{|c|}{$\mathrm{B}$} & $2.79 \times 10^{-6}$ & 6 & Fine \\
\hline \multicolumn{2}{|c|}{ Grouping } & Mean Compliance $\left(\mathrm{kPa}^{-1}\right)$ & No. of Observations & NMAS (mm) \\
\hline \multicolumn{2}{|c|}{$\mathrm{A}$} & $3.53 \times 10^{-6}$ & 4 & 12.5 \\
\hline \multicolumn{2}{|c|}{ B } & $2.53 \times 10^{-6}$ & 8 & 9.5 \\
\hline
\end{tabular}

Finally, Table 7.5 shows that the coarse-graded, 12.5-mm NMAS mixtures tend to have higher creep compliances than do fine-graded, 9.5-mm NMAS mixtures. 


\subsubsection{IDT m-value}

The model analysis was also completed using m-value as the response variable. The statistical analysis of $\mathrm{m}$-values determined by the power law (shown in Table 7.6) shows that the model $p$-value is 0.088 . Since the $p$-value is greater than the significance level of 0.05 , one must conclude that there is insufficient evidence to conclude that the main effects significantly influence the m-values.

Table 7.6 Statistical Analysis of m-value at 60 Seconds

\begin{tabular}{|c|c|c|c|c|c|c|}
\hline Source & DF & $\begin{array}{c}\text { Sums of } \\
\text { Squares }\end{array}$ & Mean Square & F Value & $\operatorname{Pr}>$ F & Significant \\
\hline Model & 5 & 0.0117 & 0.0023 & 3.32 & 0.088 & No \\
\hline Error & 6 & 0.0042 & 0.0007 & & & \\
\hline Corrected Total & 11 & 0.0159 & & & & \\
\hline
\end{tabular}

\subsection{Summary and Conclusion}

A combination of high creep compliance (low creep stiffness) and high strength contribute to an HMA mixture's resistance to thermal cracking. The data from this study indicates that neat and modified binders having the same low temperature PG grade produce HMA mixtures with similar creep compliances regardless of the high temperature PG grade. This is to be expected since it is the low temperature PG grading that should have the most effect on the low temperature behavior of the HMA mixtures. However, binder modification does appear to increase HMA mixture tensile strengths at low temperatures, even when the binders have the same low temperature PG grade. 
The compliance data seems to indicate that at a given air voids content, the coarse-graded HMA mixtures are more susceptible to thermal cracking than finegraded mixture with the same NMAS; HMA mixtures with 9.5-mm NMAS have better resistance to thermal cracking than do the 12.5-mm NMAS mixtures. Also, the HMA mixtures with 9.5-mm NMAS have higher tensile strengths than do the 12.5-mm NMAS mixtures. Thus the smaller NMAS appears to be desirable in order to minimize thermal cracking. 


\section{CHAPTER 8. CONCLUSIONS AND RECOMMENDATIONS}

The objectives of this study were to develop a rational method of specifying field mixing and compaction temperatures for HMA mixtures that is particularly applicable to modified binders and to determine if neat and modified binders of the same performance grade provide comparable performance when incorporated into HMA mixtures.

\subsection{Mixing and Compaction Temperatures}

The HMA industry has long recognized the importance of selecting and using appropriate mixing and compaction temperatures for the design and production of HMA mixtures. With the widespread use of modified binders have come concerns that the existing test used to select these temperatures may yield excessively high temperatures. This research investigated the possibility of using the theory of Zero Shear Viscosity to determine proper mixing and compaction temperatures for HMA mixtures. This was accomplished using several field projects. The results of the experiment indicate the following:

1. No extreme temperatures $(>175 \mathrm{C}(>350 \mathrm{~F}))$ were used in determining mixing and compaction temperature for the design and production of the mixtures investigated in the study; 
2. Using the binder viscosities at 3.0 and $6.0 \mathrm{~Pa} \cdot \mathrm{s}$ as determined in the ZSV test for determining mixing and compaction temperatures, respectively, does work for HMA mixtures containing modified binders; and

3. Additional work is required to make the ZSV method compatible with all binder types. Currently, for neat binders, the standard test protocol provides a better estimation of mixing and compaction temperatures.

\subsection{Neat and Modified Binders}

Simple laboratory performance tests were used to test HMA mixture performance at high, intermediate, and low temperatures. At high temperatures rutting is the predominant HMA mixture distress while fatigue and low temperature cracking occur at intermediate and low temperatures, respectively. The work reported herein used the PURWheel laboratory wheel tracking test to study the rutting performance of HMA mixtures. Flexural beam fatigue testing was used to investigate fatigue cracking at intermediate temperatures and the Indirect Tensile Test (IDT) was used to evaluate the thermal cracking (low temperature) behavior of the mixtures. The testing was performed on various HMA mixtures containing one of four neat or modified binders (two neat, two modified) all of which were of the same PG grading. Analyses of the data indicate the following:

1. The PG 70-22 and PG 75-22 binders used in the study appear to produce HMA mixtures that have statistically significant differences in rutting susceptibility, although none of the mixtures showed excessive rutting; 
2. Binder modification in this experiment appears to significantly affect the rutting performances of the HMA mixtures. Overall, the mixtures containing modified PG75-22 binder had one-half to one-third less rutting than did mixtures containing the other three binders;

3. The neat PG 70-22 and PG 75-22 binders used appear to produce HMA mixtures with similar fatigue lives;

4. HMA mixtures made with the modified binders have longer fatigue lives than mixtures containing neat binders;

5. Variations in the temperature at which a binder meets the PG 70 grade shows no effect on the low temperature performance of the HMA mixtures tested;

6. Neat and modified binders having a -22 low temperature PG grade produce HMA mixtures with similar creep compliances regardless of the high temperature PG grade;

7. Binder modification does appear to increase HMA mixture tensile strengths at low temperatures; and

8. Overall, modified binders appear to improve the performance of HMA mixtures.

\subsection{Recommendations}

HMA mixing and compaction temperatures are traditionally determined using the standard ASTM D2493 test method that can often yield excessively high mixing and compaction temperatures for mixtures containing modified binders. The 
research reported in this study found that the ZSV method can be used with modified binders to provide reasonable mixing and compaction temperatures, but that it does not work for neat binders. The following is therefore recommended:

1. Additional work should be done to adapt the ZSV method to neat binders. This will involve additional laboratory work with verification being done in the field.

The current performance graded binder specifications use six degree increments in defining binder grades. Thus a PG 71-22 is theoretically the same high stiffness grade as a PG 75-22. The research has shown that such variations in the high temperature grade of binders can result in HMA mixture performance differences. These differences may be exacerbated if one of the binders is modified and the other neat. Given the results, the following are recommended:

1. The sample of aggregate, binder, and HMA mixture types was necessarily small in this experiment. While various relationships were established, additional testing is recommended for further analysis and validation; and

2. Conduct a field experiment based on the results of this study and compare HMA pavement performance differences (i.e., rutting, fatigue, and thermal cracking) using field-collected data.

\subsection{Implementation}

During the performance of this research two significant changes have occurred. First, the INDOT began using standard mixing and compaction temperatures for HMA laboratory mixture designs. Secondly, additional work has been done with 
the Superpave binder specification that makes it blinder to binder modification. Given these two developments, the following are suggested as implementation items:

1. The INDOT should review HMA mixture design data to determine if the new mixing and compaction temperature guidelines are effective, particularly for mixtures containing modified binders; and

2. The INDOT should adopt the new binder specification when it becomes available. 


\section{REFERENCES}

AASHTO Designation TP9-96, "Standard Test Method for Determining the Creep Compliance and Strength of Hot Mix Asphalt (HMA) Using the Indirect Tensile Test Device".

AASHTO Designation TP10-93, (Reapproved 1996), "Standard Test Method for Thermal Stress Restrained Specimen Tensile Strength".

AASHTO Designation TP8-94, (Reapproved 1996), "Standard Test Method for Determining the Fatigue Life of Compacted Hot Mix Asphalt (HMA) Subjected to Repeated Flexural Bending".

Anderson, D.A., Lapalu, L., Le, H., "Low-temperature thermal cracking of asphalt binders as ranked by strength and fracture properties", Transportation Research Record 1766, pp. 1-6, 2001.

ASTM D2493, Standard Viscosity-Temperature Chart for Asphalts.

Ahlrich R.C., "Influence of Aggregate Gradation and Particle Shape/Texture on Permanent Deformation of Hot Mix Asphalt Pavements", US Army Corps of Engineers, Technical Report GL-96-1, Army Engineer Waterways Experiment Station Vicksburg. MS, 1996. 
Bahia H.U., Hanson D.I., Zeng M., Zhai H., Khatri M.A., and Anderson R.M., "Characterization of Modified Asphalt Binders in Superpave Mix Design" NCHRP Report 459, National Academy Press, 2001.

Branes, H.A., Hutton J.F., and Walters K., "An Introduction to Rheology", Elsevier Science Publishers B.V., Amsterdam, 1989, p212.

Bickel and Doksum, "Mathematical Statistics: Basic Ideas and Selected Topics, Vol l", Prentice Hall, 2nd Edition, 2000, p556.

Brown, E. R., and Basset, C. E., "Effects of Maximum Aggregate Size on Rutting Potential and Other Properties of Asphalt-Aggregate Mixtures", Transportation Research Record 1259, Transportation Research Board, Washington, D.C., p. 107-119 1990.

Brown, E. R. and Cross, "A National Study of Rutting In Hot Mix Asphalt (HMA) Pavements." NCAT Report No. 92-5, National Center for Asphalt Technology, 1991.

Button, J.W., D.N. Little, Y. Kirn, and J. Ahmed, "Mechanistic Evaluation of Selected Asphalt Additives", Proceedings, The Association of Asphalt Paving Technologists, 56 p62-90, 1987.

Carpenter, S.H. and T. Van Dam, "Laboratory Performance Comparisons of Polymer-Modified and Unmodified Asphalt Concrete Mixes", TRR 1115, TRB, National Research Council, Washington, D.C. p 62-74, 1987. 
Chowdhury, A. T., Grau, J. D. C., Button, J. W. and Little, D. N. "Effect of Gradation on Permanent Deformation of Superpave Hot-Mix Asphalt", Presented at the 80th Annual Meeting of the Transportation Research Board, Washington, D.C., 2001.

Christensen, D. "Analysis of creep data from indirect tension test on asphalt concrete", Association of Asphalt Paving Technologists Technical Sessions, Vol. 67, p 458-492, 1998.

Christensen, W. D., and Bonaquist, R., "Use of Strength Tests for Evaluating the Rut Resistance of Asphalt Concrete", Asphalt Paving Technology, Association of Asphalt Paving Technologists-Proceedings of the Technical Sessions, Vol - 71, 2002, p 692- 711.

De Sombre, R., Newcomb, D. E., Chadbourn, B., and Voller, V., "Parameters to Define the Laboratory Compaction Temperature Range of Hot-Mix Asphalt", Journal of the Association of Asphalt Paving Technologies, Vol. 67, p125-152. , 1998.

Epps, A. L., "An approach to examine thermal fatigue in asphalt concrete", Journal of the association of asphalt paving technologists, Vol. 68, p319348,1999 .

Galal K A., and White T. D. "Correlations Between Superpave Asphalt Stiffness and In-Service Pavement Performance", 80th Annual Meeting of the Transportation Research Board, Washington, D.C., 2001. 
Goodrich, J.L., "Asphalt and Polymer-Modified Asphalt Properties Related to the Performance of Asphalt Concrete Mixes", Proceedings, the Association of Asphalt Paving Technologists. Vol. 57 pp 116-175,1988.

Habermann, J. A. "Design features and a preliminary study of the Purdue linear compactor and the PurWheel tracking device", Thesis, Purdue University, West Lafayette, IN, 1994.

Haddock, J.E., Pan, C., Feng, A., and White, T. D., "Effect of Gradation on Asphalt Mixture Performance", Transportation Research Record 1681, Transportation Research Board, Washington, D.C., p. 59-68, 1999.

Haddock J.E., "Investigation of the Performance of Neat and Modified Asphalt Binders", work plan for part II research study, Joint Transportation Research Program, Project No. C-36-56L, May 2001, p14.

Hand, Adam J., Stiady, James L.; White, Thomas D.; Noureldin, A. Samy and Galal, Khaled "Gradation effects on Hot-Mix Asphalt Performance", Transportation Research Record, n 1767, Transportation Research Board, Washington, D.C., p 152-157, 2001.

Harvey J. T., Deacon J. A., Tsai B. and Monismith C. L., "Fatigue Performance Of Asphalt Concrete Mixes And Its Relationship To Asphalt Concrete Pavement Performance In California", Institute of Transportation Studies, University of California, Berkeley, October 1995,p189. 
Harvey, J.T., Deacon J.A., Tayebali A.A., Leahy R.B., and Monismith C.L., "A Reliability-Based Mix Design and Analysis System for Mitigating Fatigue Distress", Eighth International Conference on Asphalt Pavements, Seattle, Washington, 1997.

Hensley, J. and Palmer, A., "Establishing Hot Mix Asphalt Mixing and Compaction Temperatures At the Project Level", Asphalt Institute, Vol. 12 No. 2, 1998.

Hiltunen, D. R. and Roque, R. "A mechanics-based prediction model for thermal cracking of asphaltic concrete pavements", Association of Asphalt Paving Technologists Technical Sessions, Vol. 63, p 81-117, 1994.

Hiltunen, D. R. and Roque, R., "The Use of Time -Temperature Superposition of Fundamentally Characterized Asphaltic Concrete Mixtures at Low Temperatures", Engineering Properties of Asphalt Mixtures and the Relationship to their Performance, ASTM STP 1265, p. 74-93, 1995.

Kandhal, P.S. and Cooley, L.A. Jr., "Effect of Restricted Zone on Permanent Deformation of Dense-Graded Superpave Mixtures", ASTM STP 1412, p173184, 2001.

Kanerva H. K., Vinson T. S. and Zeng H., "Low-Temperature Cracking: Field Validation of the Thermal Stress Restrained Specimen Test (SHRP-A-401), National Academy of Sciences, 1994. 
Kennedy, T. W., Robert, F. L. and McGennis, R. B., "Effects of Compaction Temperature and Effort on the Engineering Properties of Asphalt Concrete Mixes", ASTM STP 829, F. T. Wagner, Ed., American Society for Testing and Materials, p 48-66, 1984.

Khatri, A., H. U. Bahia, and D. Hanson, "Mixing and Compaction Temperatures for Modified Binders Using the Superpave Gyratory Compactor", Journal of the Association of Asphalt Paving Technologies, 2001.

Kim, Y. R., Kim, N. and Khosla, N. P. "Effects of aggregate type and gradation on fatigue and permanent deformation of asphalt concrete", ASTM Special Technical Publication, n 1147, p 310-328, 1992.

Leahy, R.B., Harrigan, E.T. and Quintus, H.V. "Validation of relationships between specification properties and performance", Strategic Highway Research Program A-409, National Research Council, Washington, D.C. 1994, p104.

Lu, X. and Isacsson, U., "Influence of styrene-butadiene-styrene polymer modification on bitumen viscosity", Fuel, Vol. 76 , No. 14/15, p. 1353-1359, 1997.

Mallick, R. B., Ahlrich, R., and Brown, E. R., " Potential of Dynamic Creep to Predict Rutting", ASTM STP 1265, p194-212, 1995. 
Matthews, J. M. and Monismith, C. L., "The effect of aggregate gradation on the creep response of asphalt mixtures and pavement rutting estimates", ASTM Special Technical Publication, n 1147, p 329-343, 1992.

McGennis, Robert B., R. Michael Anderson, Thomas W. Kennedy and Mansour Solaimanian, "Background of Superpave Asphalt Mixture Design and Analysis." Federal Highway Administration, Office of Technology Applications, FHWA-SA-95-003, 1994.

McLeod, N. W., "Influence of Viscosity of Asphalt Cements on Compaction of Paving Mixtures in the Field", Highway Research Record No. 158, Highway Research Board, National Academy of Sciences, Washington, DC, p. 76155., 1967.

Montgomery, D.C., "Design and Analysis of Experiments", 5th Edition, Wiley; 5 edition (June 30, 2000, p672.

Neter J., Kutner M.H., Wasserman W. and Nachtsheim C.J., "Applied Linear Regression Models", McGraw-Hill/Irwin; 3 ed., 1996, p720.

"Reference Manual - Superpave Fundamentals Chapter 09 - Superpave Mix Analysis and Testing" FHWA-NHI-131053, 2000, http://www.nhi.fhwa.dot.gov/download/material/131053/RM/RML09.pdf

Roberts F.L., "Hot Mix Asphalt Materials, Mixture Design \& Construction", National Asphalt Pavement Association; 2nd edition, 1996, p575. 
Roque R, and Buttlar W. G., "Development of a measurement and analysis system to accurately determine asphalt concrete properties using the indirect tensile mode", Association of Asphalt Paving Technologists Technical Sessions, Vol. 61, p 304-332, 1992.

Roque, R., Hiltunen, D. H., Buttlar, W. G., and Farwana, T., "Development of the SHRP Superpave mixture specification test method to control thermal cracking performance of pavements", ASTM Special Technical Publication, $n$ 1265, p 55-73, 1995.

Sebaaly, P. E., D. Ridolfi, R. S. Gangavaram, and J. A. Epps. "Selecting Most Desirable Hot- Mix Asphalt Mixtures", Transportation Research Record 1590, TRB, National Research Council, Washington, D.C., p. 99-107, 1997.

Shahin, M.Y. and B.F. McCullough "Prediction of Low-Temperature and Thermal Fatigue Cracking in Flexible Pavements." Report No. CFHR 1-8-69-123-14. The University of Texas. Austin 1972.

Shenoy, A. V. "Determination of the temperature for mixing aggregates with polymer-modified asphalts", Journal of Pavement Engineering, p 33-47, 2001.

Sousa, J. B., Pais, J. C., Prates, M., Barros, R., Langlois, P. and LeClerc, A. M., "Effect of Aggregate Gradation on Fatigue Life of Asphalt Concrete Mixes", Transportation Research Record, n 1630, Sep, 1998, p 62-68. 
Stiady, J. L., "Validation of SHRP Asphalt Mixture Specification using Accelerated Testing", Ph.D. Thesis, Purdue University, West Lafayette, IN, May, 2000.

Superpave Level 1 Mix Design, Superpave series N0.2 (SP-2), Asphalt Institute, Lexington, KY, 1995.

Sybilski, D., "Zero Shear Viscosity of Bituminous Binder and its Relationship to Bituminous Mixture's Rutting Resistance", Transportation Research Record No. 1535, Transportation Research Board, National Academy of Sciences, Washington, Dc, 1996, pp. 15-21.

White, T. D., Haddock, J.E., Hand, A. T. and Fang, H, "Contributions of Pavement Structural Layers to Rutting of Hot Mix Asphalt Pavements" NCHRP Report No: 459, 2002.

Yildrim, Y., Solaimanian, and T. Kennedy, "Mixing and Compaction Temperatures for Superpave Mixes", Journal of the Association of Asphalt Paving Technologists, Vol. 69, 2000.

Young, F "Asphalt", The Magazine of Asphalt Institute Fall 1998 V.12 No.3.

Zaman, A.A., Fricke, A.L. and Beatty, C.L., "Rheological properties of rubbermodified asphalt", Journal of Transportation Engineering Vol. 121, No. 6, p. 461-467, 1995. 
Zubeck, H., Raad, L., Saboundjian, S., Minassian, G. and Ryer, J., "Constructability of Polymer-Modified Asphalts and Asphalt-Aggregate Mixtures in Alaska", FHWA-AK-RD-99-1, Federal Highway Administration, 1999. 
Appendix A. Determining Mixing and Compaction Temperatures 


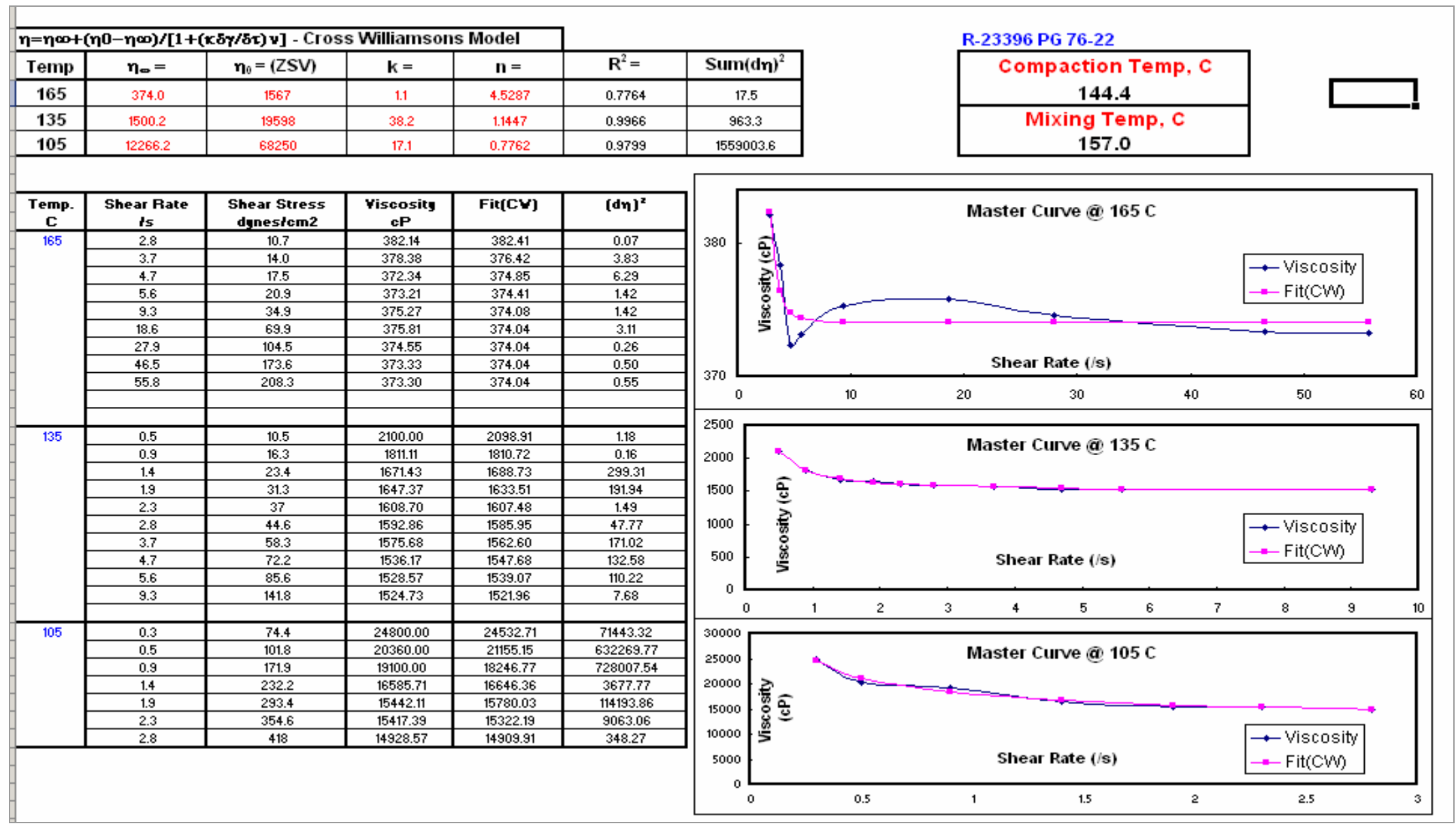

Figure A1 R-23396 ZSV Temperature Calculation 


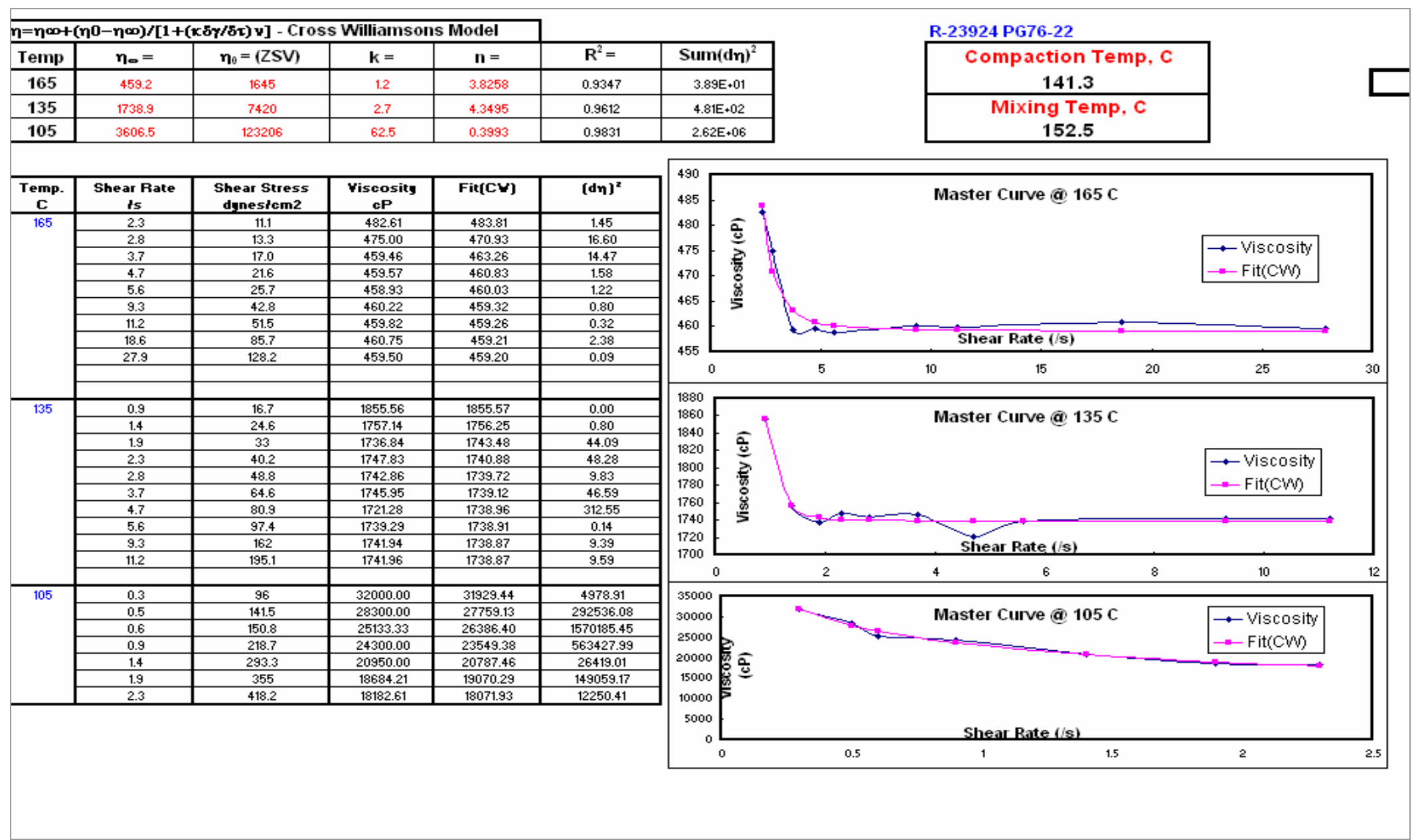

Figure A2 R-23924 ZSV Temperature Calculation 


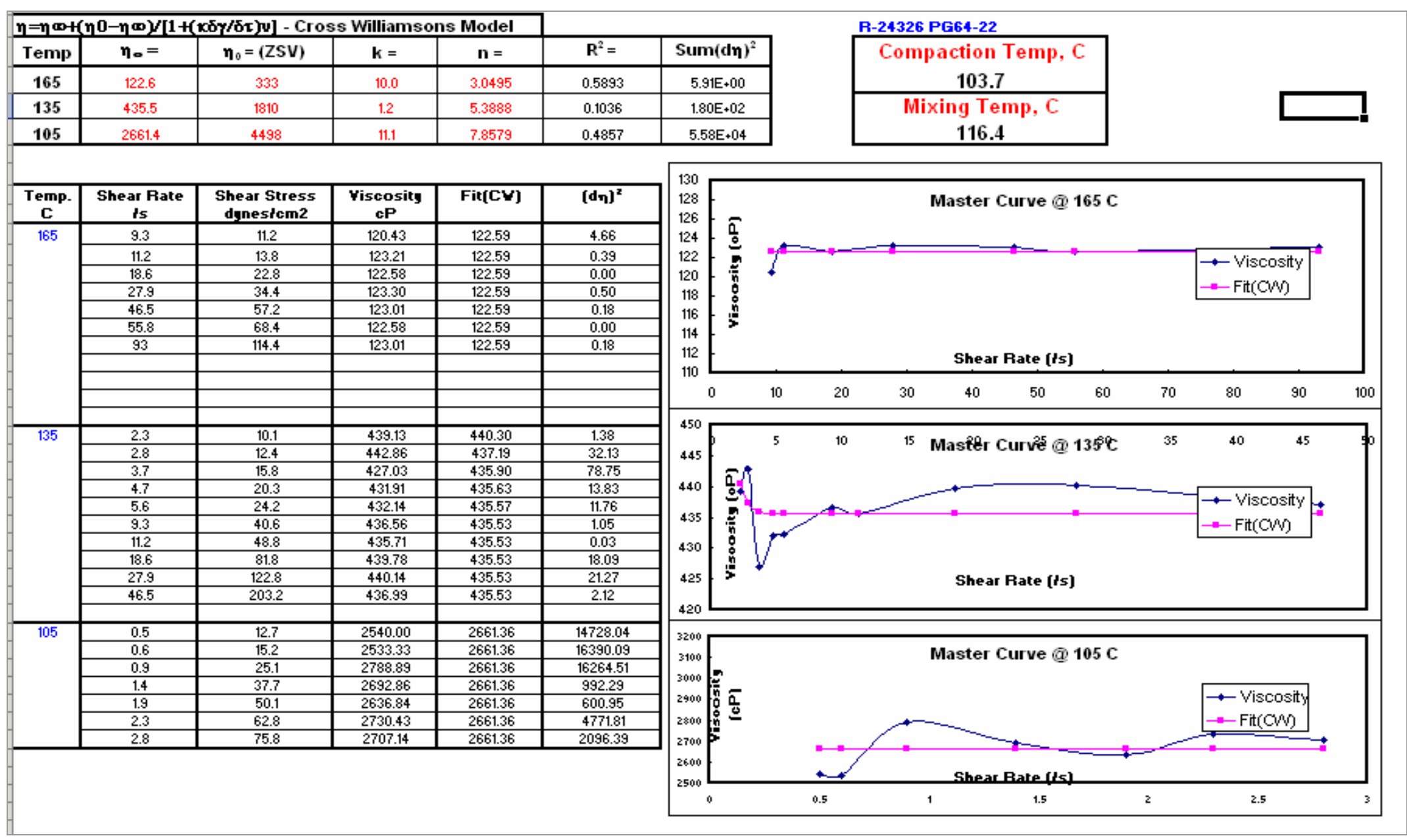

Figure A3 R-24326 ZSV Temperature Calculation 


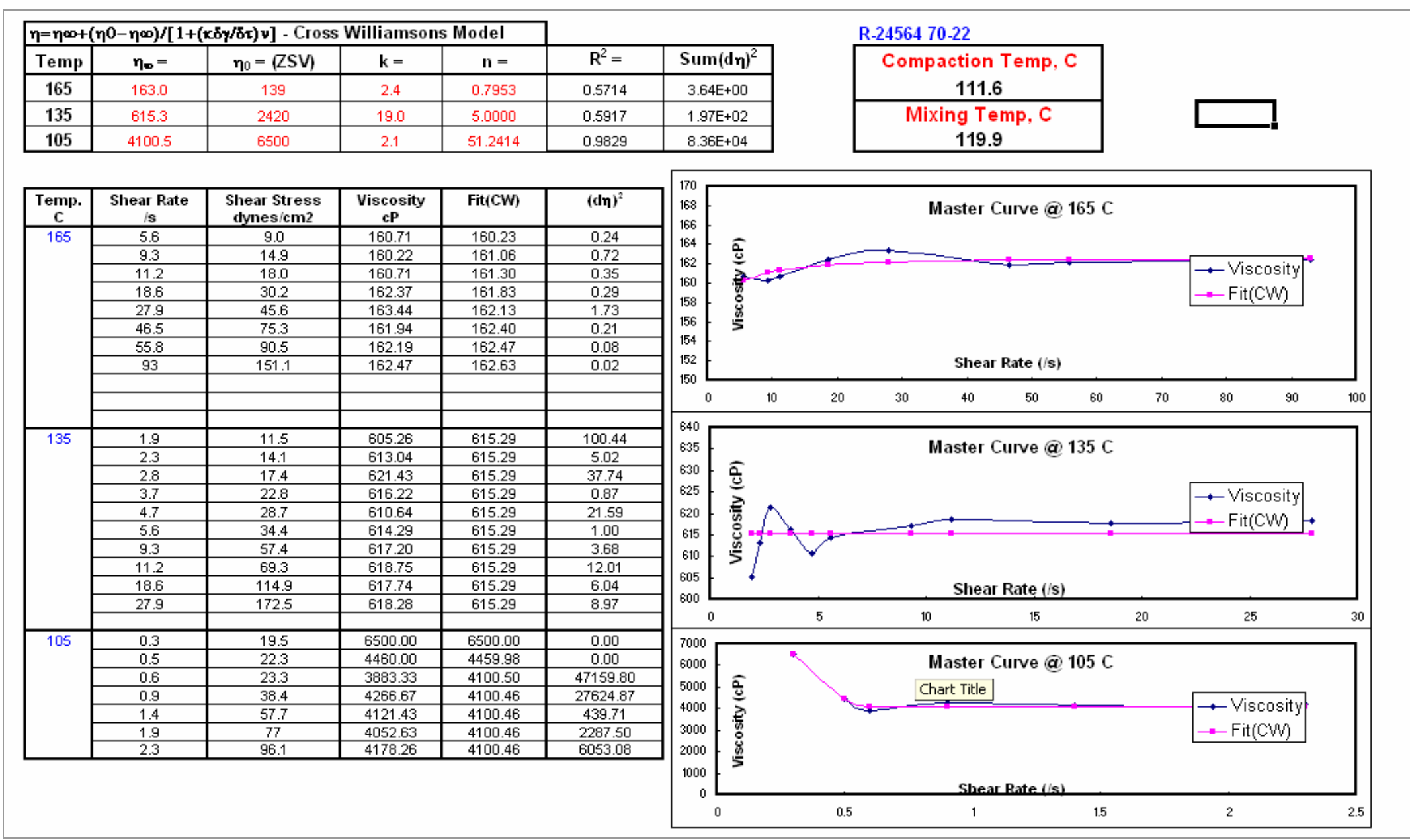

Figure A4 R-24564 ZSV Temperature Calculation 


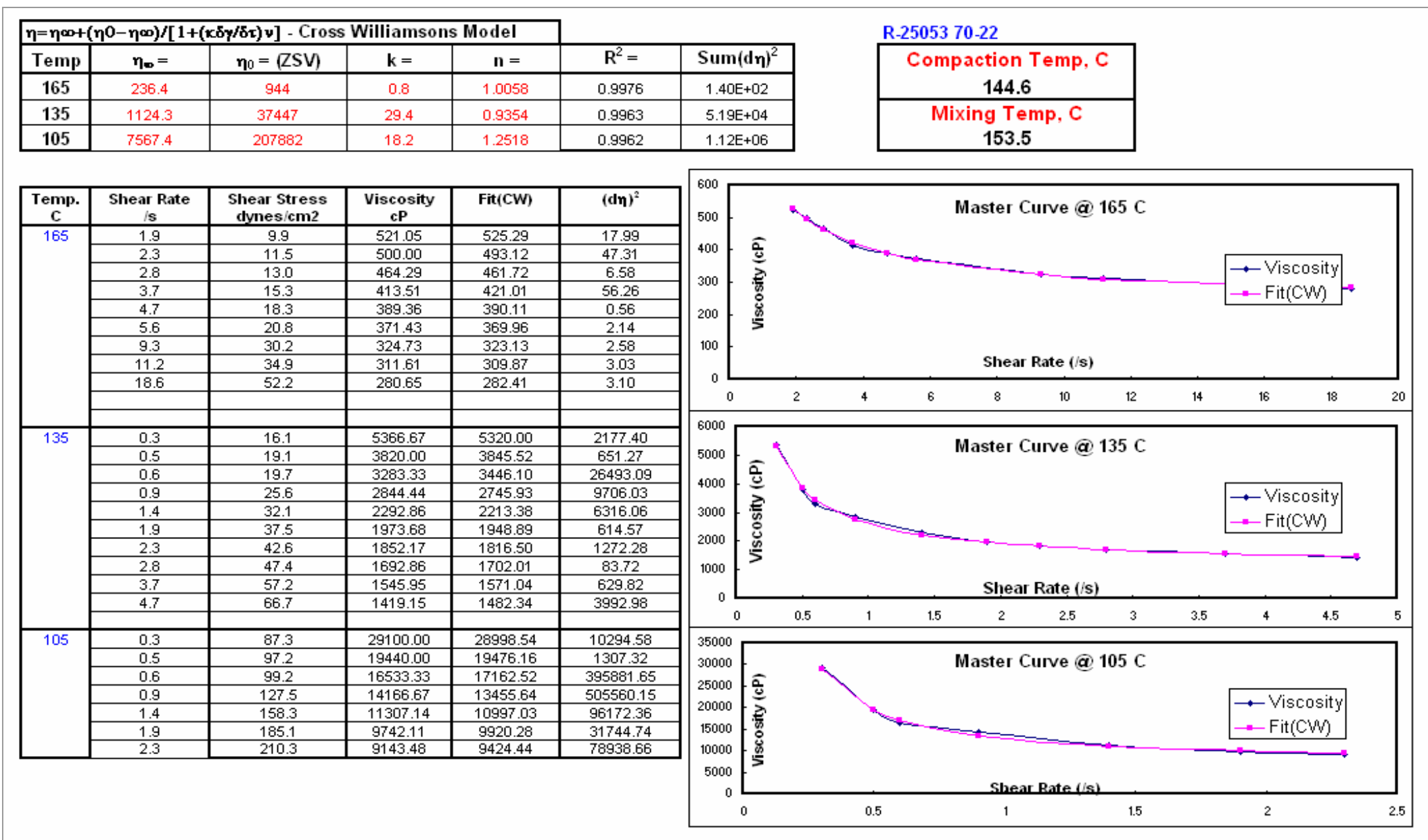

Figure A5 R-25053 ZSV Temperature Calculation 


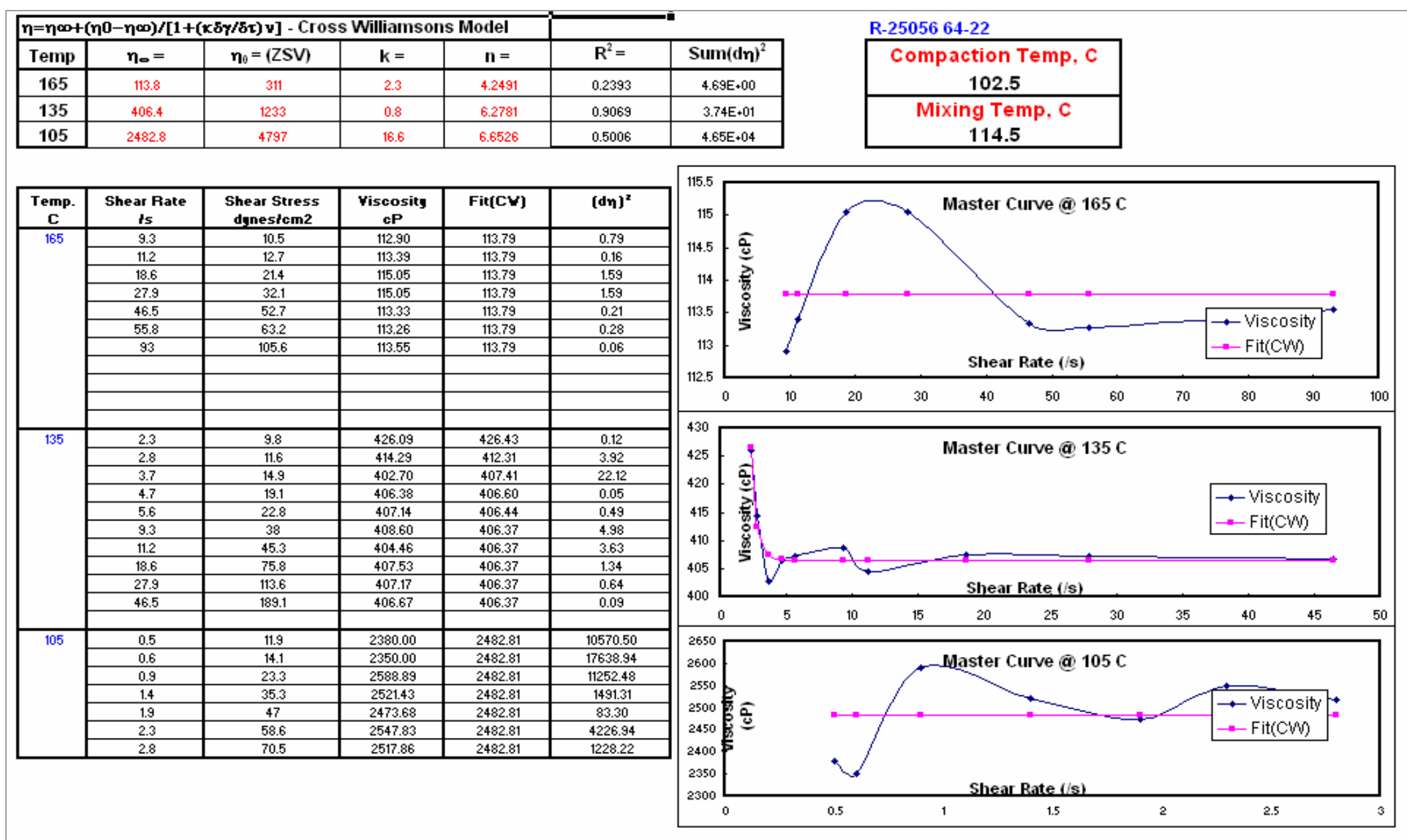

Figure A6 R-25056 ZSV Temperature Calculation 


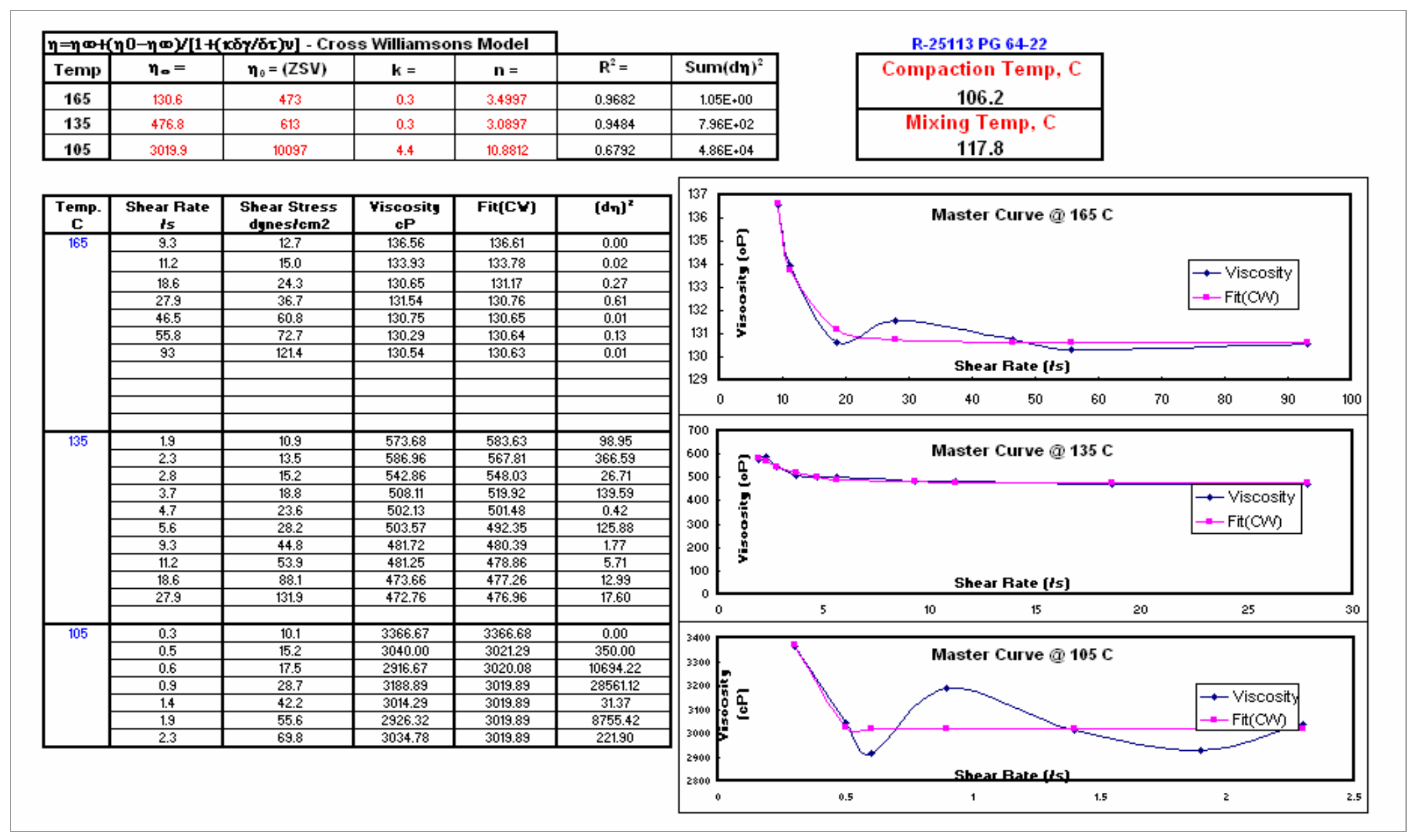

Figure A7 R-25113 ZSV Temperature Calculation 


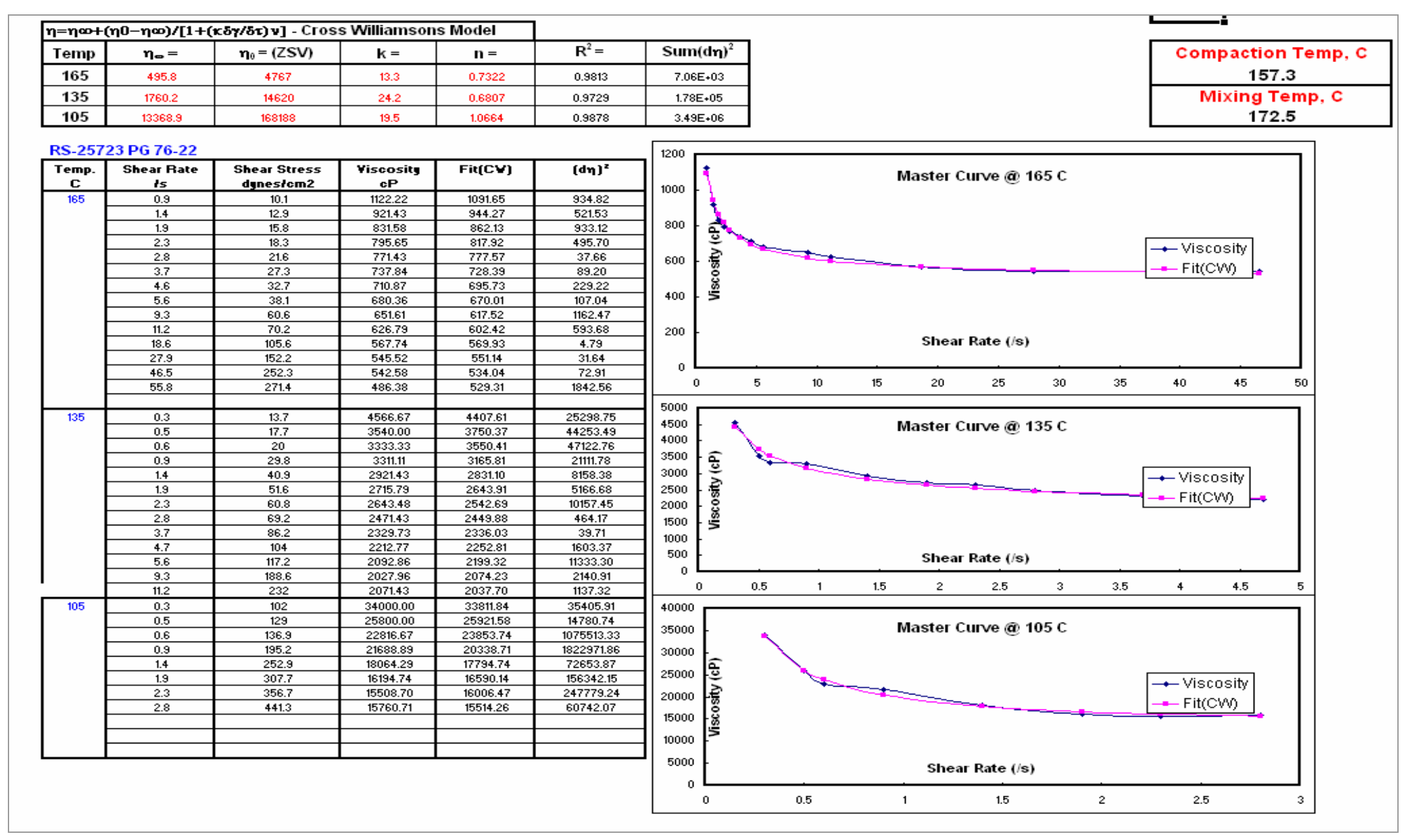

Figure A8 R-25723 ZSV Temperature Calculation 
Appendix B. PURWheel Test Data 
Table B 1 PURWheel Test Data

\begin{tabular}{|c|c|c|c|c|c|c|}
\hline $\begin{array}{c}\text { Specimen } \\
\text { Name }\end{array}$ & Replicate \# & Binder & Gradation & $\begin{array}{l}\text { NMAS, } \\
\text { mm }\end{array}$ & $\begin{array}{c}\text { Air } \\
\text { Voids, \% }\end{array}$ & $\begin{array}{l}\text { Rut Depth, } \\
\text { mm }\end{array}$ \\
\hline \multirow{4}{*}{ N70C1 } & 1 & \multirow{4}{*}{$\begin{array}{c}\text { Neat } \\
\text { PG 70-22 }\end{array}$} & Coarse & 9.5 & 8.03 & 3.204 \\
\hline & 2 & & Coarse & 9.5 & 8.07 & 3.39 \\
\hline & 3 & & Coarse & 9.5 & 7.09 & 2.89 \\
\hline & 4 & & Coarse & 9.5 & 6.65 & 2.46 \\
\hline \multirow{4}{*}{$\mathrm{N} 75 \mathrm{C} 1$} & 1 & \multirow{4}{*}{$\begin{array}{c}\text { Neat } \\
\text { PG 75-22 }\end{array}$} & Coarse & 9.5 & 7.83 & 2.75 \\
\hline & 2 & & Coarse & 9.5 & 8.28 & 2.34 \\
\hline & 3 & & Coarse & 9.5 & 7.92 & 2.4 \\
\hline & 4 & & Coarse & 9.5 & 6.03 & 1.86 \\
\hline \multirow{4}{*}{ M71C1 } & 1 & \multirow{4}{*}{$\begin{array}{c}\text { Modified } \\
\text { PG 71-22 }\end{array}$} & Coarse & 9.5 & 7.07 & 1.37 \\
\hline & 2 & & Coarse & 9.5 & 6.01 & 2.43 \\
\hline & 3 & & Coarse & 9.5 & 7.74 & 2.4 \\
\hline & 4 & & Coarse & 9.5 & 6.46 & 1.27 \\
\hline \multirow{4}{*}{ M75C1 } & 1 & \multirow{4}{*}{$\begin{array}{c}\text { Modified } \\
\text { PG 75-22 }\end{array}$} & Coarse & 9.5 & 6.05 & 0.69 \\
\hline & 2 & & Coarse & 9.5 & 6.43 & 0.48 \\
\hline & 3 & & Coarse & 9.5 & 7.94 & 0.99 \\
\hline & 4 & & Coarse & 9.5 & 6.16 & 1.36 \\
\hline \multirow{4}{*}{ N70C2 } & 1 & \multirow{4}{*}{$\begin{array}{c}\text { Neat } \\
\text { PG 70-22 }\end{array}$} & Coarse & 12.5 & 6.08 & 1.44 \\
\hline & 2 & & Coarse & 12.5 & 6.99 & 1.33 \\
\hline & 3 & & Coarse & 12.5 & 6.48 & 1.38 \\
\hline & 4 & & Coarse & 12.5 & 7.87 & 2.05 \\
\hline \multirow{4}{*}{ N75C2 } & 1 & \multirow{4}{*}{$\begin{array}{c}\text { Neat } \\
\text { PG 75-22 }\end{array}$} & Coarse & 12.5 & 7.55 & 1.98 \\
\hline & 2 & & Coarse & 12.5 & 7.49 & 1.74 \\
\hline & 3 & & Coarse & 12.5 & 7.95 & 1.97 \\
\hline & 4 & & Coarse & 12.5 & 8.25 & 2.13 \\
\hline \multirow{4}{*}{ M71C2 } & 1 & \multirow{4}{*}{$\begin{array}{c}\text { Modified } \\
\text { PG 71-22 }\end{array}$} & Coarse & 12.5 & 6.22 & 1.69 \\
\hline & 2 & & Coarse & 12.5 & 6.99 & 1.42 \\
\hline & 3 & & Coarse & 12.5 & 7.95 & 2.26 \\
\hline & 4 & & Coarse & 12.5 & 5.08 & 1.68 \\
\hline \multirow{4}{*}{ M75C2 } & 1 & \multirow{4}{*}{$\begin{array}{c}\text { Modified } \\
\text { PG 75-22 }\end{array}$} & Coarse & 12.5 & 7.13 & 1.16 \\
\hline & 2 & & Coarse & 12.5 & 7.73 & 1.3 \\
\hline & 3 & & Coarse & 12.5 & 7.95 & 1.72 \\
\hline & 4 & & Coarse & 12.5 & 9.55 & 1.69 \\
\hline \multirow{4}{*}{ N70F1 } & 1 & \multirow{4}{*}{$\begin{array}{c}\text { Neat } \\
\text { PG 70-22 }\end{array}$} & Fine & 9.5 & 6.2 & 2.09 \\
\hline & 2 & & Fine & 9.5 & 7.89 & 2.61 \\
\hline & 3 & & Fine & 9.5 & 7.03 & 2.57 \\
\hline & 4 & & Fine & 9.5 & 8.05 & 2.23 \\
\hline
\end{tabular}


Table B1 Continued

\begin{tabular}{|c|c|c|c|c|c|c|}
\hline \multirow{4}{*}{ M71F1 } & 1 & \multirow{4}{*}{$\begin{array}{c}\text { Modified } \\
\text { PG 71-22 }\end{array}$} & Fine & 9.5 & 7.36 & 6.27 \\
\hline & 2 & & Fine & 9.5 & 8.2 & 5.17 \\
\hline & 3 & & Fine & 9.5 & 6.85 & 4.35 \\
\hline & 4 & & Fine & 9.5 & 7.5 & 5.89 \\
\hline \multirow{4}{*}{ N70F2 } & 1 & \multirow{4}{*}{$\begin{array}{c}\text { Neat } \\
\text { PG } 70-22\end{array}$} & Fine & 12.5 & 6.48 & 2.42 \\
\hline & 2 & & Fine & 12.5 & 7.87 & 2.69 \\
\hline & 3 & & Fine & 12.5 & 6.4 & 2.31 \\
\hline & 4 & & Fine & 12.5 & 8.1 & 5.77 \\
\hline \multirow{4}{*}{ M71F2 } & 1 & \multirow{4}{*}{$\begin{array}{c}\text { Modified } \\
\text { PG 71-22 }\end{array}$} & Fine & 12.5 & 7.02 & 3.2 \\
\hline & 2 & & Fine & 12.5 & 4.98 & 2.23 \\
\hline & 3 & & Fine & 12.5 & 7.98 & 4.17 \\
\hline & 4 & & Fine & 12.5 & 6.04 & 2.03 \\
\hline
\end{tabular}

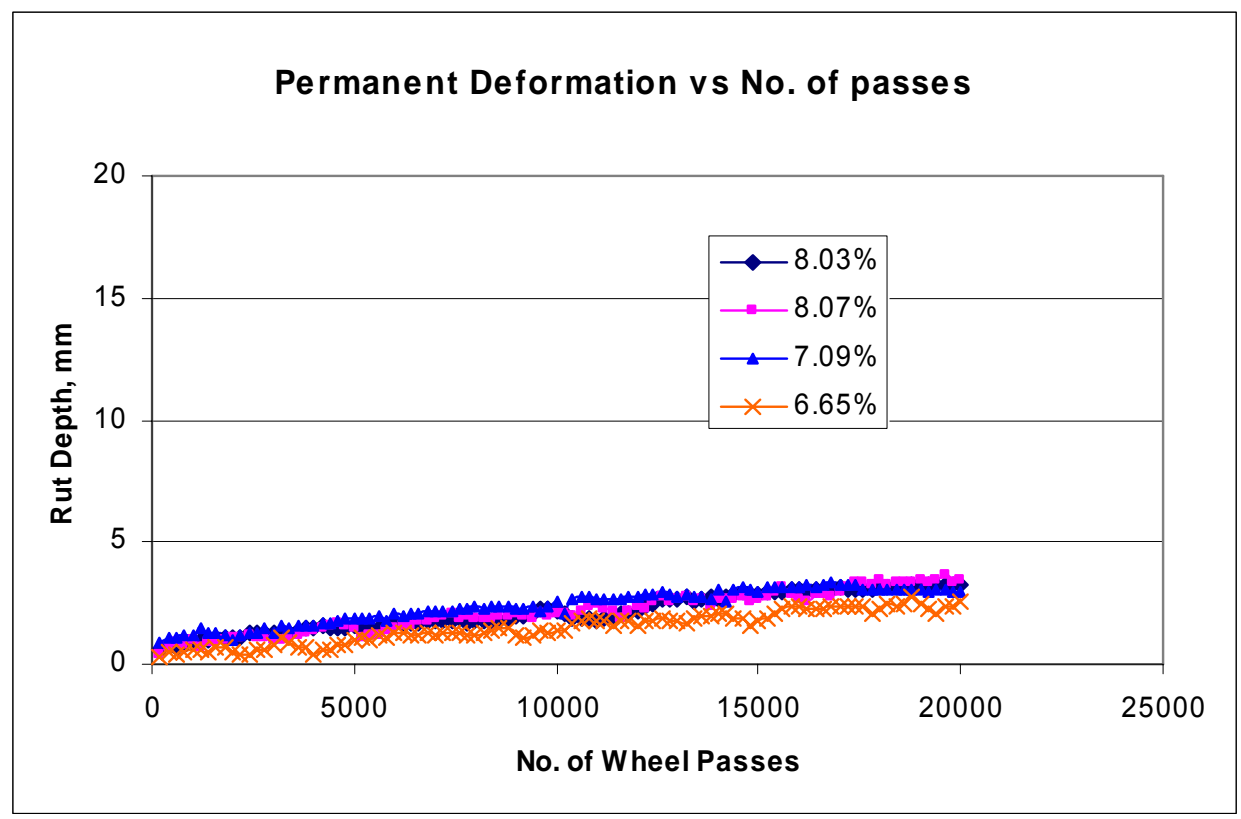

Figure B 1 Coarse-Graded, 9.5-mm Mixture with Neat PG 70-22 


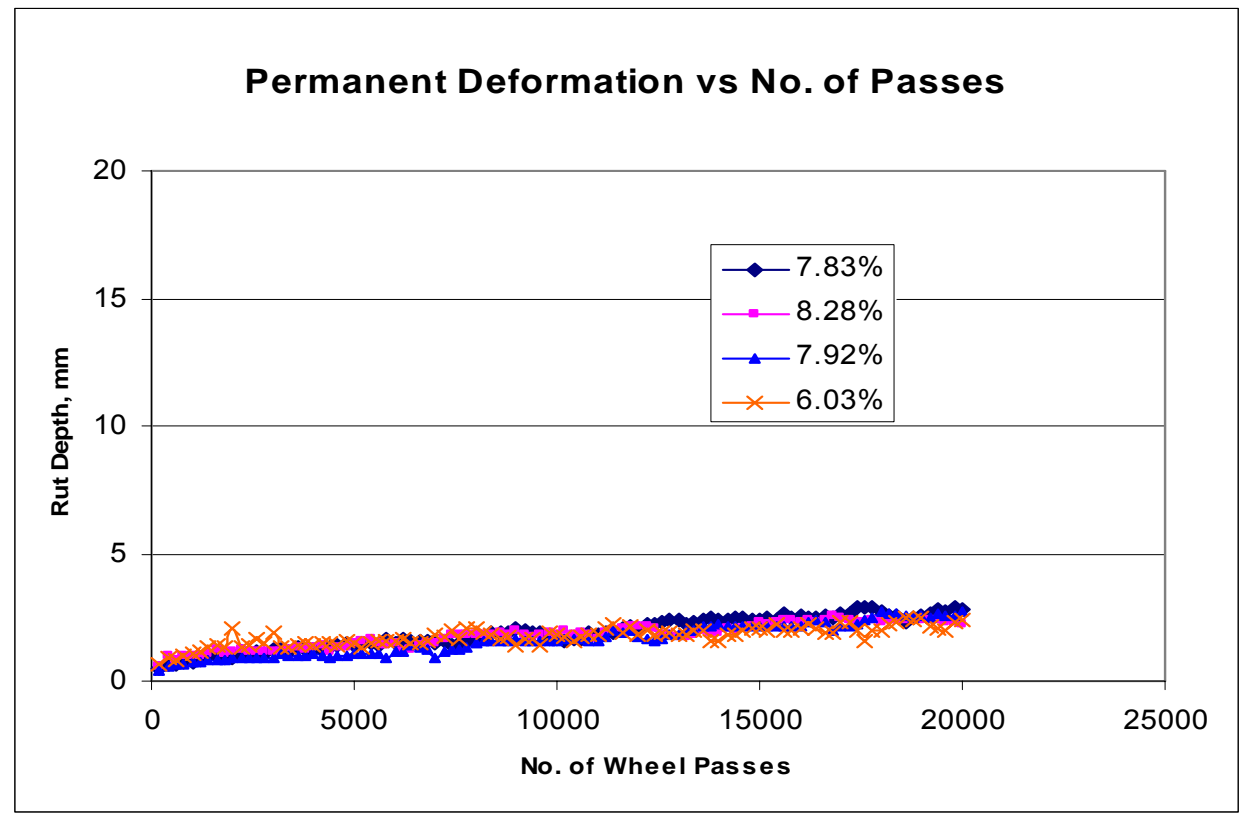

Figure B 2 Coarse-Graded, 9.5-mm Mixture with Neat PG 75-22

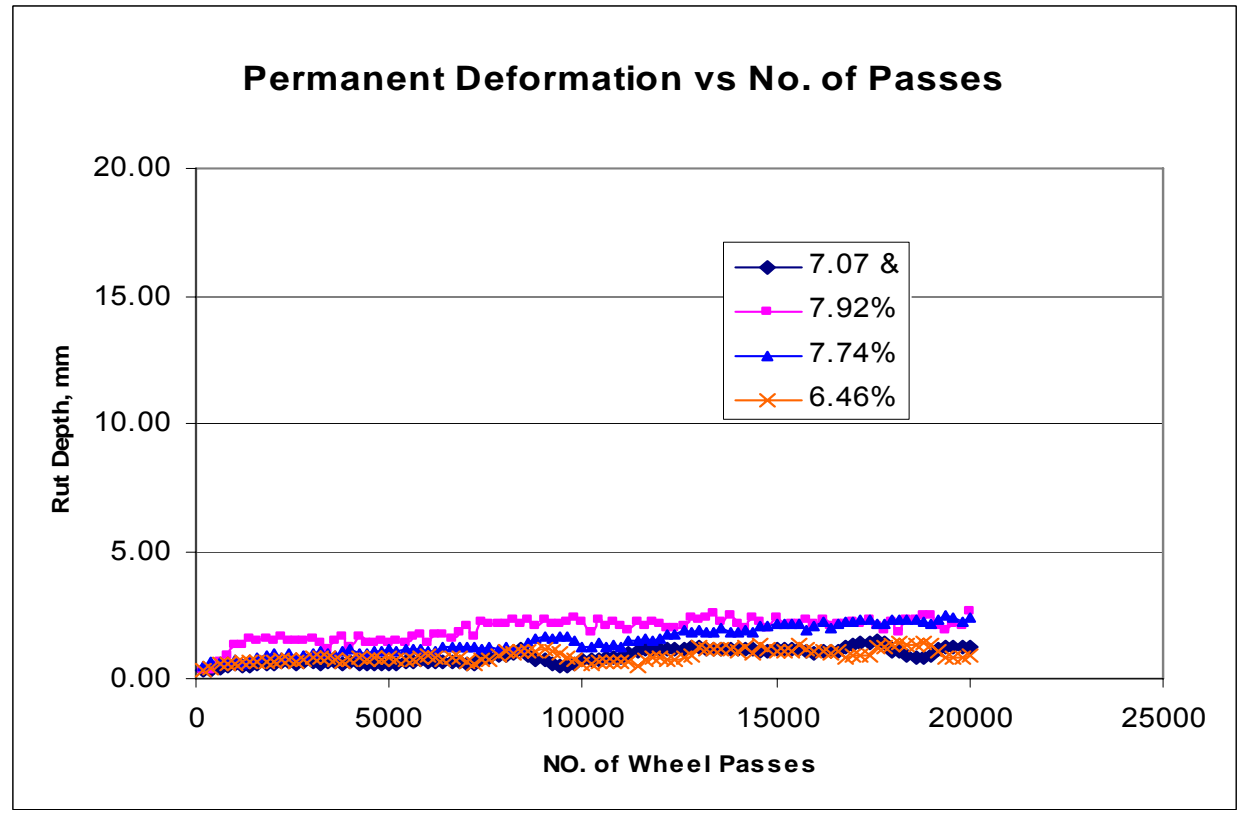

Figure B 3 Coarse-Graded, 9.5-mm Mixture with Modified PG 71-22 


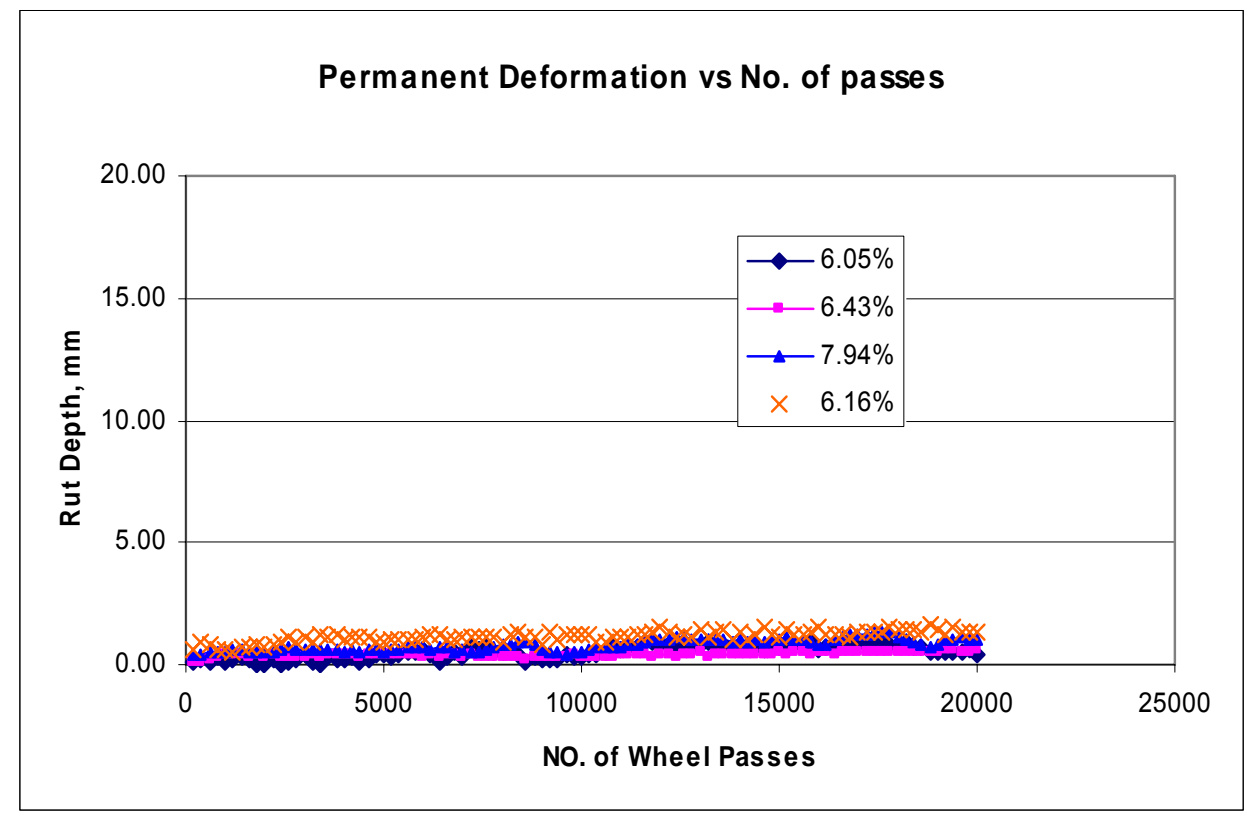

Figure B 4 Coarse-Graded, 9.5-mm Mixture with Modified PG 75-22

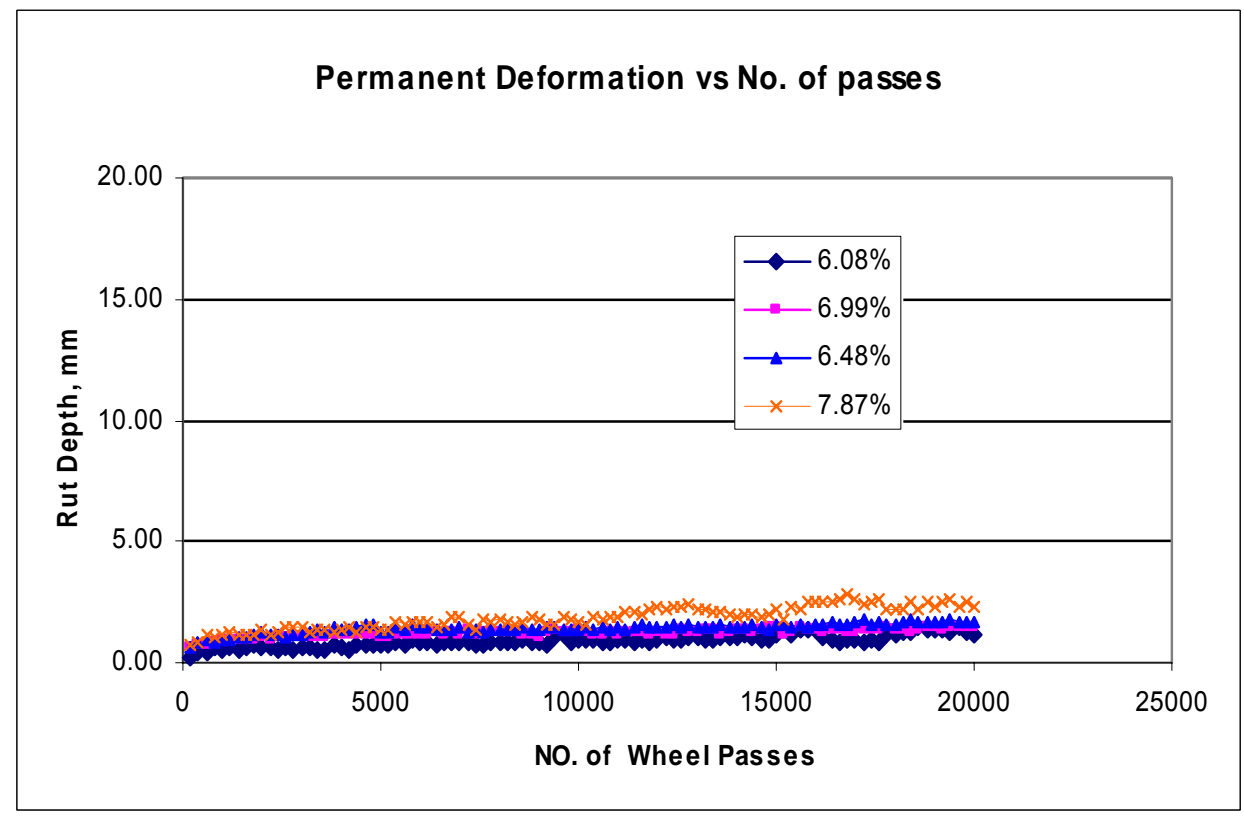

Figure B 5 Coarse-Graded, 12.5-mm Mixture with Neat PG 70-22 


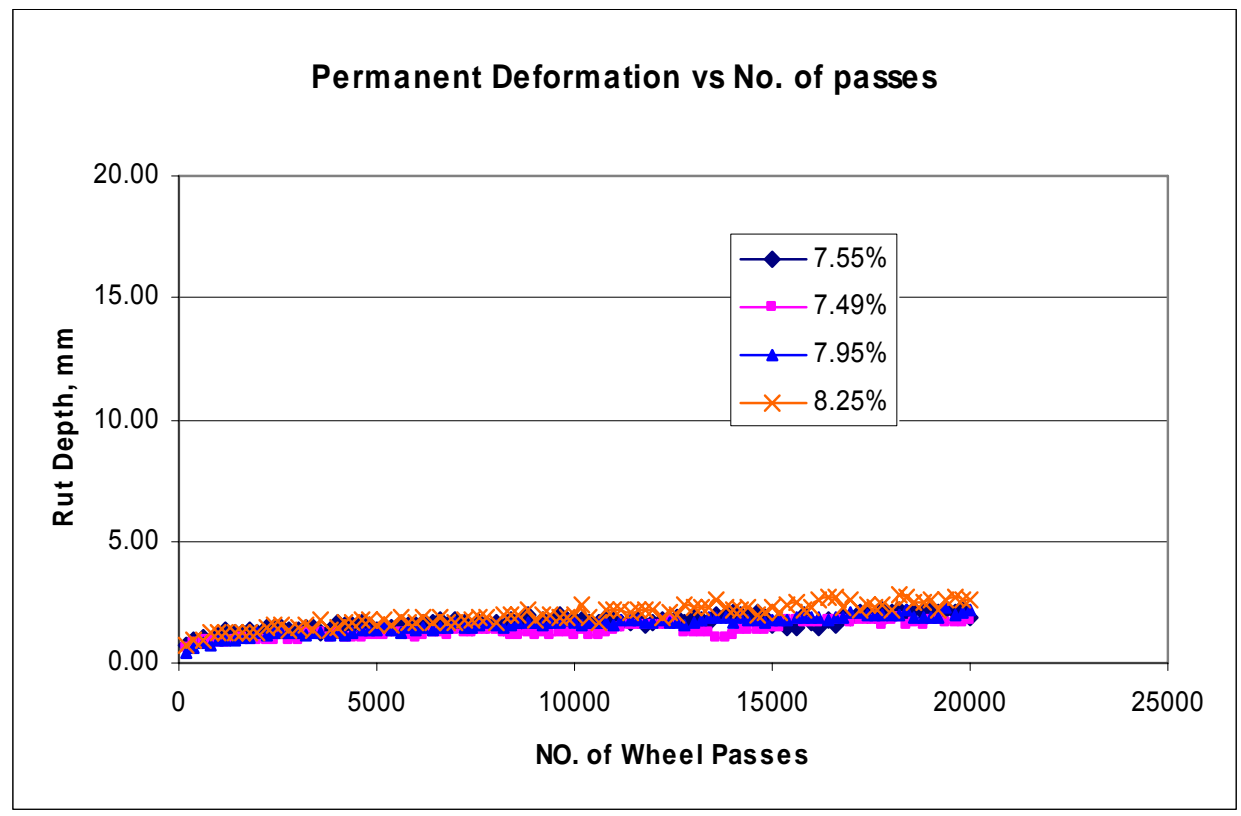

Figure B 6 Coarse-Graded, 12.5-mm Mixture with Neat PG 75-22

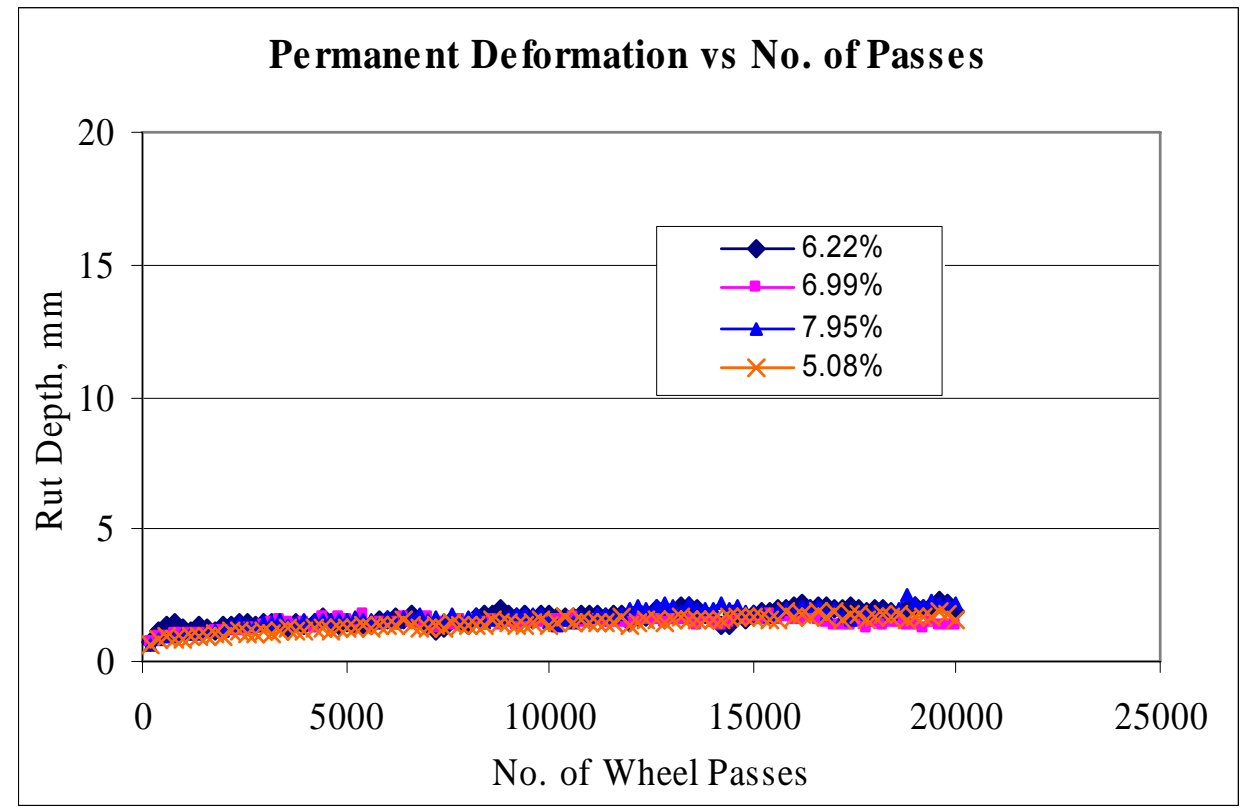

Figure B 7 Coarse-Graded, 12.5-mm Mixture with Modified PG 71-22 


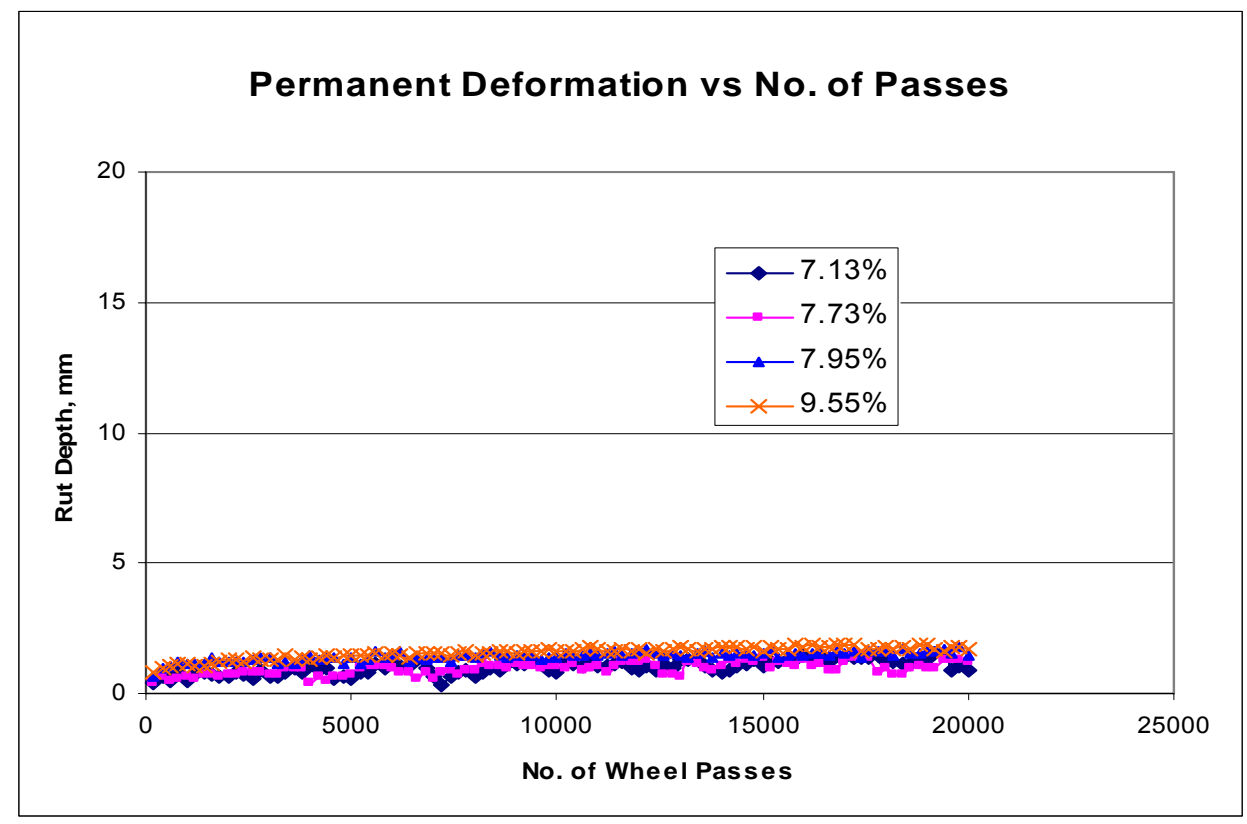

Figure B 8 Coarse-Graded, 12.5-mm Mixture with Modified PG 75-22

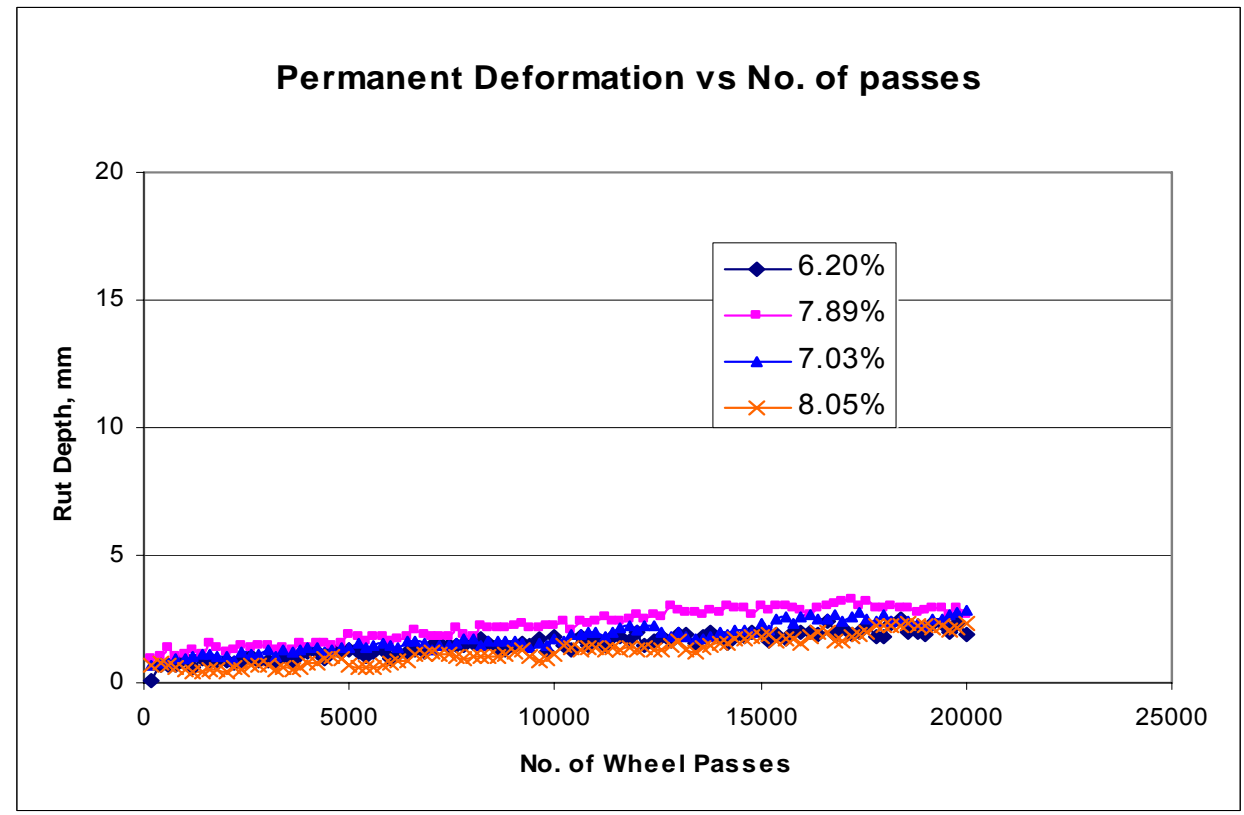

Figure B 9 Fine-Graded, 9.5-mm Mixture with Neat PG 70-22 


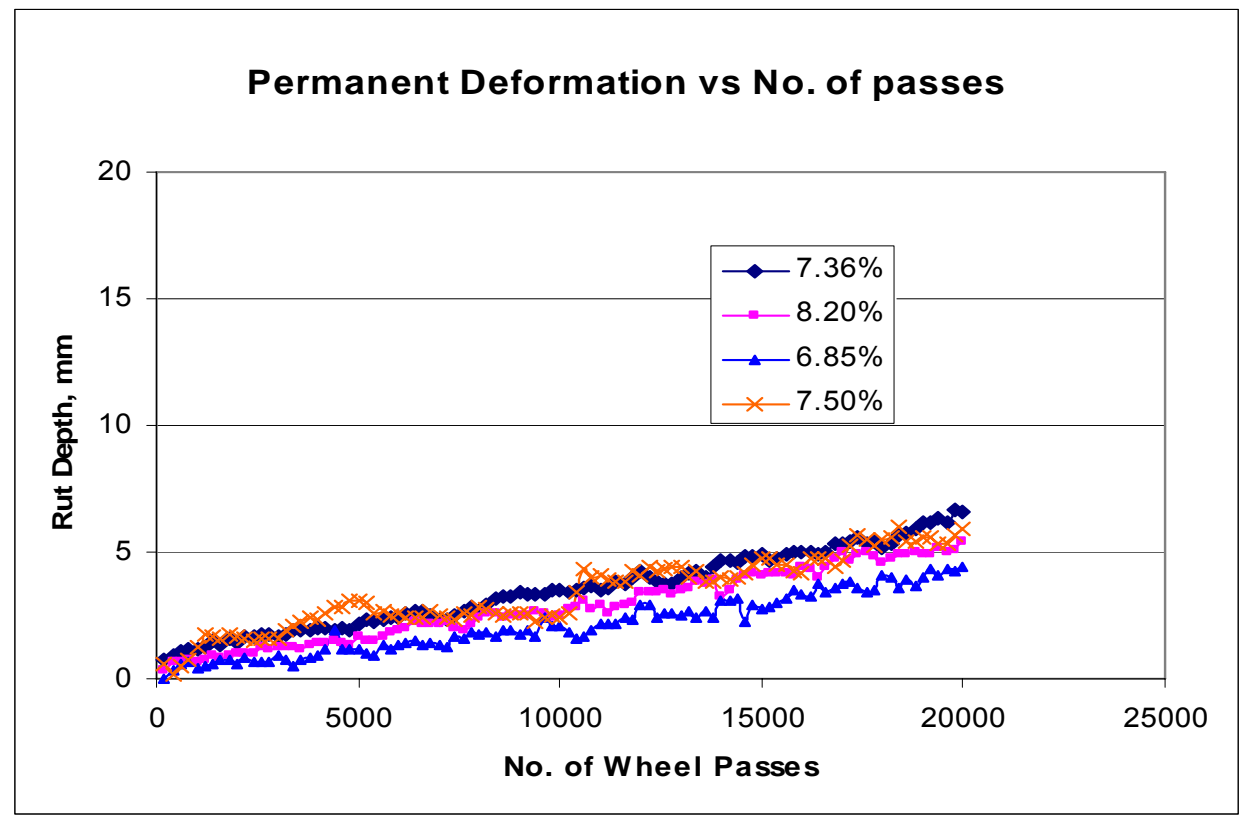

Figure B 10 Fine-Graded, 9.5-mm Mixture with Modified PG 71-22

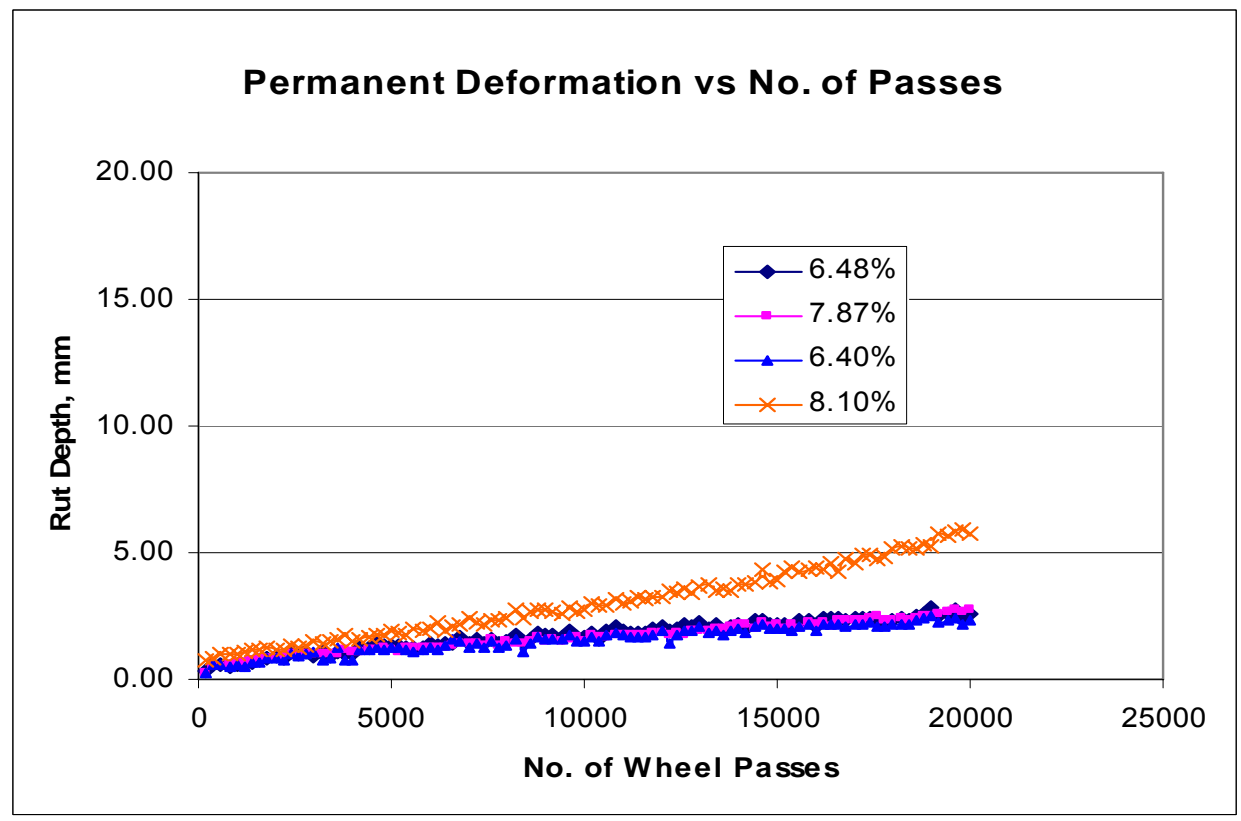

Figure B 11 Fine-Graded, 12.5-mm Mixture with Neat PG 70-22 


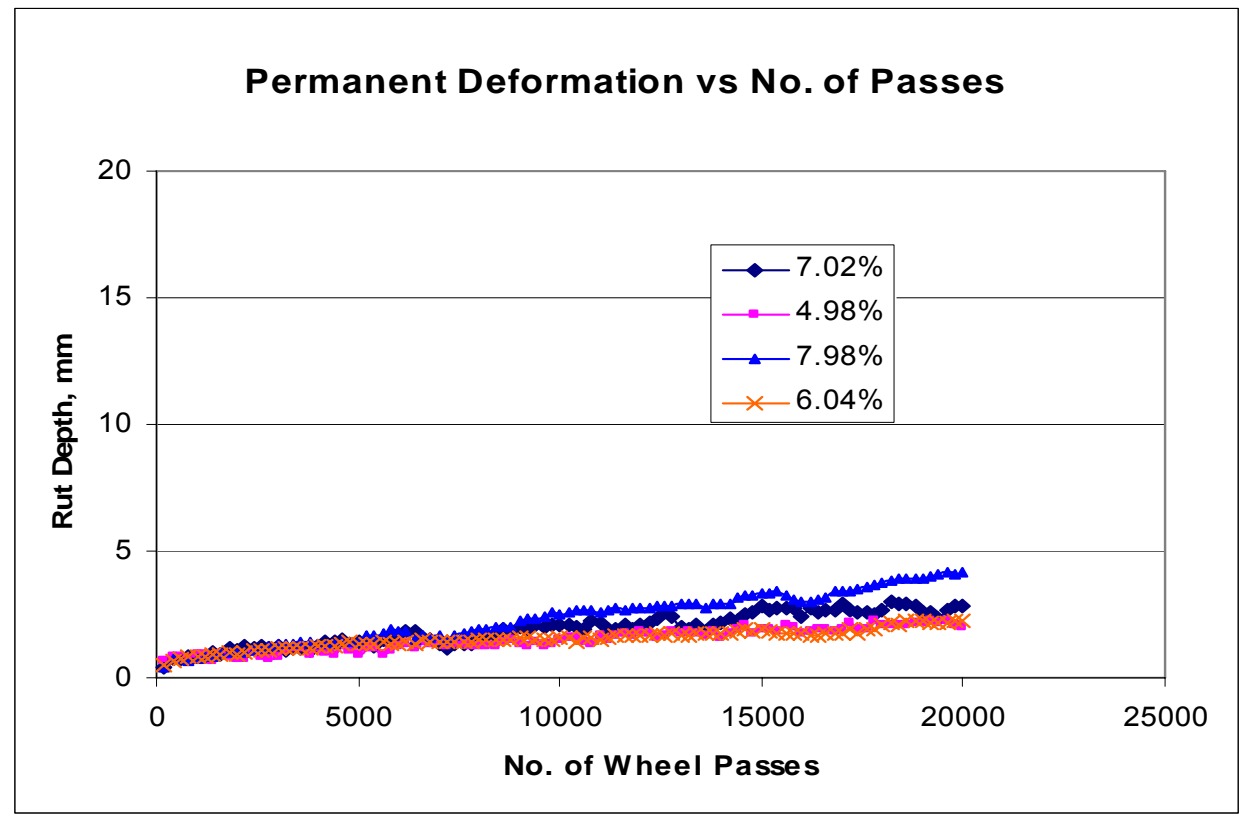

Figure B 12 Fine-Graded, 12.5-mm Mixture with Modified PG 71-22 
Appendix C. Beam Fatigue Test Data 
Table C 1 Fatigue Test Results

\begin{tabular}{|c|c|c|c|c|c|c|c|}
\hline $\begin{array}{l}\text { Specimen } \\
\text { Name }\end{array}$ & $\begin{array}{l}\text { Replicate } \\
\text { Number }\end{array}$ & PG Binder & Gradation & NMAS, mm & $\begin{array}{c}\text { Air Voids } \\
\text { Content, \% }\end{array}$ & Stiffness, MPa & Fatigue Life \\
\hline \multirow{2}{*}{ N70C1 } & 1 & \multirow{2}{*}{$\begin{array}{c}\text { Neat } \\
70-22\end{array}$} & Coarse & 9.5 & 6.21 & 6148 & 92010 \\
\hline & 2 & & Coarse & 9.5 & 6.01 & 5657 & 133130 \\
\hline \multirow{2}{*}{$\mathrm{N} 75 \mathrm{C} 1$} & 1 & \multirow{2}{*}{$\begin{array}{l}\text { Neat } \\
75-22\end{array}$} & Coarse & 9.5 & 6.09 & 5124 & 127380 \\
\hline & 2 & & Coarse & 9.5 & 6.37 & 4947 & 238430 \\
\hline \multirow{2}{*}{ M71C1 } & 1 & \multirow{2}{*}{$\begin{array}{l}\text { Modified } \\
71-22\end{array}$} & Coarse & 9.5 & 6.75 & 5165 & 223750 \\
\hline & 2 & & Coarse & 9.5 & 7.06 & 4890 & 284030 \\
\hline \multirow{2}{*}{$\mathrm{M} 75 \mathrm{C} 1$} & 1 & \multirow{2}{*}{$\begin{array}{l}\text { Modified } \\
75-22\end{array}$} & Coarse & 9.5 & 7.20 & 4571 & 697440 \\
\hline & 2 & & Coarse & 9.5 & 6.90 & 5140 & 712600 \\
\hline \multirow{2}{*}{ N70C2 } & 1 & \multirow{2}{*}{$\begin{array}{l}\text { Neat } \\
70-22\end{array}$} & Coarse & 12.5 & 6.53 & 5891 & 65560 \\
\hline & 2 & & Coarse & 12.5 & 6.99 & 5678 & 69620 \\
\hline \multirow{2}{*}{ N75C2 } & 1 & \multirow{2}{*}{$\begin{array}{l}\text { Neat } \\
75-23\end{array}$} & Coarse & 12.5 & 6.11 & 3886 & 84640 \\
\hline & 2 & & Coarse & 12.5 & 6.39 & 3287 & 75430 \\
\hline \multirow{2}{*}{ M71C2 } & 1 & \multirow{2}{*}{$\begin{array}{c}\text { Modified } \\
71-22\end{array}$} & Coarse & 12.5 & 7.89 & 3750 & 344680 \\
\hline & 2 & & Coarse & 12.5 & 6.65 & 4423 & 342310 \\
\hline \multirow{2}{*}{ M75C2 } & 1 & \multirow{2}{*}{$\begin{array}{c}\text { Modified } \\
75-22\end{array}$} & Coarse & 12.5 & 6.50 & 4060 & 1968240 \\
\hline & 2 & & Coarse & 12.5 & 7.38 & 3844 & 1224870 \\
\hline \multirow{2}{*}{ N70F1 } & 1 & \multirow{2}{*}{$\begin{array}{l}\text { Neat } \\
70-22\end{array}$} & Fine & 9.5 & 6.45 & 5409 & 377420 \\
\hline & 2 & & Fine & 9.5 & 6.49 & 5070 & 291000 \\
\hline \multirow{2}{*}{ M71F1 } & 1 & \multirow{2}{*}{$\begin{array}{l}\text { Modified } \\
71-22\end{array}$} & Fine & 9.5 & 6.43 & 4601 & 2633890 \\
\hline & 2 & & Fine & 9.5 & 6.44 & 4125 & 2240990 \\
\hline \multirow{2}{*}{ N70F2 } & 1 & \multirow{2}{*}{$\begin{array}{c}\text { Neat } \\
70-22 \\
\end{array}$} & Fine & 12.5 & 7.37 & 4725 & 247110 \\
\hline & 2 & & Fine & 12.5 & 6.53 & 5416 & 286430 \\
\hline \multirow{2}{*}{ M71F2 } & 1 & \multirow{2}{*}{$\begin{array}{c}\text { Modified } \\
71-22\end{array}$} & Fine & 12.5 & 7.60 & 5788 & 1764590 \\
\hline & 2 & & Fine & 12.5 & 7.13 & 4012 & 2004920 \\
\hline
\end{tabular}




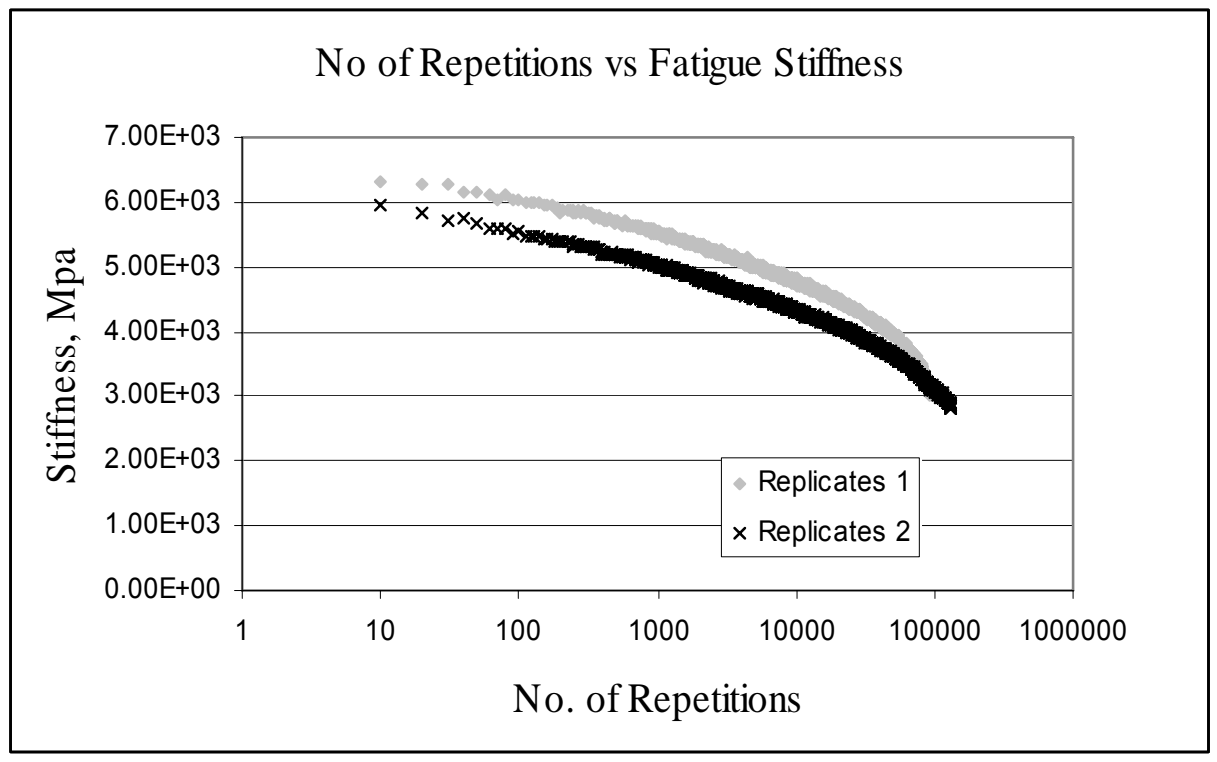

Figure C 1 Coarse-Graded, 9.5-mm Mixture with Neat PG 70-22

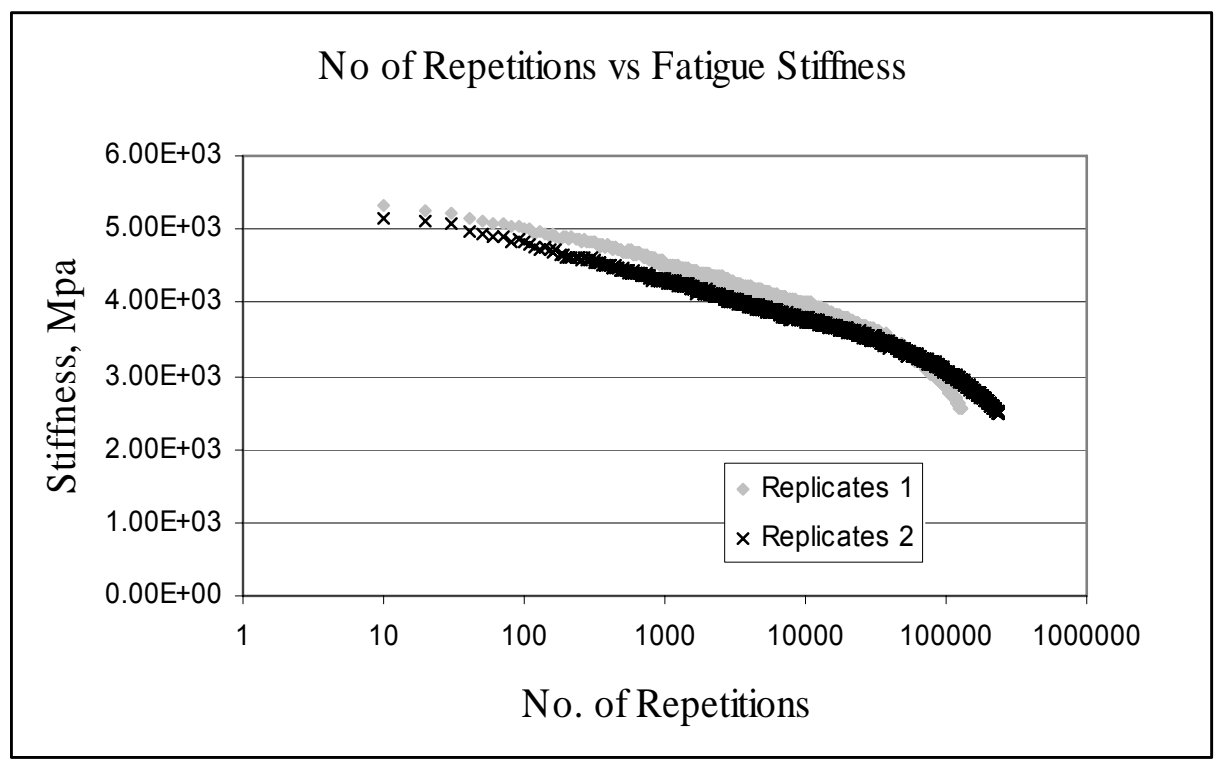

Figure C 2 Coarse-Graded, 9.5-mm Mixture with Neat PG 75-22 


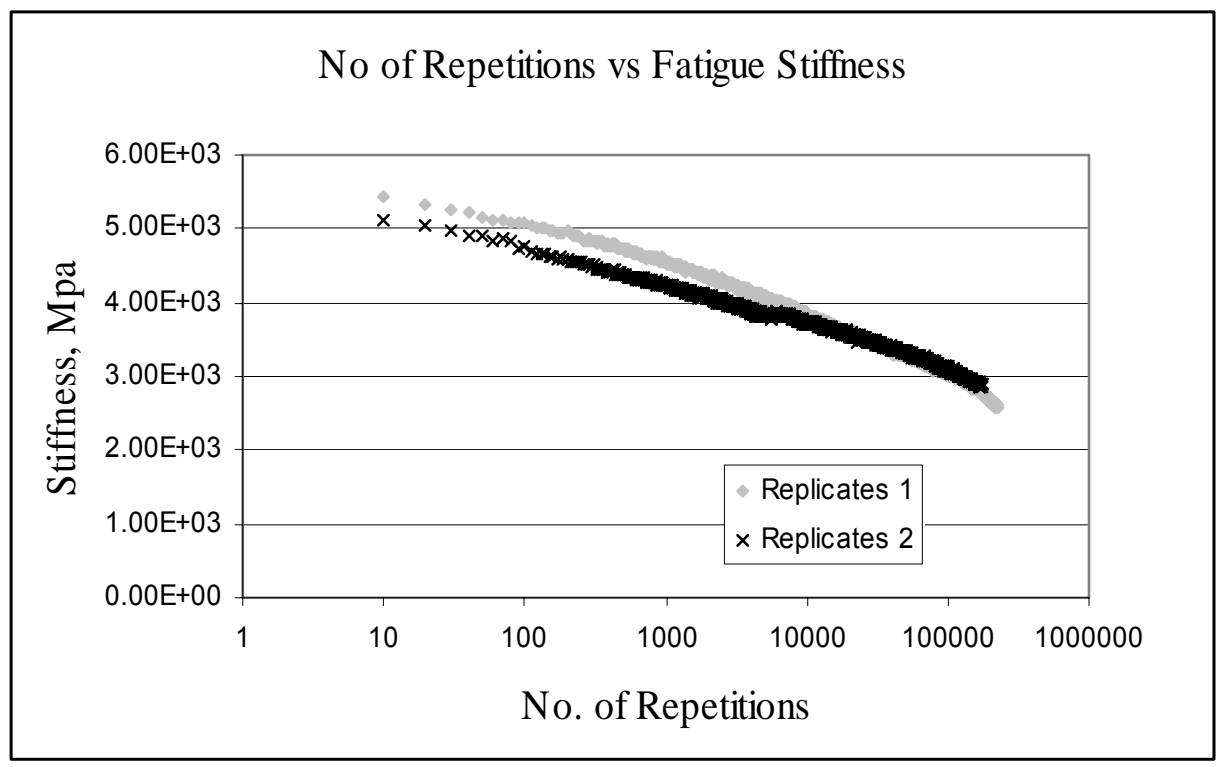

Figure C 3 Coarse-Graded, 9.5-mm Mixture with Modified PG 71-22

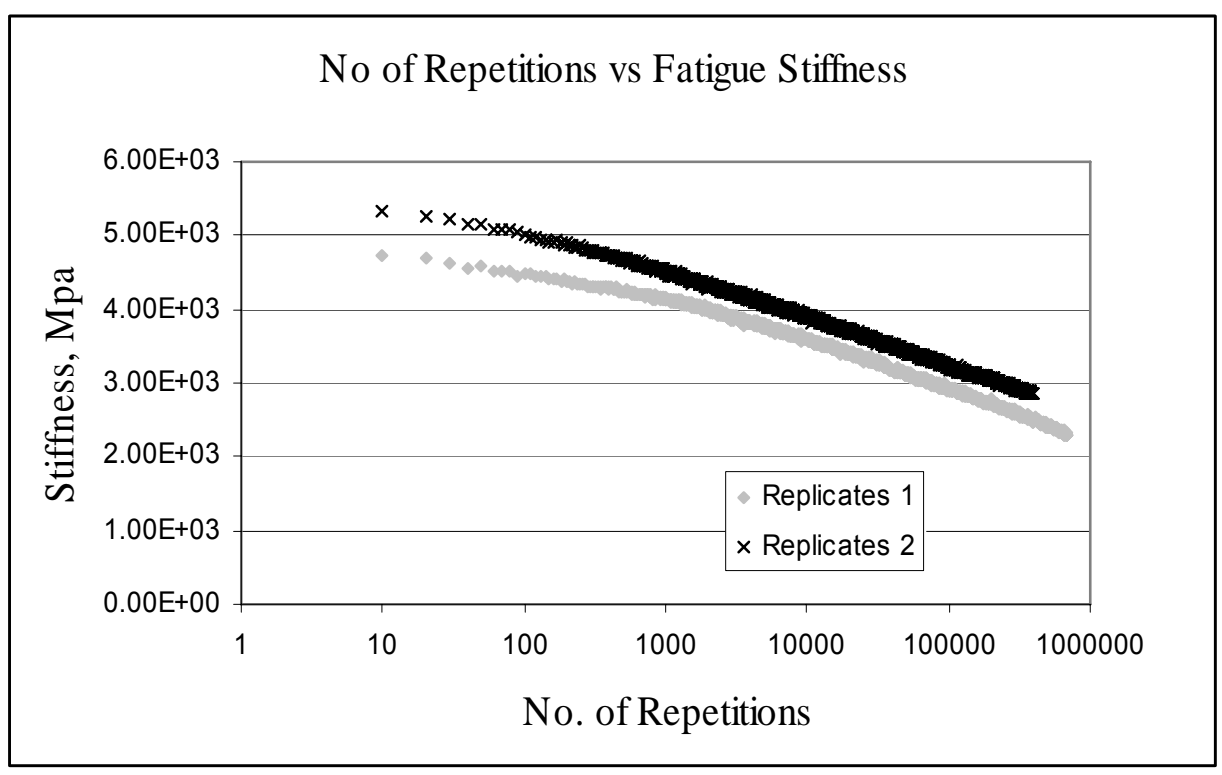

Figure C 4 Coarse-Graded, 9.5-mm Mixture with Modified PG 75-22 


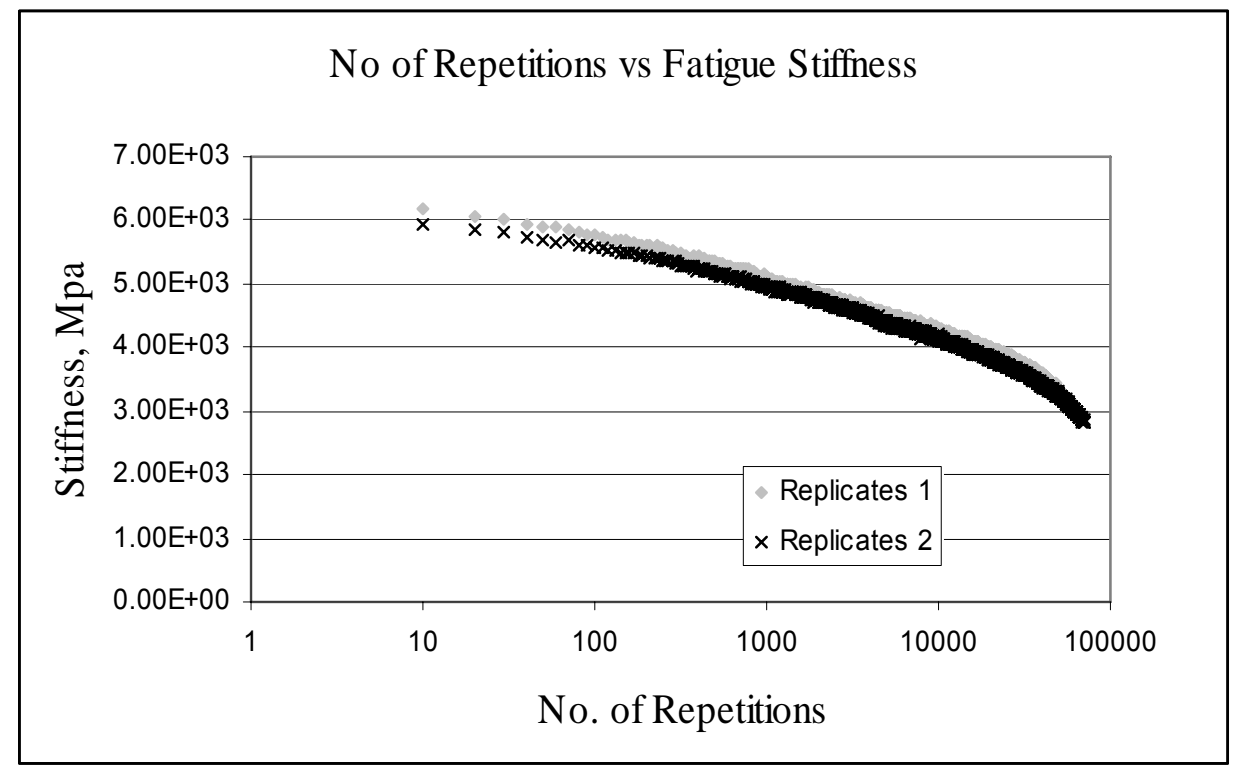

Figure C 5 Coarse-Graded, 12.5-mm Mixture with Neat PG 70-22

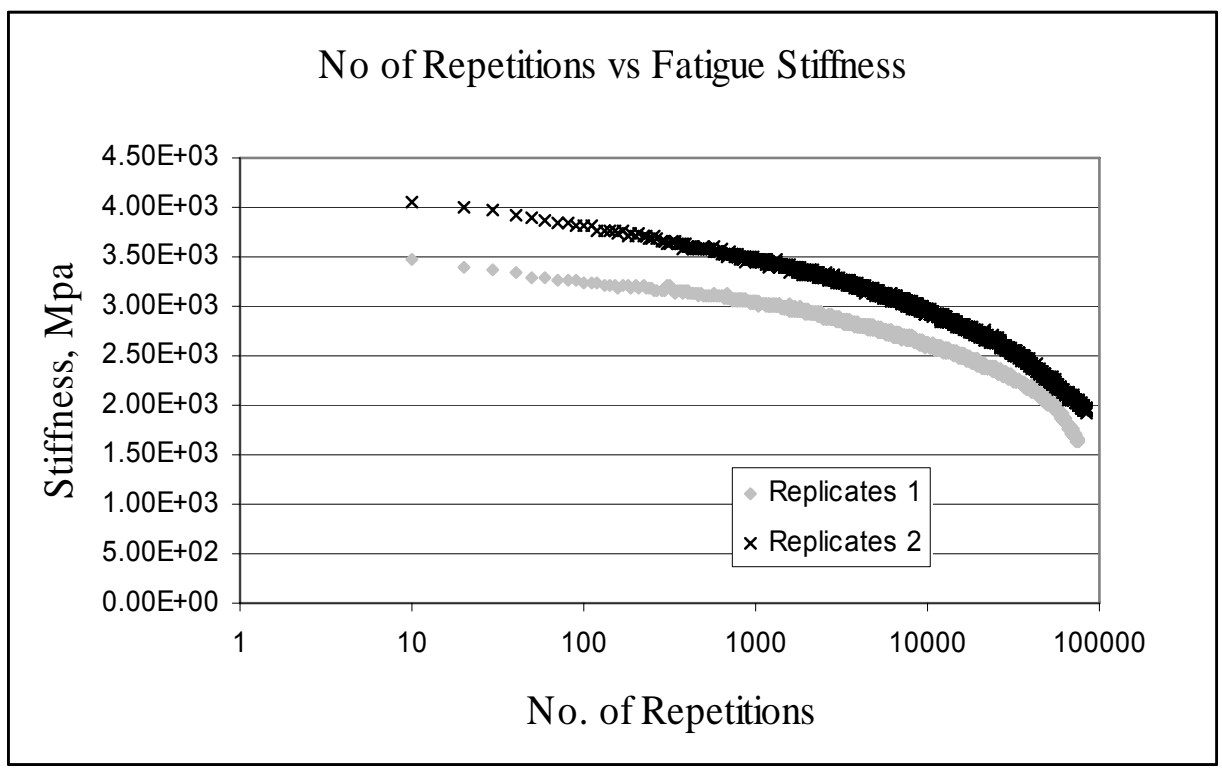

Figure C 6 Coarse-Graded, 12.5-mm Mixture with Neat PG 75-22 


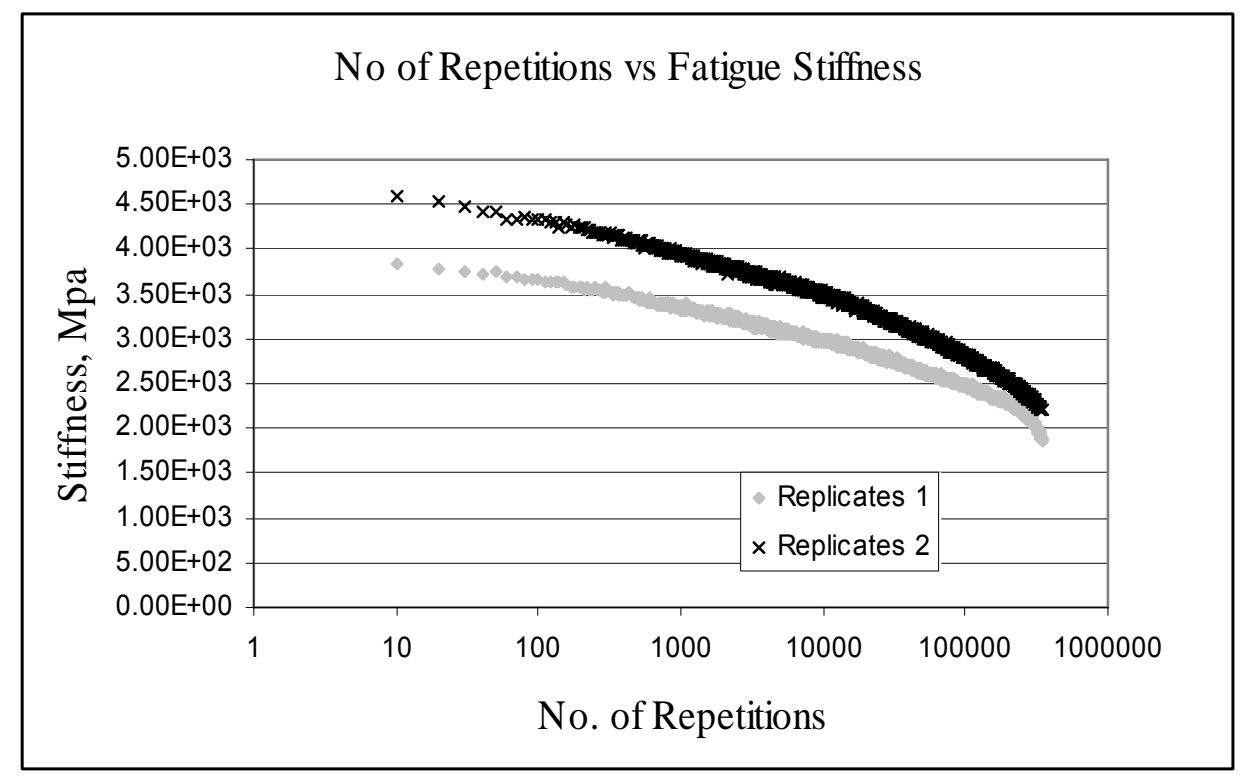

Figure C 7 Coarse-Graded, 12.5-mm Mixture with Modified PG 71-22

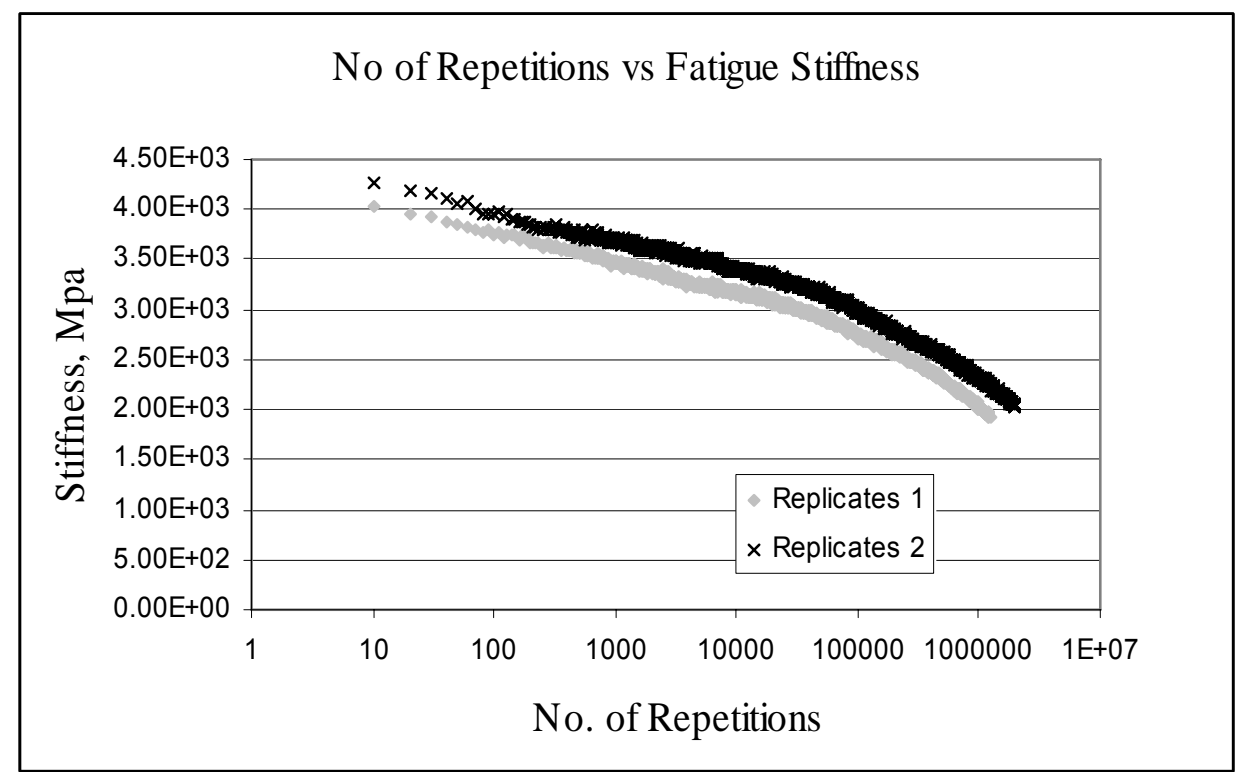

Figure C 8 Coarse-Graded, 12.5-mm Mixture with Modified PG 75-22 
No of Repetitions vs Fatigue Stiffness

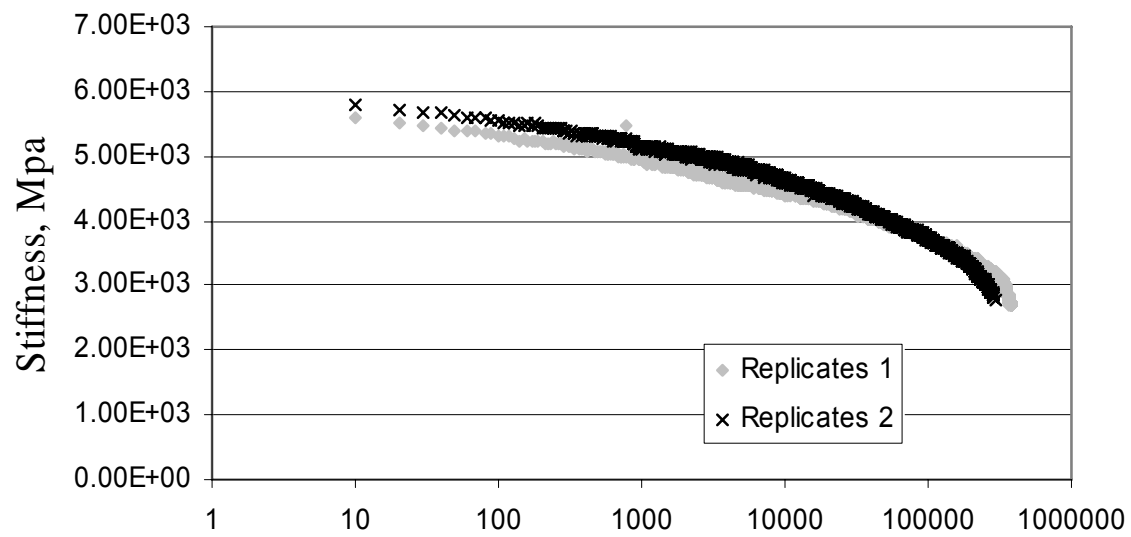

No. of Repetitions

Figure C 9 Fine-Graded, 9.5-mm Mixture with Neat PG 70-22

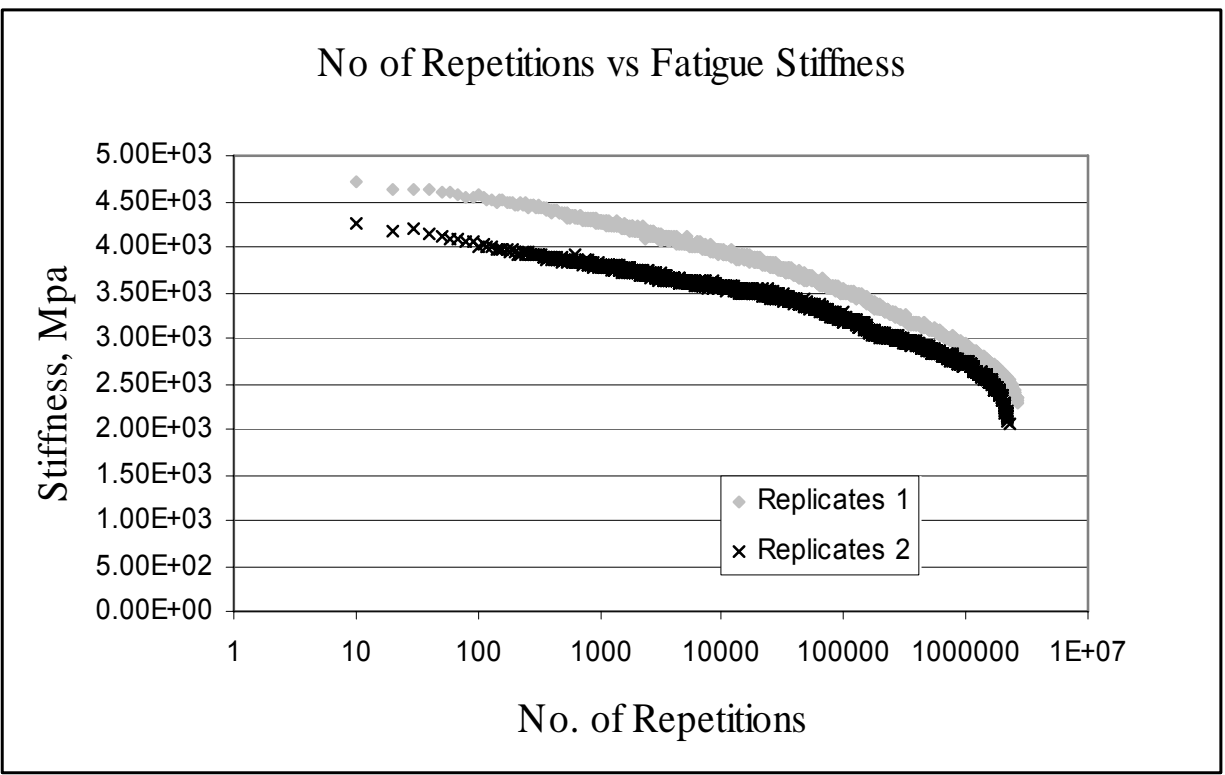

Figure C 10 Fine-Graded, 9.5-mm Mixture with Modified PG 71-22 


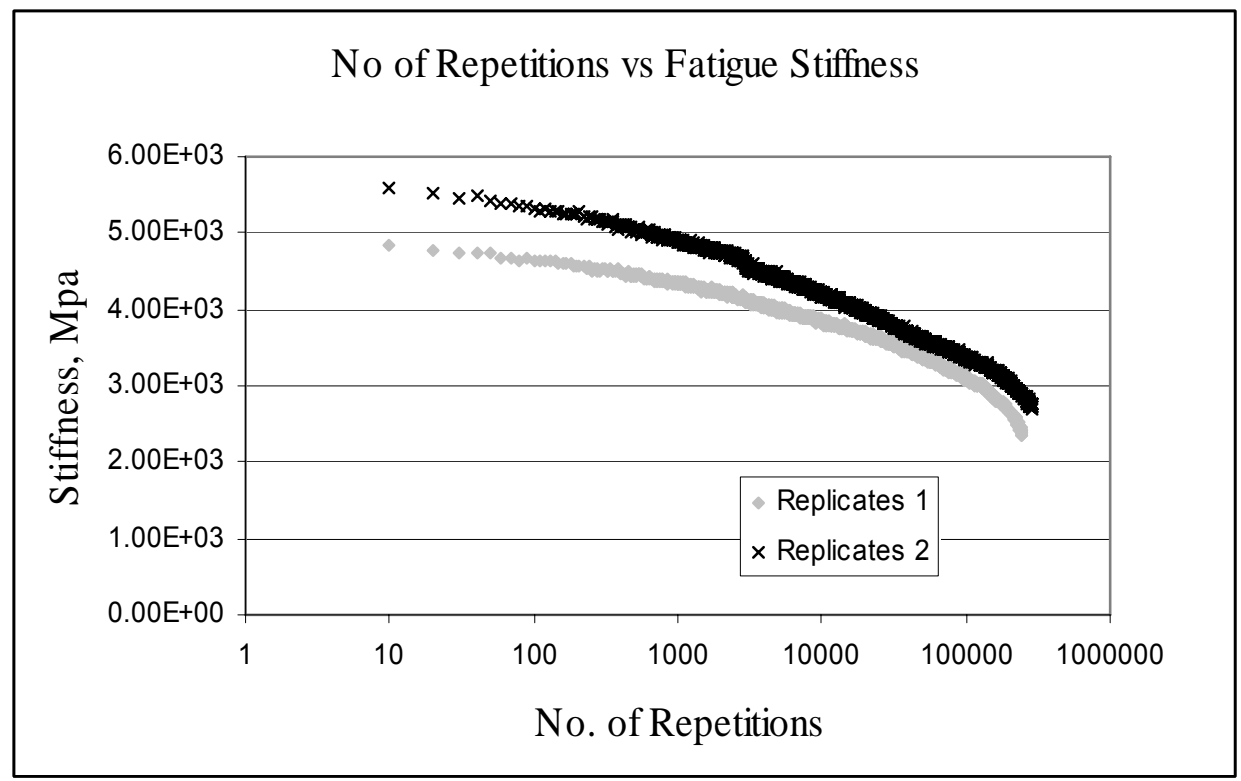

Figure C 11 Fine-Graded, 12.5-mm Mixture with Neat PG 70-22

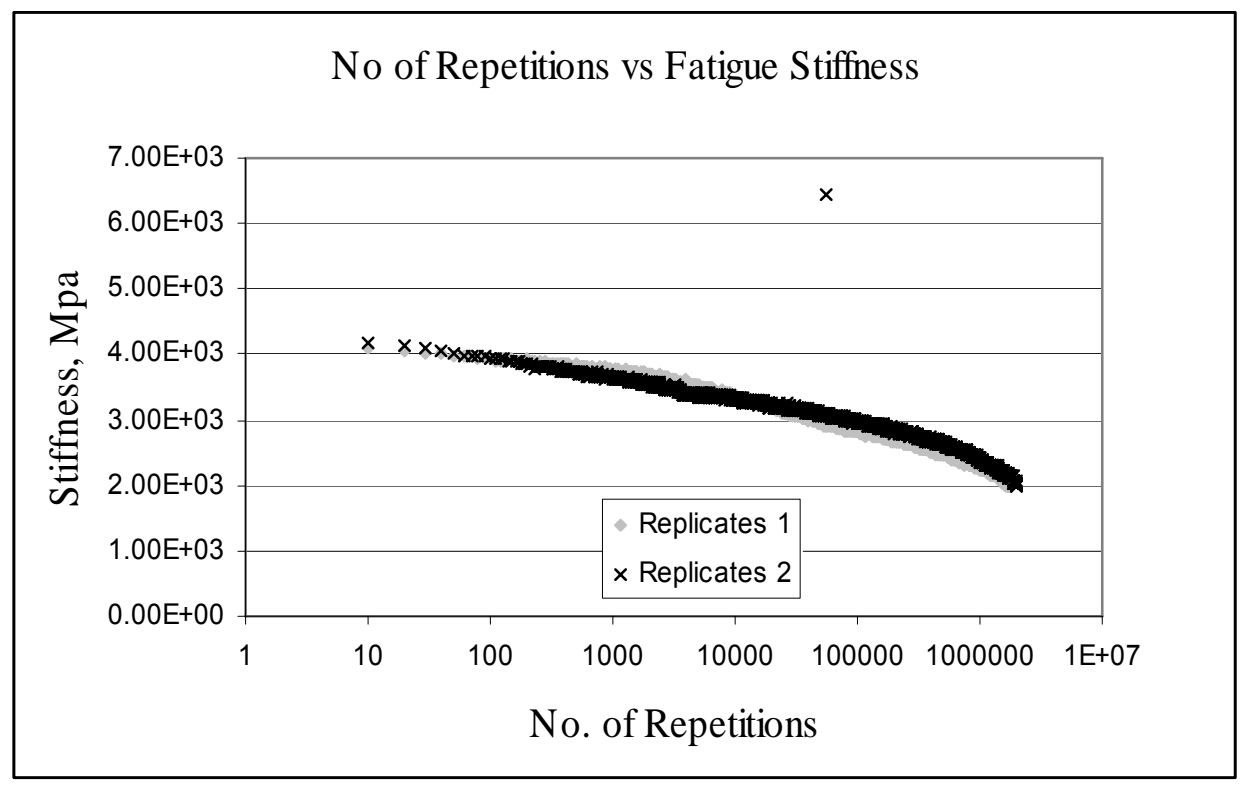

Figure C 12 Fine-Graded, 12.5-mm Mixture with Modified PG 71-22 
Appendix D. Indirect Tensile Test Data 
Table D 1 Indirect Tensile Test Results

\begin{tabular}{|c|c|c|c|c|c|c|}
\hline $\begin{array}{c}\text { Specimen } \\
\text { Name }\end{array}$ & $\begin{array}{c}\text { Replicate } \\
\text { Number }\end{array}$ & $\begin{array}{c}\text { PG } \\
\text { Binder }\end{array}$ & Gradation & $\begin{array}{c}\text { NMAS, } \\
\text { mm }\end{array}$ & $\begin{array}{c}\text { Air Voids } \\
\text { Content, } \\
\%\end{array}$ & $\begin{array}{c}\text { Tensile } \\
\text { Strength,psi, }\end{array}$ \\
\hline \multirow{3}{*}{ N70C1 } & 1 & \multirow{3}{*}{$\begin{array}{l}\text { Neat } \\
70-22\end{array}$} & Coarse & 9.5 & 6.65 & 333.22 \\
\hline & 2 & & Coarse & 9.5 & 6.95 & 442.83 \\
\hline & 3 & & Coarse & 9.5 & 7.32 & 408.81 \\
\hline \multirow{3}{*}{$\mathrm{N} 75 \mathrm{C} 1$} & 1 & \multirow{3}{*}{$\begin{array}{l}\text { Neat } \\
75-23\end{array}$} & Coarse & 9.5 & 6.09 & 470.75 \\
\hline & 2 & & Coarse & 9.5 & 6.07 & 416.91 \\
\hline & 3 & & Coarse & 9.5 & 6.18 & Ruined \\
\hline \multirow{3}{*}{ M71C1 } & 1 & \multirow{3}{*}{$\begin{array}{c}\text { Modified } \\
71-22\end{array}$} & Coarse & 9.5 & 6.55 & 475.99 \\
\hline & 2 & & Coarse & 9.5 & 6.78 & 553.96 \\
\hline & 3 & & Coarse & 9.5 & 6.68 & 560.63 \\
\hline \multirow{3}{*}{ M75C1 } & 1 & \multirow{3}{*}{$\begin{array}{c}\text { Modified } \\
75-22\end{array}$} & Coarse & 9.5 & 6.00 & 536.24 \\
\hline & 2 & & Coarse & 9.5 & 6.46 & 515.87 \\
\hline & 3 & & Coarse & 9.5 & 6.13 & 427.97 \\
\hline \multirow{3}{*}{ N70C2 } & 1 & \multirow{3}{*}{$\begin{array}{l}\text { Neat } \\
70-22\end{array}$} & Coarse & 12.5 & 6.5 & 241.99 \\
\hline & 2 & & Coarse & 12.5 & 6.31 & 404.84 \\
\hline & 3 & & Coarse & 12.5 & 6.45 & 288.61 \\
\hline \multirow{3}{*}{ N75C2 } & 1 & \multirow{3}{*}{$\begin{array}{l}\text { Neat } \\
75-23\end{array}$} & Coarse & 12.5 & 6.48 & 418.08 \\
\hline & 2 & & Coarse & 12.5 & 7.28 & 217.99 \\
\hline & 3 & & Coarse & 12.5 & 7.35 & 248.32 \\
\hline \multirow{3}{*}{ M71C2 } & 1 & \multirow{3}{*}{$\begin{array}{c}\text { Modified } \\
71-22\end{array}$} & Coarse & 12.5 & 6.16 & 408.81 \\
\hline & 2 & & Coarse & 12.5 & 6.10 & 442.83 \\
\hline & 3 & & Coarse & 12.5 & 6.54 & 333.22 \\
\hline \multirow{3}{*}{ M75C2 } & 1 & \multirow{3}{*}{$\begin{array}{c}\text { Modified } \\
75-22\end{array}$} & Coarse & 12.5 & 6.50 & 391.66 \\
\hline & 2 & & Coarse & 12.5 & 6.59 & 451.60 \\
\hline & 3 & & Coarse & 12.5 & 6.68 & 306.06 \\
\hline \multirow{3}{*}{ N70F1 } & 1 & \multirow{3}{*}{$\begin{array}{l}\text { Neat } \\
70-22\end{array}$} & Fine & 9.5 & 6.99 & 443.81 \\
\hline & 2 & & Fine & 9.5 & 6.79 & 355.38 \\
\hline & 3 & & Fine & 9.5 & 6.84 & 460.67 \\
\hline \multirow{3}{*}{ M71F1 } & 1 & \multirow{3}{*}{$\begin{array}{c}\text { Modified } \\
71-22\end{array}$} & Fine & 9.5 & 7.49 & 351.23 \\
\hline & 2 & & Fine & 9.5 & 7.43 & 514.24 \\
\hline & 3 & & Fine & 9.5 & 7.33 & 493.61 \\
\hline \multirow{3}{*}{ N70F2 } & 1 & \multirow{3}{*}{$\begin{array}{l}\text { Neat } \\
70-22\end{array}$} & Fine & 12.5 & 6.62 & 408.96 \\
\hline & 2 & & Fine & 12.5 & 6.51 & 409.22 \\
\hline & 3 & & Fine & 12.5 & 6.54 & 421.04 \\
\hline \multirow{3}{*}{ M71F2 } & 1 & \multirow{3}{*}{$\begin{array}{c}\text { Modified } \\
71-22\end{array}$} & Fine & 12.5 & 7.31 & 481.58 \\
\hline & 2 & & Fine & 12.5 & 7.25 & 496.36 \\
\hline & 3 & & Fine & 12.5 & 7.80 & 452.67 \\
\hline
\end{tabular}

